\title{
Expression of ROS-responsive genes and transcription factors after metabolic formation of $\mathrm{H}_{2} \mathrm{O}_{2}$ in chloroplasts
}

\author{
Salma Balazadeh ${ }^{1 \dagger}$, Nils Jaspert ${ }^{2+}$, Muhammad Arif ${ }^{1}$, Bernd Mueller-Roeber ${ }^{1}$ and \\ Veronica G. Maurino ${ }^{*}$ \\ 1 Institute of Biochemistry and Biology, University of Potsdam, Potsdam, Germany \\ 2 Plant Molecular Physiology and Biotechnology, Center of Excellence on Plant Sciences, Heinrich-Heine-University, Düsseldorf, Germany
}

\section{Edited by:}

Dario Leister,

Ludwig-Maximilians-University

Munich, Germany

Reviewed by:

Ian M. Møller, Aarhus University, Denmark

Jaakko Kangasjärvi, University of Helsinki, Finland

Haya Friedman, Volcani Center,

ARO, Israel

\section{*Correspondence:}

Veronica G. Maurino, Entwicklungsund Molekularbiologie der Pflanzen, Heinrich-Heine-Universität,

Universitätsstraße 1, 40225

Düsseldorf, Germany.

e-mail: veron-

ica.maurino@uni-duesseldorf.de

${ }^{\dagger}$ These authors equally contributed to this work.
Glycolate oxidase (GO) catalyses the oxidation of glycolate to glyoxylate, thereby consuming $\mathrm{O}_{2}$ and producing $\mathrm{H}_{2} \mathrm{O}_{2}$. In this work, Arabidopsis thaliana plants expressing $\mathrm{GO}$ in the chloroplasts (GO plants) were used to assess the expressional behavior of reactive oxygen species (ROS)-responsive genes and transcription factors (TFs) after metabolic induction of $\mathrm{H}_{2} \mathrm{O}_{2}$ formation in chloroplasts. In this organelle, $\mathrm{GO}$ uses the glycolate derived from the oxygenase activity of RubisCO. Here, to identify genes responding to an abrupt production of $\mathrm{H}_{2} \mathrm{O}_{2}$ in chloroplasts we used quantitative real-time PCR (qRT-PCR) to test the expression of 187 ROS-responsive genes and 1880 TFs after transferring GO and wild-type (WT) plants grown at high $\mathrm{CO}_{2}$ levels to ambient $\mathrm{CO}_{2}$ concentration. Our data revealed coordinated expression changes of genes of specific functional networks $0.5 \mathrm{~h}$ after metabolic induction of $\mathrm{H}_{2} \mathrm{O}_{2}$ production in GO plants, including the induction of indole glucosinolate and camalexin biosynthesis genes. Comparative analysis using available microarray data suggests that signals for the induction of these genes through $\mathrm{H}_{2} \mathrm{O}_{2}$ may originate in the chloroplast. The TF profiling indicated an up-regulation in $\mathrm{GO}$ plants of a group of genes involved in the regulation of proanthocyanidin and anthocyanin biosynthesis. Moreover, the upregulation of expression of TF and TF-interacting proteins affecting development (e.g., cell division, stem branching, flowering time, flower development) would impact growth and reproductive capacity, resulting in altered development under conditions that promote the formation of $\mathrm{H}_{2} \mathrm{O}_{2}$.

Keywords: glycolate oxidase, $\mathrm{H}_{2} \mathrm{O}_{2}$, ROS-responsive genes, transcription factors

\section{INTRODUCTION}

Photosynthetic organisms are confronted with reactive oxygen species (ROS), such as singlet oxygen $\left({ }^{1} \mathrm{O}_{2}\right)$, the superoxide anion radical $\left(\mathrm{O}_{2}^{-}\right)$, the hydroxyl radical $(\mathrm{OH} \cdot)$, and hydrogen peroxide $\left(\mathrm{H}_{2} \mathrm{O}_{2}\right)$, which may cause oxidative stress and damage to important biological molecules (Apel and Hirt, 2004; Møller et al., 2007). Plants in their natural environments are often exposed to sudden increases in light intensity, which results in the absorption of excitation energy in excess of that required for metabolism. In chloroplasts, when absorbed energy is in excess at photosystem II (PSII), $\mathrm{O}_{2}^{-}$is produced during the Mehler reaction by Fd-NADPH oxidase at PSI and is dismutated by superoxide dismutase (SOD) to $\mathrm{H}_{2} \mathrm{O}_{2}$ (Ort and Baker, 2002; Asada, 2006). The photorespiratory pathway consumes photosynthetic reducing energy and produces $\mathrm{H}_{2} \mathrm{O}_{2}$ in the peroxisomes through the action of glycolate oxidase (GO) (Maurino and Peterhansel, 2010). $\mathrm{H}_{2} \mathrm{O}_{2}$ is also produced during a variety of different reactions under stress conditions, often through the detoxification of ${ }^{1} \mathrm{O}_{2}$ and $\mathrm{O}_{2}^{-}$. The generated $\mathrm{H}_{2} \mathrm{O}_{2}$ is scavenged by different antioxidant/enzyme reactions: the ascorbate and glutathione cycles, ascorbate peroxidase (APX), catalase, and peroxiredoxin (PRX) (Tripathi et al., 2009).
ROS generated in the chloroplast have been implicated as triggers of signaling pathways that influence expression of nuclearencoded genes, which may initiate responses such as cell death or acclimation depending on the degree of the stress (Karpinski et al., 1999; Fryer et al., 2003; Op den Camp et al., 2003; Danon et al., 2005). $\mathrm{H}_{2} \mathrm{O}_{2}$ can take part in signaling acting as messenger either directly (e.g., by reversibly modifying critical thiol groups in target proteins; Neill et al., 2002) or by using an oxidized product as a secondary messenger (Møller et al., 2007). The $\mathrm{H}_{2} \mathrm{O}_{2}$-scavenging enzymes APX and dehydroascorbate reductase (DHAR) may act as highly efficient initiators of oxidative signaling by generating transient bursts of reduced glutathione. This in consequence triggers glutaredoxin-mediated protein oxidation (Neill et al., 2002). Crosstalk between redox pools of different cellular compartments, possibly transmitted by a redox shift in cellular components, has also been suggested to be important for control of the expression of nuclear genes (Baier and Dietz, 2005; Leister, 2005). A generalized model of $\mathrm{H}_{2} \mathrm{O}_{2}$ signal transduction pathways suggests that $\mathrm{H}_{2} \mathrm{O}_{2}$ may also directly oxidize transcription factors (TFs) in either the cytosol or the nucleus. Alternatively, $\mathrm{H}_{2} \mathrm{O}_{2}$-mediated activation of a signaling protein such as a protein kinase may activate TFs (Mittler 
et al., 2004; Miao et al., 2007). TFs would interact with cognate $\mathrm{H}_{2} \mathrm{O}_{2}$-response elements in target gene promoters thereby modulating gene expression (Foyer and Noctor, 2005). Recently, Møller and Sweetlove (2010) put forward the hypothesis that $\mathrm{H}_{2} \mathrm{O}_{2}$ itself is unlikely to be the signaling molecule that selectively regulates nuclear-encoded chloroplastic genes but rather that oxidized peptides deriving from proteolysis of oxidized proteins would act as second messengers during retrograde ROS signaling. On the other hand, using spin trapping EPR spectroscopy in addition to chemical assays (employing Amplex Red reagent), Mubarakshina et al. (2010) showed that 5\% of the $\mathrm{H}_{2} \mathrm{O}_{2}$ produced inside chloroplasts at high light intensities can actually be detected outside the organelles. This process may involve the pass of $\mathrm{H}_{2} \mathrm{O}_{2}$ through aquaporins (Bienert et al., 2007) and might be sufficient to trigger signaling processes outside the chloroplasts.

Desikan et al. (2001) showed that approximately 1\% of the transcriptome was altered in $\mathrm{H}_{2} \mathrm{O}_{2}$-treated Arabidopsis thaliana (A. thaliana) cell cultures. Although $\mathrm{H}_{2} \mathrm{O}_{2}$-responsive promoters have been identified (Desikan et al., 2001), specific $\mathrm{H}_{2} \mathrm{O}_{2}$ regulatory DNA sequences and their cognate TFs have not been isolated and characterized. In more recent studies genes involved in $\mathrm{H}_{2} \mathrm{O}_{2}$ signal transduction have been identified or proposed, including mitogen-activated protein kinases (MAPKs), various TFs of e.g., the NAC, ZAT, and WRKY families, miRNAs and others (Van Breusegem et al., 2008; Li et al., 2011; Petrov and Van Breusegem, 2012). Moreover, using genome-wide analysis of catalase deficient $A$. thaliana, $\mathrm{H}_{2} \mathrm{O}_{2}$ was inferred to regulate the expression of genes encoding specific small heat shock proteins, several TFs and candidate regulatory proteins (Vandenabeele et al., 2004; Vanderauwera et al., 2005).

To date, it is not known to which extent the chemical specificity of the ROS and the cellular compartment of their release may contribute to the multiplicity of responses that occur in plants. A major challenge is to dissect the genetic networks that control ROS signaling and to assess specific and common responses toward different types of ROS signals. To this end, the molecular, biochemical and physiological responses of $A$. thaliana to elevated in planta levels of $\mathrm{H}_{2} \mathrm{O}_{2}$ were and are being investigated in various types of model systems including mutants altered in the ROS scavenging machinery (Maurino and Flügge, 2008). However, the analysis of dynamic physiological processes using (knock-out) mutants may not always be straightforward, especially when compensatory cellular mechanisms are induced. With respect to ROS-related mutants, changing the balance of scavenging enzymes may induce compensatory mechanisms such that signaling and oxidative damage effects may not be easily separated. Moreover, invasive experimental setups like the application of oxidative stress-causing agents may induce a nonspecific oxidative stress that acts throughout the cell and triggers additional responses that may complicate the analysis of ROS signal transduction pathways (Maurino and Flügge, 2008). We have recently developed a tool to functionally dissect the action of plastid-generated $\mathrm{H}_{2} \mathrm{O}_{2}$, using plants overexpressing $\mathrm{GO}$ in plastids (GO plants; Fahnenstich et al., 2008). During photosynthesis, the oxygenase activity of ribulose 1,5-bisphosphate carboxylase/oxygenase (RubisCO) produces glycolate 2-phosphate within the chloroplasts, which is then dephosphorylated to glycolate by phosphoglycolate phosphatase (Maurino and Peterhansel, 2010). In GO plants, glycolate is oxidized to glyoxylate by the plastidic $\mathrm{GO}$, with the parallel production of $\mathrm{H}_{2} \mathrm{O}_{2}$. When growing under moderate photon fluxes and ambient $\mathrm{CO}_{2}$ concentration (photorespiratory conditions) the GO plants remain smaller than the wild type, presenting a reduced rosette diameter and yellowish leaves due to $\mathrm{H}_{2} \mathrm{O}_{2}$ accumulation (Fahnenstich et al., 2008). In contrast, in non-photorespiratory conditions (e.g., at high $\mathrm{CO}_{2}$ concentration) the oxygenase activity of RubisCO is abolished and thus, the metabolic flux through GO is suppressed, allowing GO plants to grow like wild type (Fahnenstich et al., 2008). Transferring GO plants from high to ambient $\mathrm{CO}_{2}$ concentration specifically induces $\mathrm{H}_{2} \mathrm{O}_{2}$ formation in the chloroplasts (Fahnenstich et al., 2008). These properties permit the modulation of plastidic produced $\mathrm{H}_{2} \mathrm{O}_{2}$ levels by changing light intensity and/or $\mathrm{CO}_{2}$ levels (Maurino and Flügge, 2008). Moreover, $\mathrm{H}_{2} \mathrm{O}_{2}$ is specifically generated without a concomitant accumulation of superoxide or singlet oxygen, which are common precursors of $\mathrm{H}_{2} \mathrm{O}_{2}$ during ROS generation in chloroplasts. A similar experimental set-up was employed in previous studies using catalase null mutants in which the production of peroxisomal $\mathrm{H}_{2} \mathrm{O}_{2}$ is induced by changing the conditions of plant growth from non-photorespiratory to photorespiratory conditions (e.g., high light intensity) (Dat et al., 2000; Vandenabeele et al., 2004; Vanderauwera et al., 2005). The metabolic production of $\mathrm{H}_{2} \mathrm{O}_{2}$ may avoid the pleiotropic effects discussed above but it cannot be ruled out that ROS-unrelated pleiotropic reactions may occur in both approaches due to abrupt changes in $\mathrm{CO}_{2}$ level or light intensity.

In this work we attempted to identify genes strongly responding to an abrupt production of $\mathrm{H}_{2} \mathrm{O}_{2}$ in chloroplasts of A. thaliana. To this end we tested the expressional changes of 187 nuclear-encoded ROS-responsive genes and 1880 TFs, using quantitative real-time (qRT)-PCR (Czechowski et al., 2004; Balazadeh et al., 2008; Wu et al., 2012) upon transfer of high $\mathrm{CO}_{2}$-grown $\mathrm{GO}$ and wild-type (WT) plants to ambient $\mathrm{CO}_{2}$ concentration. Our data revealed a rapid and coordinated expression response of ROS-affected genes of specific functional networks in GO including an early induction of indole glucosinolate and camalexin biosynthesis genes and an up-regulation of a group of genes involved in the regulation of proanthocyanidin and anthocyanin biosynthesis. Moreover, the upregulation of expression of TF and TF-interacting proteins affecting development (e.g., cell division, stem branching, flowering time, flower development) would impact growth and reproductive capacity, resulting in altered development under conditions that promote the formation of $\mathrm{H}_{2} \mathrm{O}_{2}$.

\section{MATERIALS AND METHODS PLANT MATERIAL}

Arabidopsis thaliana (L.) Heynh. ecotype Columbia-0 (Col-0, wild-type) constitutively expressing glycolate oxidase (GO, At3g14420) in the plastids (GO plants) under the cauliflower mosaic virus $35 \mathrm{~S}$ promoter were generated in our previous work (Fahnenstich et al., 2008). In these plants to direct the expression of GO to the chloroplats the stromal targeting presequence from 
Arabidopsis thaliana phosphoglucomutase (At5g51820) was used (Fahnenstich et al., 2008). WT and GO transgenic plants were grown in pots containing 3 parts of soil (Gebr. Patzer KG, SinntalJossa, Germany) and one part of vermiculite (Basalt Feuerfest, Linz, Austria) under a $16 \mathrm{~h}$-light $/ 8 \mathrm{~h}$-dark regime at photosynthetically active photon flux densities (PPFD) of $75 \mu \mathrm{mol}$ quanta $\mathrm{m}^{-2} \mathrm{~s}^{-1}$ at $22^{\circ} \mathrm{C}$ day $/ 18^{\circ} \mathrm{C}$ night temperatures and a $\mathrm{CO}_{2}$ concentration of $3000 \mathrm{ppm}$. After 3 weeks of growth plants were transferred to ambient $\mathrm{CO}_{2}$ concentration $(380 \mathrm{ppm})$ and the same PPFD. Whole rosettes were harvested at different time points after transfer, immediately frozen in liquid nitrogen and stored at $-80^{\circ} \mathrm{C}$ until use for RNA isolation and $\mathrm{H}_{2} \mathrm{O}_{2}$ measurements.

\section{ISOLATION OF RNA AND REAL-TIME PCR ANALYSIS}

For the large-scale qRT-PCR analysis, total RNA was extracted from $100 \mathrm{mg}$ leaves (fresh weight) using RNeasy Plant Mini kit (Qiagen, Valencia, USA) according to the manufacturer's protocol. DNAse I digestion was performed on $20-30 \mu \mathrm{g}$ of total RNA using TURBO DNase Kit (Ambion, Cambridgeshire, UK) according to manufacturer's instructions. RNA integrity was checked on $1 \%(\mathrm{w} / \mathrm{v})$ agarose gels and concentration measured with a Nanodrop ND-1000 spectrophotometer before and after DNAse treatment. Absence of genomic DNA was confirmed subsequently by quantitative PCR using primers that amplify an intron sequence of the gene At5g65080 (forward $5^{\prime}$-TTTTTTGCCCCCTTCGAATC-3' and reverse $5^{\prime}$ ATCTTCCGCCACCACATTGTAC-3'). First-strand cDNA was synthesized from $8 \mu \mathrm{g}$ to $10 \mu \mathrm{g}$ of total RNA using RevertAid ${ }^{\mathrm{TM}}$ First Strand cDNA Synthesis Kit (Fermentas, St. Leon-Rot, Germany) following the manufacturer's protocol. The efficiency of cDNA synthesis was estimated by qRT-PCR using two different primer sets annealing to the $5^{\prime}$ and $3^{\prime}$ ends, respectively, of a control gene (At3g26650, GAPDH, glyceraldehyde-3phosphate dehydrogenase). Primer sequences were as follows: for GAPDH3', forward 5'-TTGGTGACAACAGGTCAAGCA-3' and reverse 5'-AAACTTGTCGCTCAATGCAATC-3'; for GAPDH5', forward 5' $5^{\prime}$ TCTCGATCTCAATTTCGCAAAA- $3^{\prime}$ and reverse $5^{\prime}$ CGAAACCGTTGATTCCGATTC-3'. Transcript levels of each gene were normalized to ACTIN2 (At3g18780) transcript abundance (forward 5'-TCCCTCAGCACATTCCAGCAGAT- $3^{\prime}$ and reverse $5^{\prime}$-AACGATTCCTGGACCTGCCTCATC- $3^{\prime}$ ). A total of 187 ROS-responsive genes (Wu et al., 2012) and $1880 \mathrm{TFs}$ (Czechowski et al., 2004; Balazadeh et al., 2008) were analyzed by qRT-PCR as previously described (Caldana et al., 2007; Balazadeh et al., 2008). PCR reactions were run on an ABI PRISM 7900HT sequence detection system (Applied Biosystems, Darmstadt, Germany), and amplification products were visualized using SYBR Green (Applied Biosystems).

\section{$\mathrm{H}_{2} \mathrm{O}_{2}$ MEASUREMENTS}

Levels of $\mathrm{H}_{2} \mathrm{O}_{2}$ were determined using the Amplex ${ }^{\circledR}$ Red Technology (Life Technologies, Darmstadt, Germany) following the manufacturer's instructions. Amplex Red (N-acetyl3,7-dihydroxyphenoxazine) reacts with $\mathrm{H}_{2} \mathrm{O}_{2}$ in the presence of horseradish peroxidase and forms the fluorescent product resorufin. For the determinations, $100 \mathrm{mg}$ leaves (fresh weight) were ground in liquid nitrogen into a fine powder and resuspended with $0.15 \mathrm{~mL}$ extraction buffer prepared as indicated by the manufacturer. This suspension was centrifuged at $4^{\circ} \mathrm{C}$ at $13,000 \mathrm{rpm}$ for $15 \mathrm{~min}$. Five $\mu \mathrm{L}$ of the supernatant, $45 \mu \mathrm{L}$ distilled water and $50 \mu \mathrm{L}$ of Amplex ${ }^{\circledR}$ Red solution were added to a microtitre plate. After $30 \mathrm{~min}$ incubation in the dark fluorescence was measured by excitation at $560 \mathrm{~nm}$ and emission reads at $590 \mathrm{~nm}$. A calibration curve was established with known $\mathrm{H}_{2} \mathrm{O}_{2}$ concentrations.

\section{GENE EXPRESSION NETWORK ANALYSIS}

The two genes that were most strongly induced under photorespiratory conditions in GO plants at the 0.5 and $6 \mathrm{~h}$ time points (At3g02840 and At1g17180, respectively) were used as baits to identify globally coexpressed genes using the ATTED-II database (http://atted.jp), which allows evaluating genes that are coexpressed under five experimental conditions (tissue, abiotic stress, biotic stress, hormones, and light conditions) (Obayashi et al., 2009).

\section{RESULTS AND DISCUSSION INDUCTION OF $\mathrm{H}_{2} \mathrm{O}_{2}$ FORMATION IN GO PLANTS}

The production of $\mathrm{H}_{2} \mathrm{O}_{2}$ in leaves of plants overexpressing $\mathrm{GO}$ in the plastids (Fahnenstich et al., 2008) was analyzed after activation of photorespiration by transferring high $\mathrm{CO}_{2}$-grown plants to ambient- $\mathrm{CO}_{2}$ conditions. As shown in Table $\mathbf{1}$, higher levels of $\mathrm{H}_{2} \mathrm{O}_{2}$ were determined in GO than in WT plants at 0.5 and $4 \mathrm{~h}$ after transfer while GO and WT plants maintained under non-photorespiratory conditions $\left(3000 \mathrm{ppm} \mathrm{CO}_{2}\right)$ showed similar $\mathrm{H}_{2} \mathrm{O}_{2}$ levels at both time points (Table 1). Note, that as the measurements were performed using whole-leaf extracts the expected differences in chloroplastic $\mathrm{H}_{2} \mathrm{O}_{2}$ levels between $\mathrm{GO}$ and WT plants under photorespiratory condition may be higher than determined here.

\section{EXPRESSION PROFILING OF ROS MARKER GENES IN GO AND WILD-TYPE PLANTS AFTER THE INDUCTION OF $\mathrm{H}_{2} \mathrm{O}_{2}$ FORMATION IN CHLOROPLASTS}

To study the impact of an abrupt production of $\mathrm{H}_{2} \mathrm{O}_{2}$ in chloroplasts on nuclear gene expression, we analyzed transcript level changes of 187 ROS-responsive genes using a previously established qRT-PCR platform (detailed in Wu et al., 2012). The genes

Table 1 | Levels of $\mathrm{H}_{2} \mathrm{O}_{2}$ measured in whole rosettes ( $\mu \mathrm{mol} / \mathrm{g} \mathrm{FW}$ ) after shifting high $\mathrm{CO}_{2}$-grown wild-type and $\mathrm{GO}$ plants to ambient $\mathrm{CO}_{2}$ concentration for 0.5 and $4 \mathrm{~h}$.

\begin{tabular}{llllll}
\hline & \multicolumn{2}{c}{$\mathbf{0 . 5} \mathbf{~}$} & & \multicolumn{2}{c}{$\mathbf{4 h}$} \\
\cline { 2 - 3 } \cline { 5 - 5 } & High $\mathbf{C O}_{\mathbf{2}}$ & Ambient $\mathbf{C O}_{\mathbf{2}}$ & & High $\mathbf{C O}_{\mathbf{2}}$ & Ambient $\mathbf{C O}_{\mathbf{2}}$ \\
\hline WT & $2.4 \pm 0.2$ & $2.3 \pm 0.2$ & & $2.5 \pm 0.4$ & $2.7 \pm 0.1$ \\
GO & $2.5 \pm 0.3$ & $3.0 \pm 0.3$ & & $2.6 \pm 0.2$ & $\mathbf{3 . 4} \pm \mathbf{0 . 0}$ \\
\hline
\end{tabular}

Samples from control plants maintained in high $\mathrm{CO}_{2}$ were processed in parallel. Values indicate the mean \pm SE of three independent samples and those set in bold face indicate significant differences to the corresponding wild-type value calculated by Student's t-test $(P<0.05)$. WT, wild type. 
included in the platform were chosen from published reports and our own experiments and represent four different groups that were already shown to be rapidly induced by (1) superoxide radical $\left(\mathrm{O}_{2}^{-} ; 18\right.$ genes), (2) singlet oxygen ( ${ }^{1} \mathrm{O}_{2} ; 22$ genes), (3) $\mathrm{H}_{2} \mathrm{O}_{2}$ (53 genes), or (4) different types of ROS (general ROS-responsive genes; 94 in total).

Gene expression was analyzed in whole rosettes of 3-week-old WT and GO plants at $0.5,4,6$, and $12 \mathrm{~h}$ after shifting high- $\mathrm{CO}_{2}$ grown plants (non-photorespiratory condition) to ambient $\mathrm{CO}_{2}$ concentration (photorespiratory condition). Expression profiling was performed in two biological replicates and log-fold change ( $\log 2$ FC) ratios of expression changes were calculated for GO and WT plants by comparing gene expression levels before and after the $\mathrm{CO}_{2}$ concentration shift. A total of 131 genes were expressed in all examined samples (Table A1 in Appendix). The remaining 56 genes did not yield detectable PCR amplicons, indicating no or marginal expression under our experimental conditions.

Considering a 3-fold expression difference cut-off, 120 genes displayed differential expression in GO and/or WT plants upon transfer from high to ambient $\mathrm{CO}_{2}$ concentration; the vast majority of the affected genes (116 in total) were up-regulated, and only four genes were down-regulated (Figure 1, Table A1 in Appendix). Most noticeably, expression of 58 genes was induced in GO plants already within $0.5 \mathrm{~h}$ after the transfer to ambient $\mathrm{CO}_{2}$ condition, whilst only a single gene was induced in the wild type at the same time point (Figure 1). Importantly, however, many genes showed also high expression in the wild type at later time points after the $\mathrm{CO}_{2}$ concentration shift, but the expressional changes were in most cases more pronounced in GO than WT plants (Figure 1, and section "Early Induction of Indole Glucosinolate and Camalexin Biosynthesis Genes in GO Plants"). Thus, our data indicate that similar sets of ROS-responsive genes responded to the $\mathrm{CO}_{2}$ shift in $\mathrm{GO}$ and WT plants; however, the dynamics of the transcriptional responses were clearly different in the two types of plants, being faster and more prominent in the GO plants.

\section{EARLY INDUCTION OF INDOLE GLUCOSINOLATE AND CAMALEXIN BIOSYNTHESIS GENES IN GO PLANTS}

To identify transcripts responsive to metabolically produced $\mathrm{H}_{2} \mathrm{O}_{2}$ we focused our analysis on the 0.5 - and 6-h time points. Genes were considered differentially expressed when the fold change was more than 3 -fold $\left(\log _{2} \geq 1.56\right)$.

At $0.5 \mathrm{~h}$ after shifting plants to ambient $\mathrm{CO}_{2}$ concentration, 58 of the 131 expressed genes were induced in GO plants by more than 3-fold, whilst in the wild type the expression change was less than 3-fold, suggesting that these genes participate in early signaling steps triggered by the production of $\mathrm{H}_{2} \mathrm{O}_{2}$ under photorespiratory conditions (Table 2). After $6 \mathrm{~h}$, seven of these genes showed WT levels of expression (below 3 -fold), while 29 were further overexpressed only in GO (Table 2). Although at $6 \mathrm{~h}$ after transfer to ambient $\mathrm{CO}_{2}$ the expression fold-change (FC) of the remaining 22 genes was higher than 3 in both, GO and WT plants, the expression change between $\mathrm{GO}$ and $\mathrm{WT}\left(\mathrm{FC}_{\mathrm{GO}} / \mathrm{FC}_{\mathrm{WT}}\right)$ was higher than 2 for 16 of these genes (Table 2), indicating that their higher expression in GO plants was triggered by the elevated levels of $\mathrm{H}_{2} \mathrm{O}_{2}$.

Later responding genes, which were affected only after $6 \mathrm{~h}$ under photorespiratory conditions, were also identified. From the 23 genes that showed an expression change of above 3 -fold in GO, 13 were only induced in GO, while 10 genes were induced in both, $\mathrm{GO}$ and WT. The FC ratio in $\mathrm{GO}$ and $\mathrm{WT}\left(\mathrm{FC}_{\mathrm{GO}} / \mathrm{FC}_{\mathrm{WT}}\right)$ was above 2 for the 10 genes (Table 3), indicating that their expression in GO plants is controlled by the higher levels of $\mathrm{H}_{2} \mathrm{O}_{2}$, similar to the early-responsive genes.

\section{$0.5 \mathrm{~h}$ (ambient $\mathrm{CO}_{2} / \mathrm{high} \mathrm{CO}_{2}$ )}
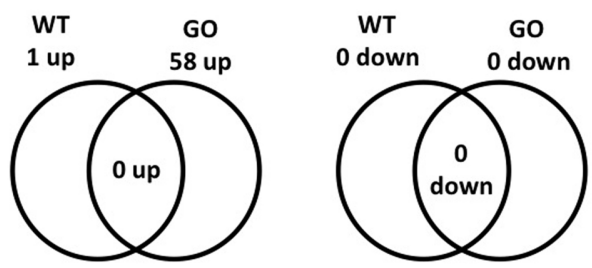

$6 \mathrm{~h}$ (ambient $\mathrm{CO}_{2} / \mathrm{high} \mathrm{CO}_{2}$ )
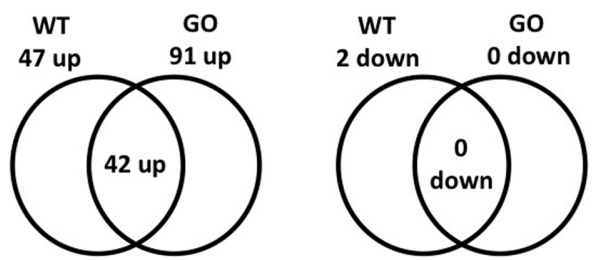

$4 \mathrm{~h}$ (ambient $\mathrm{CO}_{2} /$ high $\mathrm{CO}_{2}$ )
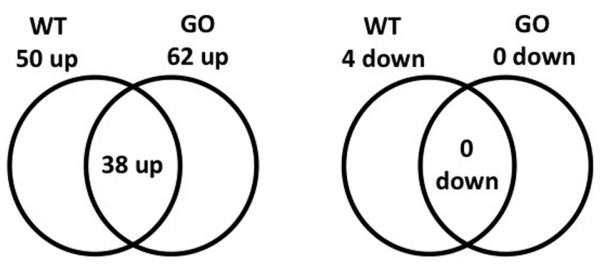

$12 \mathrm{~h}$ (ambient $\mathrm{CO}_{2} / \mathrm{high} \mathrm{CO}_{2}$ )
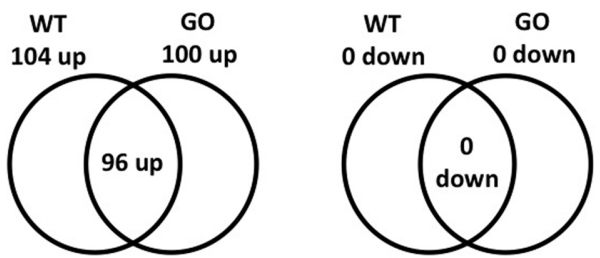

FIGURE 1 | Venn diagram of the number of ROS-responsive genes differentially expressed in wild-type and GO plants at different time points (0.5, 4, 6 , and $12 \mathrm{~h})$ after the transfer of plants grown at high $\mathrm{CO}_{2}$ concentration $(3000 \mathrm{ppm})$ to ambient $\mathrm{CO}_{2}$ concentration $(380 \mathrm{ppm})$. 
Table 2 | ROS-responsive genes (58 in total) the expression of which was enhanced by more than 3-fold in GO plants $0.5 \mathrm{~h}$ after shifting plants grown at high $\mathrm{CO}_{2}$ concentration $(3000 \mathrm{ppm})$ to ambient $\mathrm{CO}_{2}$ concentration $(380 \mathrm{ppm})$.

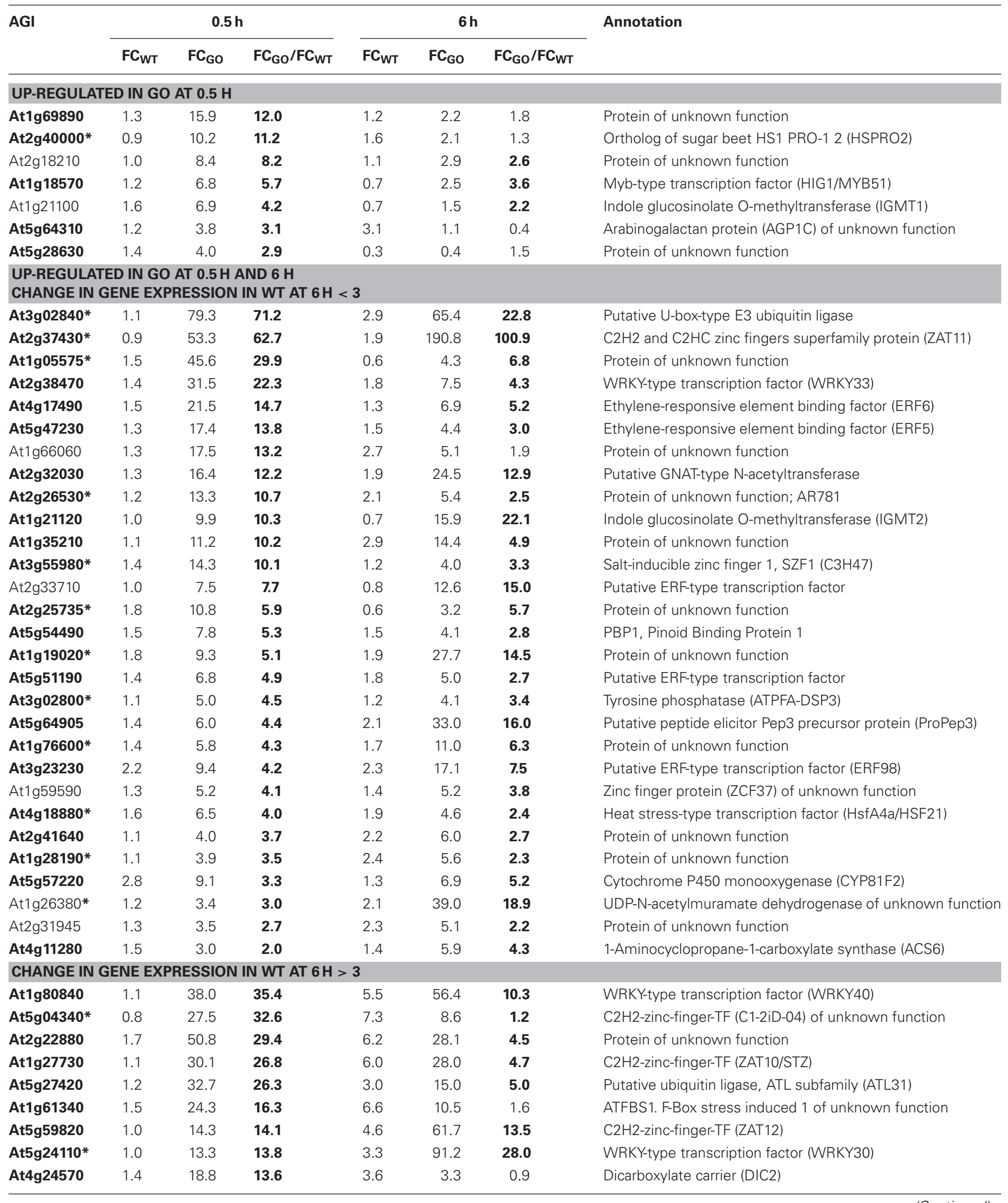


Table 2 | Continued

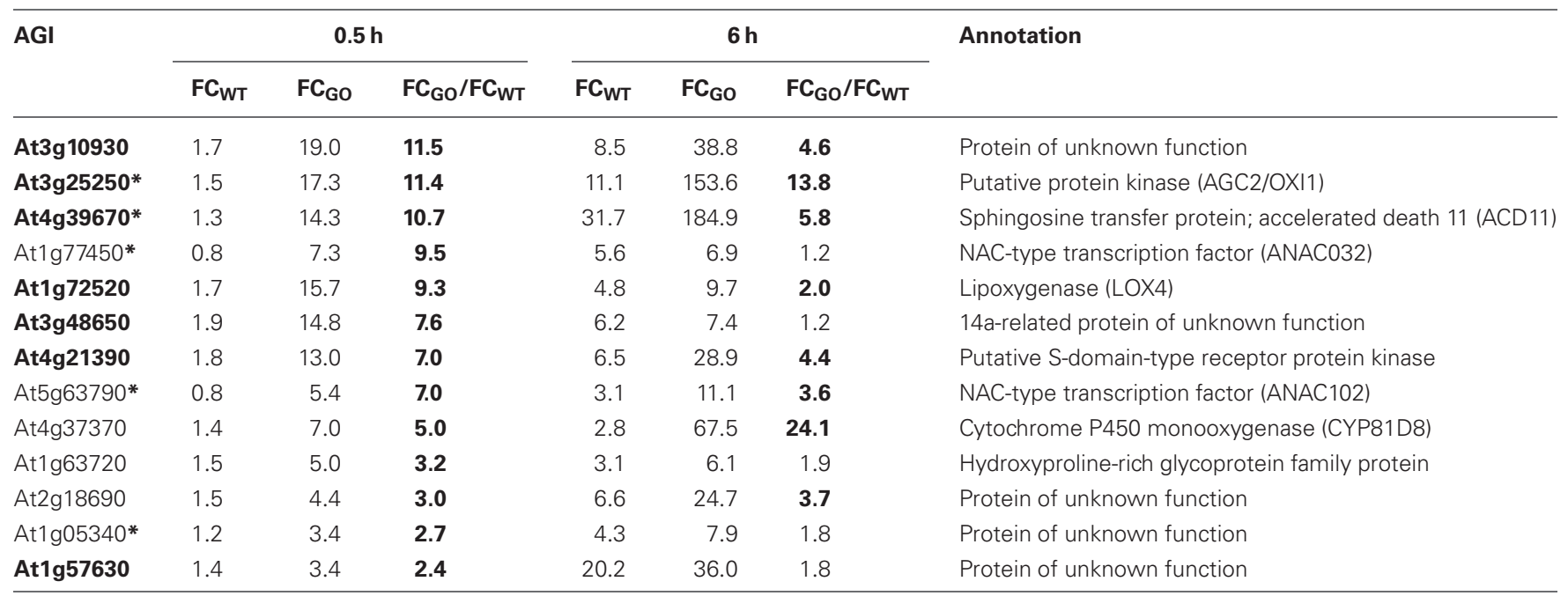

Genes are listed according to the difference of the expression change between $G O$ and wild-type (WT) plants (FC $G O / F C_{W T}$ ) at 0.5 h. FC $G O / F C_{W T}$ values higher than 2 are shown in bold face. AGl: gene identification number given by the Arabidopsis Genome Initiative. Genes also induced in catalase loss-of function mutants are highlighted with an asterisk (*) (Inzé et al., 2012). Genes included in the same gene coexpression network of At3g02840 (putative U-box-type E3 ubiquitin ligase) are highlighted in bold face (http://atted.jp; Obayashi et al., 2009). The gene annotation was retrieved from TAIR (http://arabidopsis.org/index.jsp).

The most highly up-regulated gene in GO plants at $0.5 \mathrm{~h}$ after induction of $\mathrm{H}_{2} \mathrm{O}_{2}$ production was At3g02840 (encoding a putative U-box-type E3 ubiquitin ligase, known to respond immediately-early to fungal elicitation) (Table 2). We used the ATTED-II database (http://atted.jp; Obayashi et al., 2009) to discover genes coexpressed with At3g02840 and observed that 45 of the 58 genes induced at $0.5 \mathrm{~h}$ after induction of $\mathrm{H}_{2} \mathrm{O}_{2}$ production cluster together (Table 2), indicating that metabolically produced $\mathrm{H}_{2} \mathrm{O}_{2}$ in $\mathrm{GO}$ plants induces the coordinate expression of functionally related genes. A similar analysis using the most highly expressed gene at $6 \mathrm{~h}$ after induction of $\mathrm{H}_{2} \mathrm{O}_{2}$ production (Atlg17180, encoding glutathione S-transferase Tau 25) indicated that another group of eight genes are coordinately expressed in GO plants at this later time point (Table 3).

Recently, Inzé et al. (2012) listed the 85 most strongly $\mathrm{H}_{2} \mathrm{O}_{2}$-responsive genes in catalase loss-of-function mutants shifted from low- to high-light conditions, where $\mathrm{H}_{2} \mathrm{O}_{2}$ is produced in peroxisomes by the action of photorespiratory GOs. Interestingly, 23 of the 81 genes, which changed their expression in the GO plants were also differentially expressed in catalase loss-of-function mutants (Tables 2 and 3), indicating that they respond to enhanced levels of $\mathrm{H}_{2} \mathrm{O}_{2}$ independent of the site of its generation; the remaining genes may then represent candidates preferentially responsive to $\mathrm{H}_{2} \mathrm{O}_{2}$ produced in chloroplasts. Many of the genes up-regulated in $\mathrm{GO}$ plants encode proteins or TFs of currently unknown specific functions. Interestingly, however, several of the early-responsive genes are involved in tryptophan-derived biosynthesis of the phytoanticipins camalexin and indole glucosinolates, i.e., secondary metabolites that have antifungal and insect-deterring functions (Kliebenstein et al., 2001; Bednarek et al., 2009). These genes encode (1) the transcription factor WRKY33 (At2g38470), which is involved in controlling camalexin biosynthesis (Birkenbihl et al., 2012); (2) the Myb-type transcription factor HIG1/MYB51 (Atlg18570) involved in the positive regulation of indole glucosinolate biosynthesis by activating several target genes (Gigolashvili et al., 2007); (3) the O-methyltransferases IGMT1 (At1g21100) and IGMT2 (Atlg21120), which catalyze the transfer of a methyl group to the hydroxy indole glucosinolate hydroxyindol-3-ylmethylglucosinolate $(4$ and $1 \mathrm{OH}-\mathrm{I} 3 \mathrm{M}$, respectively) to form methoxyindol-3-ylmethylglucosinolate (4 and 1MO-I3M, respectively) (Pfalz et al., 2011); and (4) cytochrome P450 monooxygenase CYP81F2 (At5g57220), that is essential for the pathogen-induced accumulation of 4-methoxyindol-3ylmethylglucosinolate (4MI3G) (Bednarek et al., 2009). Our data thus show the early induction of indole glucosinolate and camalexin biosynthesis genes in $\mathrm{GO}$ plants after metabolic formation of $\mathrm{H}_{2} \mathrm{O}_{2}$ through the activation of genes encoding enzymes involved in intermediate metabolite conversions and of TFs that act on several target genes of these biosynthetic pathways.

\section{TRANSCRIPTION FACTOR PROFILING}

To understand the potential effects of overexpression of GO in chloroplasts on the nuclear transcriptional program, we next broadened our analysis by testing the expression of $1880 \mathrm{TFs}$ using a highly sensitive quantitative real-time PCR (qRT-PCR) platform (Czechowski et al., 2004; Balazadeh et al., 2008). Considering the data obtained from the profiling of the ROSresponsive genes, we analyzed the expression at $0.5 \mathrm{~h}$ after induction of $\mathrm{H}_{2} \mathrm{O}_{2}$ production to capture the early-responsive TFs. Expression profiling was performed in two biological replicates and log-fold change (log2 FC) ratios of expression changes were calculated for GO and WT plants by comparing gene expression levels before and after the transfer of plants grown at high $\mathrm{CO}_{2}$ to ambient $\mathrm{CO}_{2}$. 
Table 3 | ROS-responsive genes (23 in total) the expression of which was enhanced more than 3-fold in GO plants $6 \mathrm{~h}$ after shifting plants grown at high $\mathrm{CO}_{2}$ concentration to ambient $\mathrm{CO}_{2}$ concentration.

\begin{tabular}{|c|c|c|c|c|c|c|c|}
\hline \multirow[t]{2}{*}{ AGI } & \multicolumn{3}{|c|}{$0.5 \mathrm{~h}$} & \multicolumn{3}{|c|}{$6 \mathrm{~h}$} & \multirow[t]{2}{*}{ Annotation } \\
\hline & $\mathrm{FC}_{\mathrm{WT}}$ & $\mathrm{FC}_{\mathrm{GO}}$ & $\mathrm{FC}_{\mathrm{GO}} / \mathrm{FC}_{\mathrm{WT}}$ & $\mathrm{FC}_{\mathrm{WT}}$ & $\mathrm{FC}_{\mathrm{GO}}$ & $\mathrm{FC}_{\mathrm{GO}} / \mathrm{FC}_{\mathrm{WT}}$ & \\
\hline \multicolumn{8}{|c|}{$\begin{array}{l}\text { UP-REGULATED IN GO AT } 6 \text { H } \\
\text { CHANGE IN GENE EXPRESSION IN WT }<3\end{array}$} \\
\hline At1g26420 & 1.5 & 1.6 & 1.1 & 2.4 & 17.6 & 7.3 & Putative reticuline dehydrogenase \\
\hline At2g15480 & 1.0 & 2.8 & 2.8 & 1.2 & 7.2 & 6.0 & UDP-dependent glycosyl transferase (UGT73B5) \\
\hline At1g10040 & 1.2 & 1.8 & 1.5 & 2.1 & 10.4 & 5.0 & Putative hydrolase \\
\hline At2g29490 & 0.7 & 1.9 & 2.8 & 2.3 & 10.4 & 4.5 & Tau glutathione S-transferase (GSTU1) \\
\hline At5g46080 & 1.1 & 1.9 & 1.8 & 1.2 & 3.7 & 3.1 & Putative protein kinase \\
\hline At1g80820 & 1.2 & 1.5 & 1.3 & 2.5 & 7.8 & 3.1 & Cinnamoyl CoA reductase, involved in lignin biosynthesis \\
\hline At3g09410 & 1.2 & 0.8 & 0.7 & 1.2 & 3.2 & 2.7 & Putative pectin acetylesterase \\
\hline At2g29500* & 1.0 & 1.1 & 1.2 & 1.5 & 3.8 & 2.5 & HSP20-type protein (HSP17.6B-Cl); unknown function \\
\hline At4g22530* & 1.3 & 0.8 & 0.7 & 2.4 & 5.9 & 2.4 & Putative methyltransferase \\
\hline At4g15975 & 1.7 & 1.3 & 0.7 & 1.6 & 3.7 & 2.4 & Putative ubiquitin ligase (RRE4/ATL17) \\
\hline At2g38340 & 1.0 & 0.7 & 0.7 & 2.7 & 6.1 & 2.2 & Putative AP2-type transcription factor (DREB2E) \\
\hline At3g13790 & 1.3 & 1.3 & 1.1 & 2.5 & 5.0 & 2.0 & Putative cell wall invertase (CwINV1) \\
\hline At1g76070 & 1.2 & 2.6 & 2.2 & 1.6 & 3.3 & 2.0 & Protein of unknown function \\
\hline \multicolumn{8}{|c|}{ CHANGE IN GENE EXPRESSION IN WT > 3} \\
\hline At1g17180 & 0.6 & 0.9 & 1.4 & 7.5 & 104.0 & 13.8 & Tau glutathione S-transferase (GSTU25) \\
\hline At1g15520 & 1.2 & 0.8 & 0.7 & 12.4 & 111.9 & 9.0 & ABC transporter (ABCG40/PDR12) \\
\hline At1g17170 & 1.0 & 1.3 & 1.4 & 5.7 & 40.4 & 7.0 & Tau glutathione S-transferase (GSTU24) \\
\hline At1g74360 & 1.0 & 2.2 & 2.2 & 4.2 & 14.2 & 3.4 & Putative LRR-type receptor protein kinase \\
\hline At2g38250* & 1.2 & 1.7 & 1.4 & 4.4 & 13.7 & 3.1 & Putative trihelix-type transcription factor \\
\hline At5g51060 & 1.3 & 1.0 & 0.7 & 14.4 & 44.0 & 3.1 & Respiratory burst oxidase homolog (AtRBOHC/RHD2) \\
\hline At5g20230 & 1.5 & 2.8 & 1.8 & 9.9 & 28.3 & 2.9 & Senescence associated gene (BCB/SAG14) \\
\hline At2g41380 & 1.1 & 1.2 & 1.1 & 9.6 & 21.2 & 2.2 & Putative S-adenosyl-L-methionine-dependent methyltransferase \\
\hline At1g13340 & 1.0 & 2.1 & 2.0 & 3.4 & 6.8 & 2.0 & Protein of unknown function \\
\hline At5g48850 & 1.1 & 0.8 & 0.7 & 3.3 & 7.4 & 2.2 & Protein of unknown function (ATSDI1) \\
\hline
\end{tabular}

Genes are listed according to the difference of the expression change between $G O$ and wild-type (WT) plants (FC $G O / F C_{W T}$ ) at 6 h. FC $C_{G O} / F C_{W T}$ values higher than 2 are shown in bold face. AGl: gene identification number given by the Arabidopsis Genome Initiative. Genes also induced in catalase loss-of function mutants are highlighted with an asterisk (*) (Inzé et al., 2012). Genes included in the same gene coexpression network of At1g17180 (GSTU25) are highlighted in bold face (http://atted.jp; Obayashi et al., 2009). The gene annotation was retrieved from TAIR (http://arabidopsis.org/index.jsp).

TFs most strongly responding to $\mathrm{H}_{2} \mathrm{O}_{2}$ were identified by comparing their expression FC in GO and WT plants. A TF was considered differentially expressed when the FC in GO was more than 3 -fold $\left(\log _{2} \geq 1.56\right)$ and less than 2-fold in the wild type $\left(\log _{2} \geq 1.0\right)$ (Table 4). Analysis of transcript profiles revealed that the expression of 1449 genes, representing $77 \%$ of all TF genes tested, could be detected (Table A2 in Appendix). The remaining 23\% (431 of the $1880 \mathrm{TFs}$ ) did not yield detectable PCR amplicons, indicating no or very weak expression in the tested material.

At $0.5 \mathrm{~h}$ after shifting plants to ambient $\mathrm{CO}_{2}$ concentration, 78 of the 1449 genes were induced by more than 3-fold in GO plants, whereas in WT plants the expression changes of the same genes were less than 2-fold (Table 4). Using published data the involvement/participation of the TFs in specific biological processes (Table 4) could be assessed, which allowed the classification of the TFs into five functional groups (FG) enriched with specific gene ontology categories (Figure 2). FG1 contains TFs involved in the regulation of proanthocyanidin and anthocyanin biosynthesis
(Table 4 and Figure 2). The TFs TT8 and MYB75 affecting the gene expression of dihydroflavonol 4-reductase (Debeaujon et al., 2003) are included in this FG. FG2 contains TFs affecting developmental processes like lateral root formation (GATA23), flowering (FD1, ANAC089, TEM2 and SNZ), shoot branching (MYB2 and BRC2), senescence (ANAC092/ORE1) and cell division (ANAC068 and HAT4) (Table 4 and Figure 2). The activation of these TFs in GO plants would result in altered growth and flowering (see below and Fahnenstich et al., 2008). FG3 includes TFs and TF-interacting proteins negatively regulating jasmonate (JA) signaling (JAZ7, JAZ8, JAZ9, JAZ10, WRKY50, and WRKY51; Chico et al., 2008; Staswick, 2009; Gao et al., 2011) (Table 4 and Figure 2). JAZ proteins bind directly to the key transcription factor MYC2 and thereby prevent JA-dependent gene transcription (Chini et al., 2007; Pauwels et al., 2010). At the same time JAZ genes are rapidly induced by JA and some are MYC2-regulated. This feedback loop regulation would provide a rapid on and off switch of the pathway involving JA. Transcriptional activation of JAZ genes was found to occur in response to several biotic 
Table 4 | Transcription factors the expression of which was enhanced by more than 3-fold in GO plants, but less than 2-fold in wild-type plants $0.5 \mathrm{~h}$ after shifting plants grown at high $\mathrm{CO}_{2}$ concentration to ambient $\mathrm{CO}_{2}$ concentration.

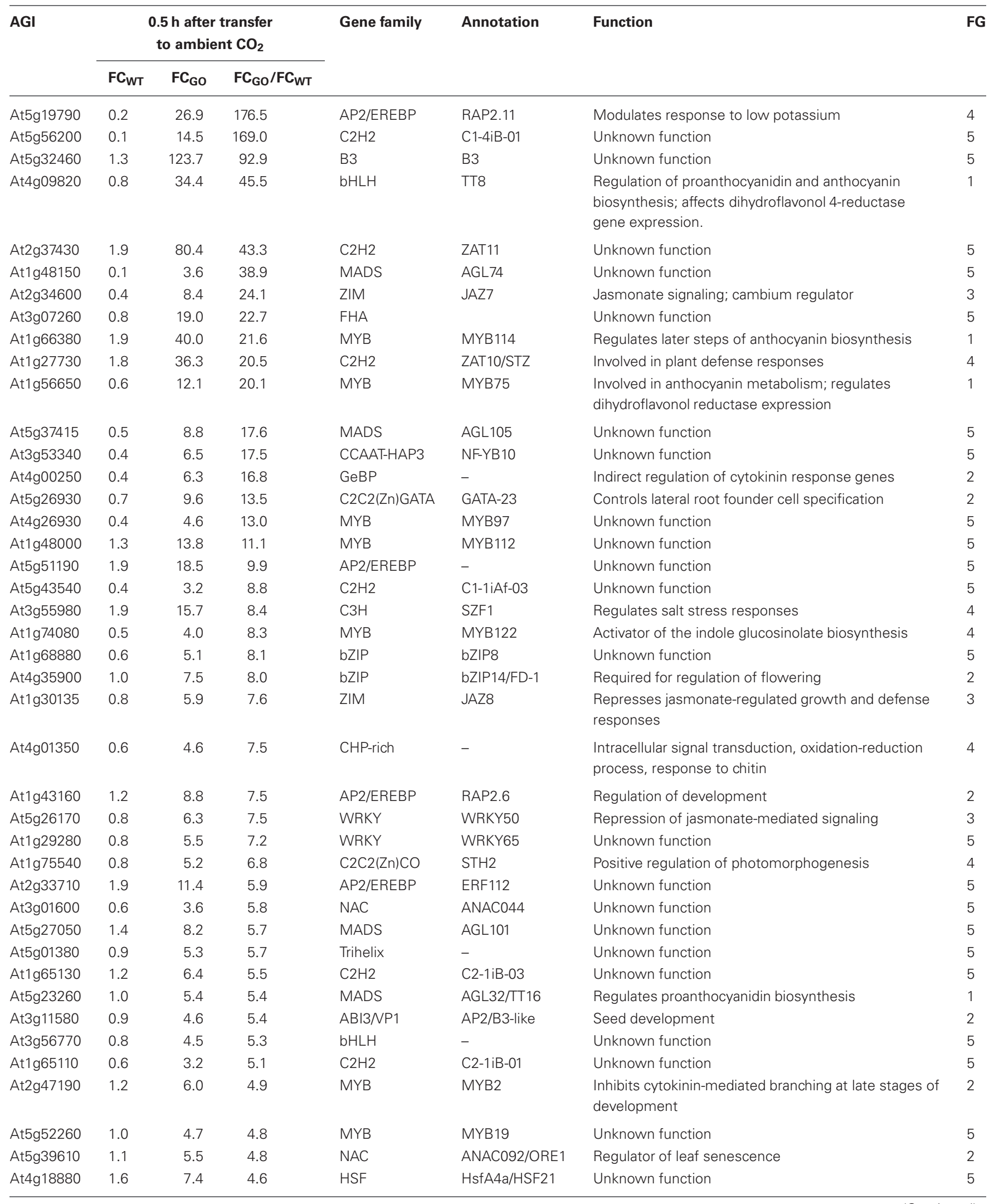


Table 4 | Continued

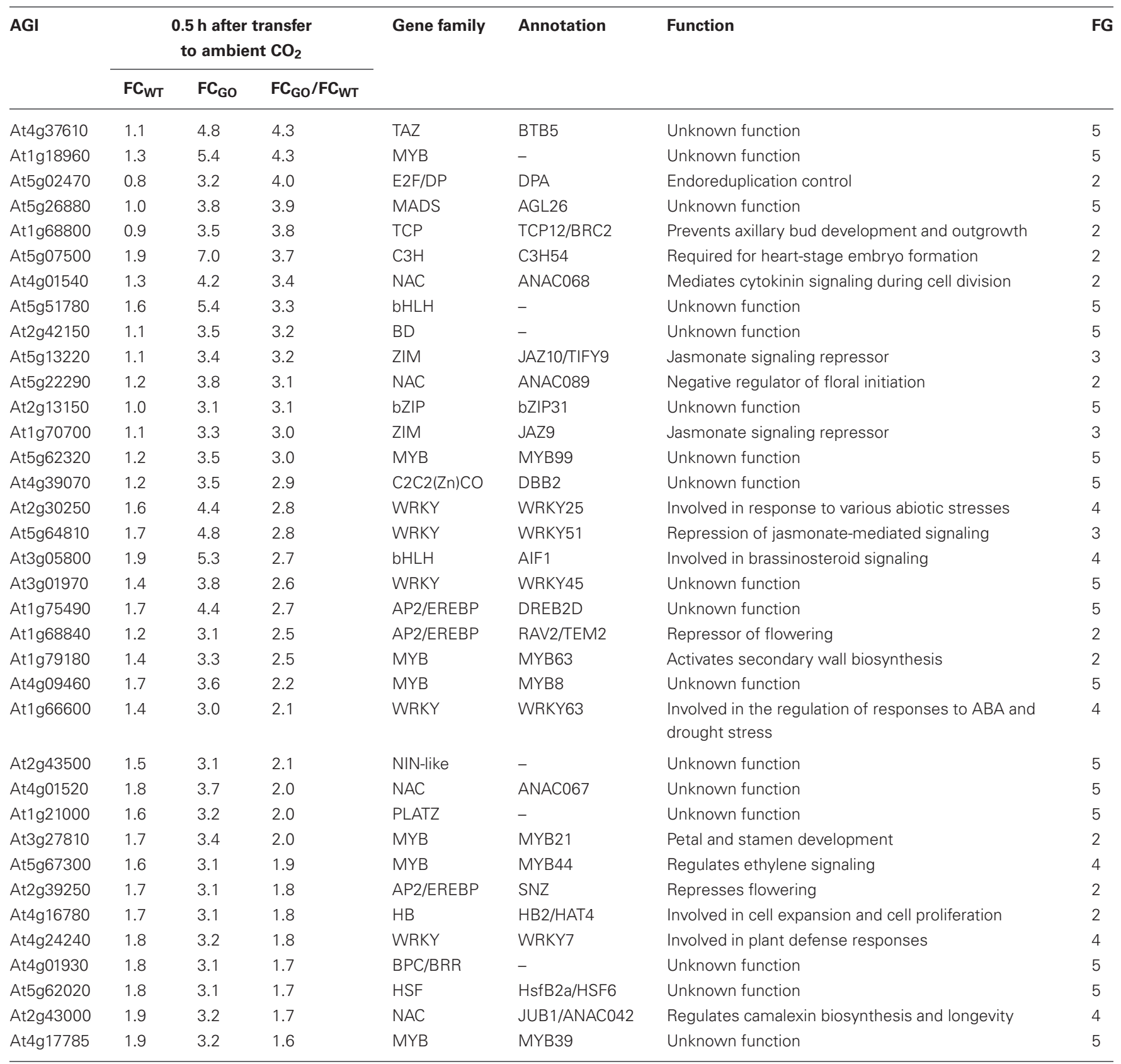

Genes are listed according to the difference of the expression change between GO and wild-type (WT) plants (FC GO/FCWT). AGl: gene identification number given by the Arabidopsis Genome Initiative. A function was described for a gene when its involvement in a biological process/function was experimentally backed up as described in PubMed (www.ncbi.n/m.nih.gov/pubmed) or TAlR (http://arabidopsis.org/index.jsp). FG: functional group.

and abiotic challenges (Yan et al., 2007). JAZ proteins would also exert their effects on post-wound inhibition of vegetative growth in A. thaliana (Yan et al., 2007) and as repressors of necrosis and/or programmed cell death during development in tobacco (Oh et al., 2012). In GO plants, the action of JAZ genes together with those of FG2 would impact growth and reproductive capacity, resulting in altered development under conditions that promote the formation of $\mathrm{H}_{2} \mathrm{O}_{2}$. FG4 includes TFs with diverse functions in plant defense and signaling, e.g., activators of tryptophan-derived biosynthesis of camalexin (JUB1/ANAC042) and indole glucosinolates (MYB122), as well as regulators of photomorphogenesis (STH2) (Table 4 and Figure 2). The early activation of camalexin and indole glucosinolate biosynthesis was also observed in the analysis performed with the ROS-responsive gene platform (Table 1). Finally, FG5 includes TFs with currently unknown functions (Table 4 and Figure 2). 
FG1

Proanthocyanidin and anthocyanin biosynthesis

e.g., TT8, TT16, MYB75, MYB114

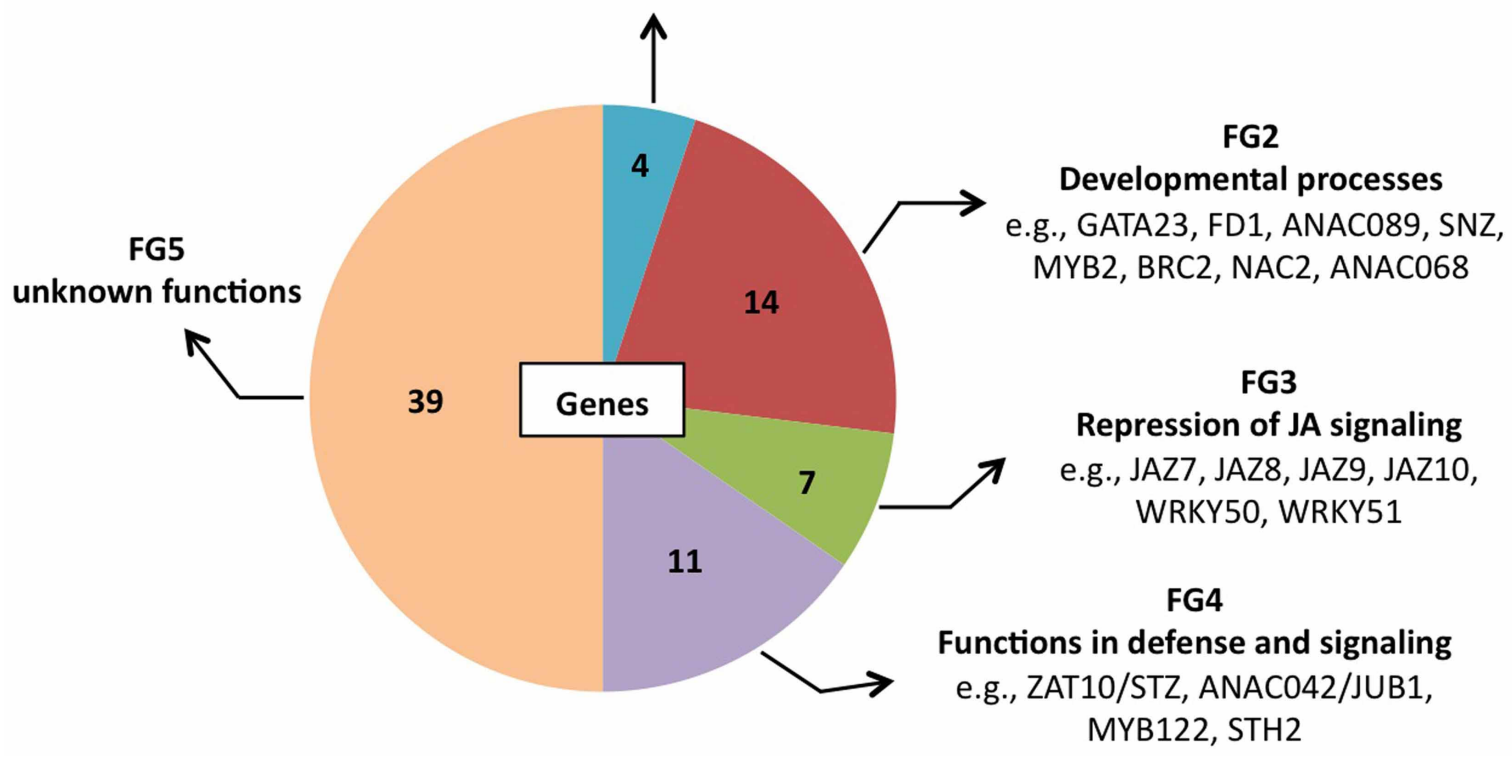

FIGURE 2 | Pie chart representation of the five functional groups (FG) of early $\mathrm{H}_{\mathbf{2}} \mathrm{O}_{\mathbf{2}}$-responsive TFs in GO plants. FG5 includes genes for which a distinct biological function has not been reported yet.

Table 5 | Transcription factors the expression of which was reduced by more than $\mathbf{3 - f o l d}$ in $\mathrm{GO}$ plants $0.5 \mathrm{~h}$ after shifting plants grown at high $\mathrm{CO}_{2}$ concentration to ambient $\mathrm{CO}_{2}$ concentration.

\begin{tabular}{|c|c|c|c|c|c|c|}
\hline \multirow[t]{2}{*}{ AGI } & \multicolumn{3}{|c|}{$\begin{array}{l}0.5 \mathrm{~h} \text { after transfer } \\
\text { to ambient } \mathrm{CO}_{2}\end{array}$} & \multirow[t]{2}{*}{ Gene family } & \multirow[t]{2}{*}{ Annotation } & \multirow[t]{2}{*}{ Function } \\
\hline & $\mathrm{FC}_{\mathrm{WT}}$ & $\mathrm{FC}_{\mathrm{GO}}$ & $\mathrm{FC}_{\mathrm{WT}} / \mathrm{FC}_{\mathrm{GO}}$ & & & \\
\hline At3g02310 & 47.1 & 0.12 & 380.8 & MADS & SEP2/AGL4 & Flower and ovule development \\
\hline At3g13850 & 2.0 & 0.02 & 129.5 & AS2 (LOB) I & ASL30/LBD22 & Unknown function \\
\hline At4g00260 & 21.6 & 0.23 & 92.1 & B3 & MEE45 & Maternal effect embryo arrest 45 \\
\hline At3g60460 & 4.6 & 0.26 & 17.9 & MYB & DUO1 & Plays essential role in sperm cell specification \\
\hline At2g45650 & 3.4 & 0.20 & 17.3 & MADS & AGL6/RSB1 & $\begin{array}{l}\text { Involved in axillary bud formation; control of flowering time and } \\
\text { lateral organ development }\end{array}$ \\
\hline At5g26950 & 2.0 & 0.17 & 12.2 & MADS & AGL93 & Unknown function \\
\hline At3g56660 & 1.3 & 0.26 & 5.0 & bZIP & bZIP49 & Unknown function \\
\hline At5g23000 & 0.6 & 0.18 & 3.3 & MYB & MYB37/RAX1 & $\begin{array}{l}\text { Regulates axillary meristem formation; earliest spatial marker for } \\
\text { future axillary meristems }\end{array}$ \\
\hline
\end{tabular}

Genes are listed according to the difference of the expression change between wild-type (WT) and GO plants (FC WT/FC GO). A function was described for a gene when its involvement in a biological process/function was experimentally backed up as described in PubMed (www.ncbi.nlm.nih.gov/pubmed) or TAlR (http://arabidopsis.org/index.jsp). 
The analysis of the transcript profiles at $0.5 \mathrm{~h}$ after induction of $\mathrm{H}_{2} \mathrm{O}_{2}$ production in $\mathrm{GO}$ plants (Table A2 in Appendix) also revealed a group of 13 genes that are down-regulated in GO relative to WT plants (Table 5). The function of five of these genes is currently unknown, but interestingly, the remaining eight genes positively control developmental processes. The down-regulation of expression of these TFs in GO plants together with the upregulation of expression of TFs negatively affecting development (see FG2, Table 3) would act in concert to arrest growth and especially to delay the transition from the vegetative to the reproductive phase. Consistently, our previous results showed that GO plants growing under photorespiratory conditions are smaller than WT plants, presenting a reduced rosette diameter and a delay in flowering time (Fahnenstich et al., 2008).

\section{CONCLUDING REMARKS}

The metabolic induction of $\mathrm{H}_{2} \mathrm{O}_{2}$ formation in chloroplasts of GO plants under photorespiratory conditions triggered a faster and more prominent transcriptional response of ROS-responsive genes in these plants than in wild type. The changes of the transcriptional activities observed in GO plants early after induction

\section{REFERENCES}

Apel, K., and Hirt, H. (2004). Reactive oxygen species: metabolism, oxidative stress, and signal transduction. Annu. Rev. Plant Biol. 55, 373-399.

Asada, K. (2006). Production and scavenging of reactive oxygen species in chloroplasts and their fuction. Plant Physiol. 141, 391-396.

Baier, M., and Dietz, K.-J. (2005). Chloroplasts as source and target of cellular redox regulation: a discussion on chloroplast redox signals in context of plant physiology. J. Exp. Bot. 56, 1449-1462.

Balazadeh, S., Riaño-Pachón, D. M., and Mueller-Roeber, B. (2008). Transcription factors regulating leaf senescence in Arabidopsis thaliana. Plant Biol. 1, 63-75.

Bednarek, P., Pislewska-Bednarek, M., Svatos, A., Schneider, B., Doubsky, J., Mansurova, M., et al. (2009). A glucosinolate metabolism pathway in living plant cells mediates broad-spectrum antifungal defense. Science 323, 101-106.

Bienert, G. P., Møller, A. L., Kristiansen, K. A., Schulz, A., Møller, I. M., Schjoerring, J. K., et al. (2007). Specific aquaporins facilitate the diffusion of hydrogen peroxide across membranes. J. Biol. Chem. 282, 1183-1192.

Birkenbihl, R. P., Diezel, C., and Somssich, I. E. (2012). Arabidopsis WRKY33 is a key transcriptional regulator of hormonal and metabolic responses toward Botrytis cinerea infection. Plant Physiol. 159, 266-285.
Caldana, C., Scheible, W. R., MuellerRoeber, B., and Ruzicic, S. (2007). A quantitative RT-PCR platform for high-throughput expression profiling of 2500 rice transcription factors. Plant Meth. 3, 7.

Chico, J. M., Chini, A., Fonseca, S. and Solano, R. (2008). JAZ repressors set the rhythm in jasmonate signaling. Curr. Opin. Plant Biol. 11, 486-494.

Chini, A., Fonseca, S., Fernandez, G., Adie, B., Chico, J. M., Lorenzo, O., et al. (2007). The JAZ family of repressors is the missing link in jasmonate signalling. Nature 448, 666-671.

Czechowski, T., Bari, R. P., Stitt, M., Scheible, W. R., and Udvardi, M. K. (2004). Real-time RT-PCR profiling of over 1400 Arabidopsis transcription factors: unprecedented sensitivity reveals novel root- and shoot-specific genes. Plant J. 38, 366-379.

Dat, J., Vandenabeele, S., Vranová, E., Van Montagu, M., Inzé, D., and Van Breusegem, F. (2000). Dual action of the active oxygen species during plant stress responses. Cell Mol. Life Sci. 57, 779-795.

Danon, A., Miersch, O., Felix, G., Camp, R. G., and Apel, K. (2005). Concurrent activation of cell deathregulating signalling pathways by singlet oxygen in Arabidopsis thaliana. Plant J. 41, 68-80.

Debeaujon, I., Nesi, N., Perez, P., Devic, M., Grandjean, O., Caboche, M., et al. (2003). Proanthocyanidinaccumulating cells in Arabidopsis

of $\mathrm{H}_{2} \mathrm{O}_{2}$ production in chloroplasts suggest the establishment of responses that resemble those occurring at early times after wounding or herbivore attack, where $\mathrm{H}_{2} \mathrm{O}_{2}$ is also produced (Orozco-Cardenas and Ryan, 1999). These responses include (1) the retardation of development, which in part would be linked to JA signaling, and (2) the production of the phytoanticipins indole glucosinolates and camalexin. As in the case of herbivore attack, the retardation of development such as reductions in growth and reproduction observed in GO plants could be regarded as a strategy to allow more resource allocation to support defense and tolerance responses (Zavala and Baldwin, 2006). The data also suggest that signals for the early induction of indole glucosinolate and camalexin biosynthesis genes in $\mathrm{GO}$ plants through $\mathrm{H}_{2} \mathrm{O}_{2}$ may originate in chloroplasts as these genes showed no modified expression in catalase loss-of-function mutants (Inzé et al., 2012).

\section{ACKNOWLEDGMENTS}

Financial support was provided by the Deutsche Forschungsgemeinschaft (DFG) through grant MA 2379/11-1 to Veronica G. Maurino, and through grant MU 1199/14-1 (FOR 948) to Bernd Mueller-Roeber.

testa: regulation of differentiation and role in seed development. Plant Cell 15, 2514-2531.

Desikan, R., Mackerness, S., Hancock, and Neill, S. J. (2001). Regulation of the Arabidopsis transcriptome by oxidative stress. Plant Physiol. 127, 159-172.

Fahnenstich, H., Scarpeci, T. E., Valle, E. M., Flügge, U. I., and Maurino, V. G. (2008). Generation of $\mathrm{H}_{2} \mathrm{O}_{2}$ in chloroplasts of Arabidopsis thaliana overexpressing glycolate oxidase as an inducible system to study oxidative stress. Plant Physiol. 148, 719-729.

Foyer, C. H., and Noctor, G. (2005) Redox homeostasis and antioxidant signaling: a metabolic interface between stress perception and physiological responses. Plant Cell 17, 1866-1875.

Fryer, M. J., Ball, L., Oxborough, K., Karpinski, S., Mullineaux, P. M., and Baker, N. R. (2003). Control of ascorbate peroxidase 2 expression by hydrogen peroxide and leaf water status during excess light stress reveals a functional organisation of Arabidopsis leaves. Plant J. 33, 691-705.

Gao, Z., Chung, E. H., Eitas, T. K., and Dangl, J. L. (2011). Plant intracellular innate immune receptor Resistance to Pseudomonas syringae pv. maculicola 1 (RPM1) is activated at, and functions on, the plasma membrane. Proc. Natl. Acad. Sci. U.S.A. 108, 8915.

Gigolashvili, T., Yatusevich, R., Berger, B., Müller, C., and Flügge, U. I.
(2007). The R2R3-MYB transcription factor HAG1/MYB28 is a regulator of methionine-derived glucosinolate biosynthesis in Arabidopsis thaliana. Plant J. 51, 247-261.

Inzé, A., Vanderauwera, S., Hoeberichts, F. A., Vandorpe, M., Van Gaever, T., and Van Breusegem, F. (2012). A subcellular localization compendium of hydrogen peroxide-induced proteins. Plant Cell Environ. 35, 308-320.

Karpinski, S., Reynoldsm, H., Karpinska, B., Wingsle, G., Creissen, G., and Mullineaux, P. (1999). Systemic signalling and acclimation in response to excess excitation energy in Arabidopsis. Science 23, 654-657.

Kliebenstein, D. J., Kroymann, J., Brown, P., Figuth, A., Pedersen, D., Gershenzon, J., et al. (2001). Genetic control of natural variation in Arabidopsis glucosinolate accumulation. Plant Physiol. 126, 811-825.

Leister, D. (2005). Genomics-based dissection of the cross-talk of chloropalsts with the nucleus and mitochondria in Arabidopsis. Gene 354, 110-116.

Li, T., Li, H., Zhang, Y. X., and Liu, J. Y. (2011). Identification and analysis of seven $\mathrm{H}_{2} \mathrm{O}_{2}$-responsive miRNAs and 32 new miRNAs in the seedlings of rice (Oryza sativa L. ssp. indica). Nucleic Acids Res. 39, 2821-2833.

Maurino, V. G., and Flügge, U. I. (2008). Experimental systems to assess the effects of reactive oxygen 
species in plant tissues. Plant Signal. Behav. 3, 919-924.

Maurino, V. G., and Peterhansel, C. (2010). Photorespiration: current status and approaches for metabolic engineering. Curr. Opin. Plant Biol. $13,248-255$.

Miao, Y., Laun, T. M., Smykowski, A., and Zentgraf, U. (2007). Arabidopsis MEKK1 can take a short cut: it can directly interact with senescence-related WRKY53 transcription factor on the protein level and can bind to its promoter. Plant Mol. Biol. 65, 63-76.

Mittler, R., Vandeerauwera, S., Gollery, M., and Van Breusegem, F. (2004). Reactive oxygen gene network of plants. Trends Plant Sci. 9, 490-498.

Møller, I. M., Jensen, P. E., and Hansson, A. (2007). Oxidative modifications to cellular components in plants. Ann. Rev. Plant Biol. 58, 459-481.

Møller, I. M., and Sweetlove, L. J. (2010). ROS signalling-specificity is required. Trends Plant Sci. 15, 370-374.

Mubarakshina, M. M., Ivanov, B. N., Naydov, I. A., Hillier, W., Badger, M. R., and Krieger-Liszkay, A. (2010). Production and diffusion of chloroplastic $\mathrm{H}_{2} \mathrm{O}_{2}$ and its implication to signalling. J. Exp. Bot. 61, 3577-3587.

Neill, S., Desikan, R., and Hancock, J. (2002). Hydrogen peroxide signaling. Curr. Opin. Plant Biol. 5, 388-395.

Obayashi, T., Hayashi, S., Saeki, M., Ohta, H., and Kinoshita, K. (2009). ATTED-II provides coexpressed gene networks for
Arabidopsis. Nucleic Acids Res. 37, 987-991.

Oh, Y., Baldwin, I. T., and Gális, I. (2012). NaJAZh regulates a subset of defense responses against herbivores and spontaneous leaf necrosis in Nicotiana attenuata plants. Plant Physiol. 159, 769-788.

Op den Camp, R. G. L., Przybyla, D., Ochsenbein, C., Laloi, C., Kim, C., Danon, A., et al. (2003). Rapid induction of distinct stress responses after the release of singlet oxygen in Arabidopsis. Plant Cell 15, 2320-2332.

Orozco-Cardenas, M., and Ryan, C. A. (1999). Hydrogen peroxide is generated systemically in plant leaves by wounding and systemin via the octadecanoid pathway. Proc. Natl. Acad. Sci. U.S.A. 96, 6553-6557.

Ort, D. R., and Baker, N. R. (2002). A photoprotective role for $\mathrm{O}_{2}$ as an alternative electron sink in photosynthesis? Curr. Opin. Plant Biol. 5, 193-198.

Pauwels, L., Barbero, G. F., Geerinck, J., Tilleman, S., Grunewald, W., Perez, A. C., et al. (2010). NINJA connects the co-repressor TOPLESS to jasmonate signalling. Nature 464, 788-791.

Petrov, V. D., and Van Breusegem, F. (2012). Hydrogen peroxide- a central hub for information flow in plant cells. AoB Plants. 2012, pls014. doi: 10.1093/aobpla/pls014

Pfalz, M., Mikkelsen, M. D., Bednarek, P., Olsen, C. E., Halkier, B. A., and Kroymann, J. (2011). Metabolic engineering in Nicotiana benthamiana reveals key enzyme functions in Arabidopsis indole glucosinolate modification. Plant Cell 23, 716-729.

Staswick, P. E. (2009). The tryptophan conjugates of jasmonic and indole-3-acetic acids are endogenous auxin inhibitors. Plant Physiol. 150, 1310-1321.

Tripathi, B. N., Bhatt, I., and Dietz, K. J. (2009). Peroxiredoxins: a less studied component of hydrogen peroxide detoxification in photosynthetic organisms. Protoplasma 235 , 3-15.

Van Breusegem, F., Bailey-Serres, J., and Mittler, R. (2008). Unraveling the tapestry of networks involving reactive oxygen species in plants. Plant Physiol. 147, 978-984.

Vandenabeele, S., Vanderauwera, S., Vuylsteke, M., Rombauts, S., Langebartels, C., Seidlitz, H. K., et al. (2004). Catalase deficiency drastically affects gene expression induced by high light in Arabidopsis thaliana. Plant J. 39, 45-58.

Vanderauwera, S., Zimmermann, P., Rombauts, S., Vandenabeele, S., Langebartels, C., Gruissem, W., et al. (2005). Genome-wide analysis of hydrogen peroxide-regulated gene expression in Arabidopsis reveals a high light-induced transcriptional cluster involved in anthocyanin biosynthesis. Plant Physiol. 139, 806-821.

Wu, A., Allu, A. D., Garapati, P. Siddiqui, H., Dortay, H., Zanor, M.I., et al. (2012). JUNGBRUNNEN1, a reactive oxygen species-responsive NAC transcription factor, regulates longevity in Arabidopsis. Plant Cell 24, 482-506.
Yan, Y., Stolz, S., Chetelat, A., Reymond, P., Pagni, M., Dubugnon, L., et al. (2007). A downstream mediator in the growth repression limb of the jasmonate pathway. Plant Cell 19, 2470-2483.

Zavala, J. A., and Baldwin, I. T. (2006). Jasmonic acid signalling and herbivore resistance traits constrain regrowth after herbivore attack in Nicotiana attenuata. Plant Cell Environ. 29, 1751-1760.

Conflict of Interest Statement: The authors declare that the research was conducted in the absence of any commercial or financial relationships that could be construed as a potential conflict of interest.

Received: 17 August 2012; accepted: 01 October 2012; published online: 01 November 2012.

Citation: Balazadeh S, Jaspert N, Arif $M$, Mueller-Roeber B and Maurino VG (2012) Expression of ROS-responsive genes and transcription factors after metabolic formation of $\mathrm{H}_{2} \mathrm{O}_{2}$ in chloroplasts. Front. Plant Sci. 3:234. doi: 10.3389/fpls.2012.00234

This article was submitted to Frontiers in Plant Physiology, a specialty of Frontiers in Plant Science.

Copyright (c) 2012 Balazadeh, Jaspert, Arif, Mueller-Roeber and Maurino. This is an open-access article distributed under the terms of the Creative Commons Attribution License, which permits use, distribution and reproduction in other forums, provided the original authors and source are credited and subject to any copyright notices concerning any third-party graphics etc. 


\section{APPENDIX}

Table A1 | Expression profile of 131 ROS-responsive genes in wild-type (WT) and GO plants after transferring seedlings to ambient $\mathrm{CO}_{2}$ concentration.

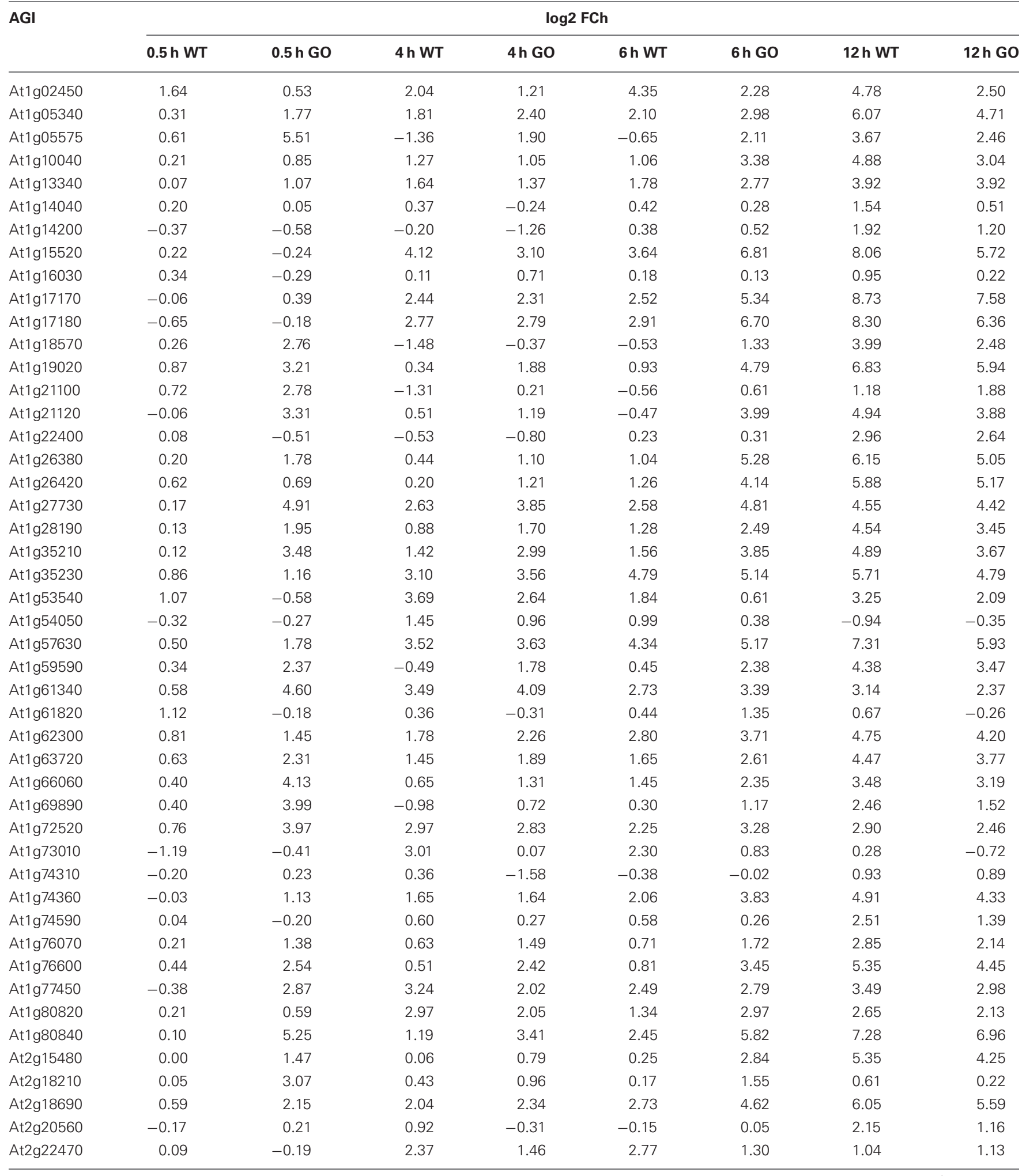


Table A1 | Continued

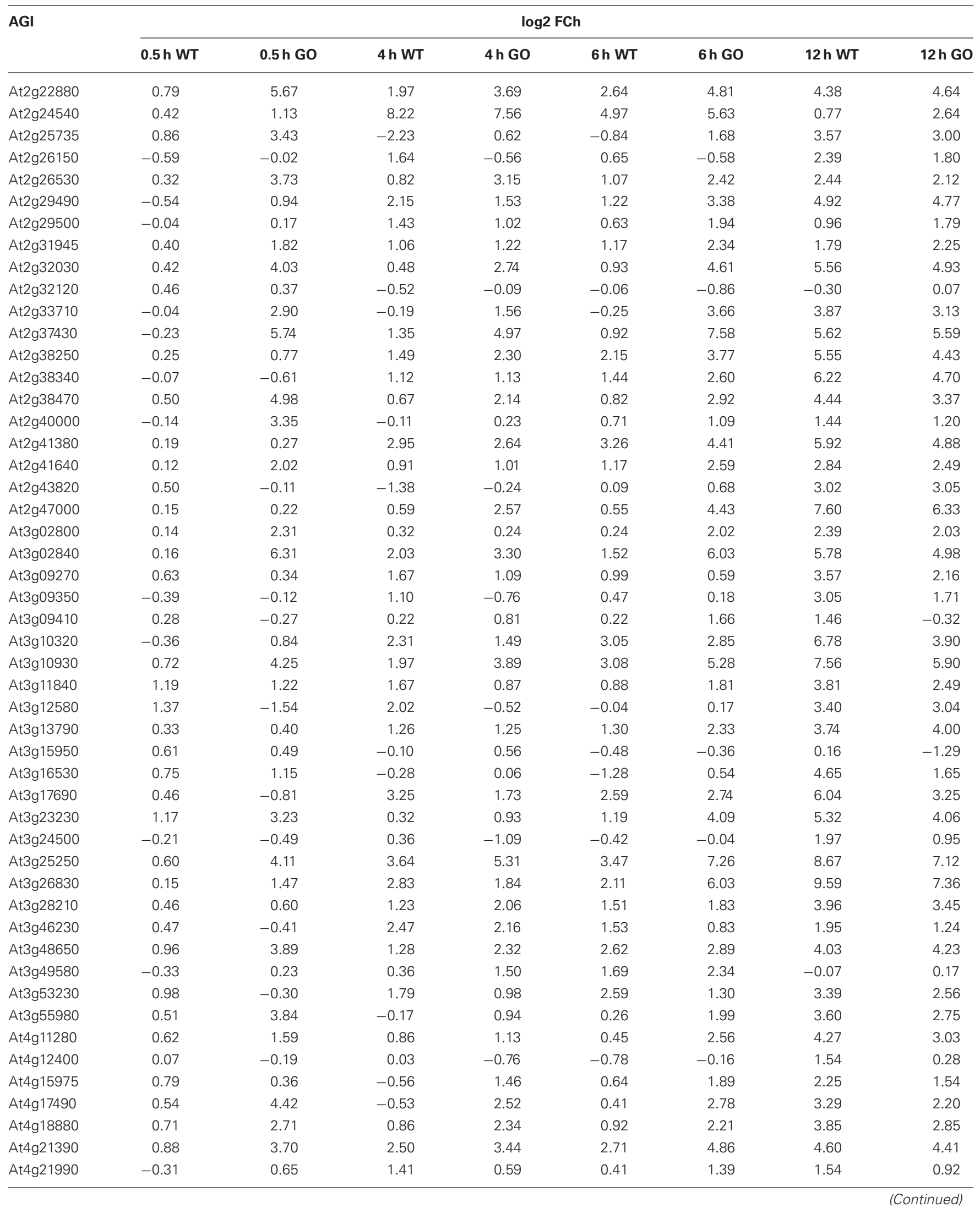


Table A1 | Continued

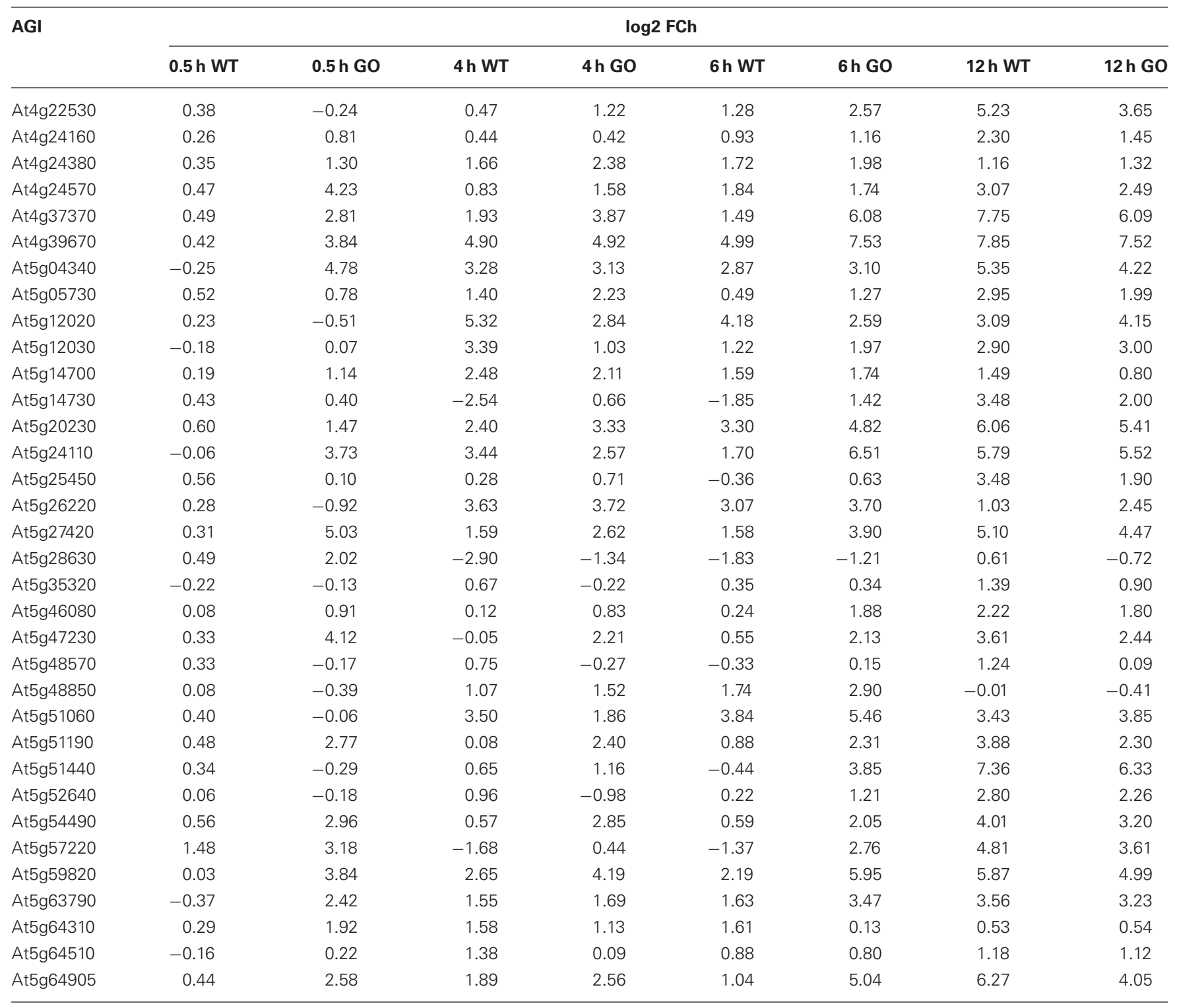

Numbers indicate log2 fold-change (FCh) expression ratio of genes after transferring plants to ambient $\mathrm{CO}_{2}$ concentration compared to high $\mathrm{CO}_{2}$ concentration. Values are means of two biological replicates. 
Table A2 | Numbers indicate log2 fold-change (FCh) expression ratio of genes after transferring plants to ambient $\mathrm{CO}_{2}$ concentration compared to high $\mathrm{CO}_{2}$ concentration.

\begin{tabular}{|c|c|c|c|}
\hline \multirow[t]{2}{*}{ AGI } & \multirow[t]{2}{*}{ Gene family } & \multicolumn{2}{|c|}{$\log 2 \mathrm{FCh}$} \\
\hline & & $0.5 \mathrm{~h}$ WT & $0.5 \mathrm{~h} \mathrm{GO}$ \\
\hline At1g01030 & ABI3NP1 & 0.74 & 0.97 \\
\hline At3g16280 & AP2/EREBP & 0.34 & 0.49 \\
\hline At3g16770 & AP2/EREBP & 0.28 & 0.61 \\
\hline At2g30470 & ABI3NP1 & -0.01 & -0.02 \\
\hline At3g20310 & AP2/EREBP & 0.82 & 0.98 \\
\hline At2g36080 & $\mathrm{ABI3/NP1}$ & 0.53 & 1.08 \\
\hline At2g46870 & ABI3NP1 & -0.03 & -0.16 \\
\hline At3g11580 & $\mathrm{AB|3/NP1}$ & -0.23 & 2.19 \\
\hline At3g23230 & AP2/EREBP & 1.28 & 4.67 \\
\hline At3g25730 & AP2/EREBP & 0.05 & 0.61 \\
\hline At3g61970 & ABI3/NP1 & -0.11 & 0.10 \\
\hline At3g25890 & AP2/EREBP & 0.18 & 0.54 \\
\hline At4g01500 & ABI3/NP1 & 0.92 & 0.50 \\
\hline At3g50260 & AP2/EREBP & 4.28 & 4.54 \\
\hline At4g21550 & ABI3/NP1 & -1.81 & -3.72 \\
\hline At3g54320 & AP2/EREBP & 0.63 & 0.32 \\
\hline At5g60450 & ARF & 0.02 & -0.28 \\
\hline At3g18990 & B3 & -0.02 & 0.53 \\
\hline At5g62000 & ARF & 0.38 & 0.47 \\
\hline At3g46770 & B3 & -1.55 & 0.31 \\
\hline At1g04880 & ARID & 0.01 & -0.59 \\
\hline At3g53310 & B3 & -0.46 & 0.31 \\
\hline At1g20910 & ARID & 0.22 & 0.32 \\
\hline At4g00260 & B3 & 4.43 & -2.09 \\
\hline At4g01580 & B3 & -0.21 & 0.06 \\
\hline At1g76110 & ARID & 0.00 & 0.43 \\
\hline At1g76510 & ARID & 0.03 & 0.81 \\
\hline At4g31620 & B3 & 1.67 & -0.99 \\
\hline At2g46040 & ARID & 0.14 & 0.29 \\
\hline At3g13350 & ARID & -0.31 & 0.31 \\
\hline At3g43240 & ARID & -0.01 & 0.03 \\
\hline At4g31650 & B3 & -0.28 & -0.17 \\
\hline At4g32010 & ABI3/NP1 & 0.36 & 0.21 \\
\hline At5g06250 & ABI3/NP1 & -0.53 & -0.16 \\
\hline At3g57600 & AP2/EREBP & 0.24 & 0.25 \\
\hline At1g14510 & Alfin & 0.10 & 0.17 \\
\hline At3g60490 & AP2/EREBP & 0.06 & 1.23 \\
\hline At2g02470 & Alfin & 0.29 & 0.45 \\
\hline At3g61630 & AP2/EREBP & 0.68 & 0.94 \\
\hline At3g11200 & Alfin & -0.15 & 0.33 \\
\hline At4g06746 & AP2/EREBP & 1.76 & 3.06 \\
\hline At3g42790 & Alfin & -0.01 & 0.42 \\
\hline At4g11140 & AP2/EREBP & -0.16 & -0.03 \\
\hline At5g05610 & Alfin & 0.10 & 0.51 \\
\hline At4g13040 & AP2/EREBP & 0.29 & 0.88 \\
\hline At5g20510 & Alfin & -0.54 & 0.10 \\
\hline At5g26210 & Alfin & -0.11 & 0.58 \\
\hline At4g16750 & AP2/EREBP & -0.56 & 1.55 \\
\hline
\end{tabular}

(Continued)
Table A2 | Continued

\begin{tabular}{|c|c|c|c|}
\hline \multirow[t]{2}{*}{ AGI } & \multirow[t]{2}{*}{ Gene family } & \multicolumn{2}{|c|}{$\log 2$ FCh } \\
\hline & & $0.5 \mathrm{~h}$ WT & $0.5 \mathrm{~h} \mathrm{GO}$ \\
\hline At1g01250 & AP2/EREBP & -0.28 & 0.58 \\
\hline At4g17490 & AP2/EREBP & 4.25 & 5.93 \\
\hline At1g03800 & AP2/EREBP & 1.34 & 0.43 \\
\hline At4g17500 & AP2/EREBP & 1.21 & 2.79 \\
\hline At1g07900 & AS2 (LOB) I & 1.44 & 2.66 \\
\hline At1g16530 & AS2 (LOB) I & 1.40 & 0.91 \\
\hline At4g33280 & B3 & 0.70 & 0.00 \\
\hline At1g31320 & AS2 (LOB) I & 0.77 & 0.35 \\
\hline At4g34400 & B3 & 2.13 & -0.37 \\
\hline At1g65620 & AS2 (LOB) I & 0.21 & 0.09 \\
\hline At5g18000 & B3 & -1.97 & -0.43 \\
\hline At5g18090 & B3 & -0.20 & -0.09 \\
\hline At5g32460 & B3 & 0.41 & 6.95 \\
\hline At2g19820 & AS2 (LOB) I & 0.64 & 1.07 \\
\hline At5g58280 & B3 & -0.34 & -2.35 \\
\hline At2g28500 & AS2 (LOB) I & 2.53 & 4.01 \\
\hline At5g60130 & B3 & -1.04 & 0.36 \\
\hline At5g60140 & B3 & 0.34 & 0.37 \\
\hline At2g30340 & AS2 (LOB) I & 0.19 & 0.81 \\
\hline At1g06160 & AP2/EREBP & -0.34 & 1.14 \\
\hline At4g23750 & AP2/EREBP & 0.75 & 0.56 \\
\hline At4g25470 & AP2/EREBP & 6.18 & 6.85 \\
\hline At1g12630 & AP2/EREBP & -0.01 & 0.40 \\
\hline At4g25480 & AP2/EREBP & 6.17 & 5.68 \\
\hline At1g12890 & AP2/EREBP & 1.89 & 2.51 \\
\hline At4g27950 & AP2/EREBP & 0.73 & -0.08 \\
\hline At1g13260 & AP2/EREBP & 0.63 & 1.06 \\
\hline At4g28140 & AP2/EREBP & 5.79 & 8.83 \\
\hline At4g31060 & AP2/EREBP & -0.16 & -0.16 \\
\hline At1g16060 & AP2/EREBP & 0.22 & 0.42 \\
\hline At4g32800 & AP2/EREBP & -0.09 & 0.94 \\
\hline At1g19210 & AP2/EREBP & 3.96 & 4.18 \\
\hline At4g34410 & AP2/EREBP & 6.02 & 8.13 \\
\hline At1g21910 & AP2/EREBP & -0.50 & 0.27 \\
\hline At4g36900 & AP2/EREBP & 0.31 & 1.15 \\
\hline At1g22190 & AP2/EREBP & 5.46 & 2.69 \\
\hline At4g36920 & AP2/EREBP & -0.12 & 0.06 \\
\hline At1g22810 & AP2/EREBP & 6.10 & 7.03 \\
\hline At4g37750 & AP2/EREBP & 0.16 & 0.01 \\
\hline At1g01260 & $\mathrm{bHLH}$ & 0.40 & 0.98 \\
\hline At2g40470 & AS2 (LOB) I & -0.03 & 1.14 \\
\hline At1g02340 & bHLH & -0.38 & 0.48 \\
\hline At1g03040 & $\mathrm{bHLH}$ & 0.05 & 0.42 \\
\hline At1g05805 & $\mathrm{bHLH}$ & 0.26 & 0.69 \\
\hline At1g06150 & bHLH & 0.09 & -0.14 \\
\hline At2g45420 & AS2 (LOB) I & -0.51 & 1.14 \\
\hline At1g06170 & bHLH & -0.71 & 0.30 \\
\hline At1g09250 & bHLH & -0.08 & 0.96 \\
\hline At3g11090 & AS2 (LOB) I & -0.12 & 0.14 \\
\hline At1g09530 & $\mathrm{bHLH}$ & 0.01 & 0.32 \\
\hline
\end{tabular}


Table A2 | Continued

\begin{tabular}{|c|c|c|c|}
\hline \multirow[t]{2}{*}{ AGI } & \multirow[t]{2}{*}{ Gene family } & \multicolumn{2}{|c|}{$\log 2$ FCh } \\
\hline & & $0.5 \mathrm{~h}$ WT & $0.5 \mathrm{~h} \mathrm{GO}$ \\
\hline At3g13850 & AS2 (LOB) I & 1.00 & -6.02 \\
\hline At1g10120 & bHLH & -0.24 & -0.09 \\
\hline At3g26620 & AS2 (LOB) I & 0.44 & 1.02 \\
\hline At1g10610 & bHLH & -0.31 & -0.23 \\
\hline At3g27650 & AS2 (LOB) I & -0.85 & 0.20 \\
\hline At1g12860 & bHLH & -0.38 & 0.00 \\
\hline At1g22985 & AP2/EREBP & -0.01 & 0.73 \\
\hline At4g39780 & AP2/EREBP & 1.31 & 1.31 \\
\hline At5g05410 & AP2/EREBP & 2.04 & 2.95 \\
\hline At1g25560 & AP2/EREBP & -0.64 & 0.28 \\
\hline At5g07580 & AP2/EREBP & -1.35 & -0.87 \\
\hline At5g10510 & AP2/EREBP & 0.85 & -0.42 \\
\hline At1g28360 & AP2/EREBP & 1.36 & 0.70 \\
\hline At5g11190 & AP2/EREBP & -0.20 & 0.55 \\
\hline At1g28370 & AP2/EREBP & 4.77 & 6.09 \\
\hline At5g11590 & AP2/EREBP & 0.72 & 1.28 \\
\hline At1g33760 & AP2/EREBP & 2.49 & 3.60 \\
\hline At5g13330 & AP2/EREBP & 0.32 & 0.69 \\
\hline At1g36060 & AP2/EREBP & 1.26 & 0.20 \\
\hline At5g13910 & AP2/EREBP & -0.26 & -0.89 \\
\hline At1g43160 & AP2/EREBP & 0.23 & 3.13 \\
\hline At1g44830 & AP2/EREBP & -2.15 & -0.73 \\
\hline At1g46768 & AP2/EREBP & 1.17 & 1.07 \\
\hline At3g27940 & AS2 (LOB) I & -0.16 & 0.39 \\
\hline At1g18400 & bHLH & -0.34 & 0.85 \\
\hline At1g22490 & bHLH & 0.09 & 0.48 \\
\hline At3g50510 & AS2 (LOB) I & -0.42 & -0.90 \\
\hline At4g00210 & AS2 (LOB) I & -0.04 & -0.62 \\
\hline At1g26260 & bHLH & 0.27 & 0.61 \\
\hline At4g00220 & AS2 (LOB) I & 0.19 & 0.64 \\
\hline At1g27660 & bHLH & -0.17 & 0.58 \\
\hline At4g22700 & AS2 (LOB) I & 2.94 & 6.51 \\
\hline At1g29950 & bHLH & -0.04 & 0.21 \\
\hline At5g63090 & AS2 (LOB) I & -0.61 & 1.16 \\
\hline At1g31050 & bHLH & -0.13 & 0.66 \\
\hline At1g32640 & $\mathrm{bHLH}$ & 1.91 & 2.86 \\
\hline At1g35460 & bHLH & 0.12 & 0.70 \\
\hline At5g19790 & AP2/EREBP & -2.72 & 4.75 \\
\hline At1g50640 & AP2/EREBP & 1.59 & 1.23 \\
\hline At5g25190 & AP2/EREBP & 0.01 & 0.99 \\
\hline At5g25390 & AP2/EREBP & -1.43 & 1.04 \\
\hline At5g25810 & AP2/EREBP & -0.56 & 0.18 \\
\hline At1g53170 & AP2/EREBP & 2.63 & 3.00 \\
\hline At1g53910 & AP2/EREBP & 0.13 & 0.61 \\
\hline At5g44210 & AP2/EREBP & 1.55 & 1.59 \\
\hline At5g47220 & AP2/EREBP & 1.15 & 2.75 \\
\hline At1g63040 & AP2/EREBP & 1.40 & 1.52 \\
\hline At5g47230 & AP2/EREBP & 4.34 & 4.94 \\
\hline At1g64380 & AP2/EREBP & 4.20 & 4.16 \\
\hline At1g68550 & AP2/EREBP & 0.10 & -0.13 \\
\hline
\end{tabular}

(Continued)
Table A2 | Continued

AGI Gene family $\quad \log 2 \mathrm{FCh}$

\begin{tabular}{|c|c|c|c|}
\hline & & $0.5 \mathrm{~h} W T$ & $0.5 \mathrm{~h} \mathrm{GO}$ \\
\hline At5g51190 & AP2/EREBP & 0.91 & 4.21 \\
\hline At1g68840 & AP2/EREBP & 0.32 & 1.62 \\
\hline At1g43770 & bHLH & -0.44 & 0.19 \\
\hline At3g02550 & AS2 (LOB) ॥ & 0.40 & -0.76 \\
\hline At3g49940 & AS2 (LOB) II & 1.10 & 1.64 \\
\hline At1g51070 & bHLH & 0.12 & 0.63 \\
\hline At4g37540 & AS2 (LOB) ॥ & 0.47 & 1.39 \\
\hline At1g51140 & bHLH & -0.08 & 0.61 \\
\hline At5g67420 & AS2 (LOB) ॥ & 1.15 & 1.20 \\
\hline At1g59640 & bHLH & 0.02 & -0.10 \\
\hline At1g04100 & Aux/IAA & -0.74 & 0.52 \\
\hline At1g04240 & Aux/IAA & -0.77 & 0.28 \\
\hline At1g62975 & bHLH & 0.22 & 0.71 \\
\hline At1g04250 & Aux/IAA & -0.33 & 0.99 \\
\hline At1g63650 & bHLH & -0.09 & 0.44 \\
\hline At1g04550 & Aux/IAA & 0.18 & 0.50 \\
\hline At1g15050 & Aux/IAA & 0.46 & 0.92 \\
\hline At1g68240 & bHLH & 0.35 & 0.59 \\
\hline At1g15580 & Aux/IAA & 0.12 & 1.26 \\
\hline At1g68810 & bHLH & -0.02 & 0.74 \\
\hline At1g51950 & Aux/IAA & -0.20 & 0.45 \\
\hline At1g68920 & bHLH & -0.18 & 0.15 \\
\hline At1g71130 & AP2/EREBP & -0.06 & 0.73 \\
\hline At5g52020 & AP2/EREBP & 1.59 & 2.60 \\
\hline At5g53290 & AP2/EREBP & 0.94 & -0.17 \\
\hline At1g71520 & AP2/EREBP & 3.60 & 5.02 \\
\hline At5g57390 & AP2/EREBP & 0.39 & 0.17 \\
\hline At1g72360 & AP2/EREBP & -0.55 & 0.43 \\
\hline At5g60120 & AP2/EREBP & 0.40 & 0.42 \\
\hline At5g61590 & AP2/EREBP & -2.96 & -1.76 \\
\hline At1g74930 & AP2/EREBP & 4.49 & 4.80 \\
\hline At5g61600 & AP2/EREBP & 2.71 & 3.70 \\
\hline At1g75490 & AP2/EREBP & 0.73 & 2.15 \\
\hline At5g61890 & AP2/EREBP & 1.25 & 1.22 \\
\hline At1g77200 & AP2/EREBP & -0.98 & 0.45 \\
\hline At5g64750 & AP2/EREBP & 2.48 & 2.27 \\
\hline At1g77640 & AP2/EREBP & 0.09 & -0.48 \\
\hline At5g65130 & AP2/EREBP & 0.56 & 0.64 \\
\hline At1g78080 & AP2/EREBP & 2.43 & 2.50 \\
\hline At5g65510 & AP2/EREBP & -0.63 & -1.49 \\
\hline At1g79700 & AP2/EREBP & -0.22 & 0.66 \\
\hline At1g52830 & Aux/IAA & -0.12 & 0.08 \\
\hline At1g69010 & bHLH & 0.15 & 0.79 \\
\hline At1g80390 & Aux/IAA & 1.08 & 1.72 \\
\hline At2g01200 & Aux/IAA & 0.54 & 1.25 \\
\hline At1g72210 & bHLH & 1.02 & -0.58 \\
\hline At2g22670 & Aux/IAA & 0.01 & 0.19 \\
\hline At1g73830 & $\mathrm{bHLH}$ & -1.22 & -0.72 \\
\hline At2g33310 & Aux/IAA & 0.04 & 0.16 \\
\hline At2g46990 & Aux/IAA & 0.07 & 1.22 \\
\hline
\end{tabular}

(Continued) 
Table A2 | Continued

\begin{tabular}{|c|c|c|c|}
\hline \multirow[t]{2}{*}{ AGI } & \multirow[t]{2}{*}{ Gene family } & \multicolumn{2}{|c|}{$\log 2 \mathrm{FCh}$} \\
\hline & & $0.5 \mathrm{~h} W T$ & $0.5 \mathrm{~h} \mathrm{GO}$ \\
\hline At3g04730 & Aux/IAA & -0.10 & 0.48 \\
\hline At3g15540 & Aux/IAA & -0.25 & 0.47 \\
\hline At2g18300 & bHLH & -0.68 & 0.05 \\
\hline At3g16500 & Aux/IAA & 0.10 & 0.71 \\
\hline At2g20095 & bHLH & -0.12 & -0.12 \\
\hline At3g17600 & Aux/IAA & -0.27 & 1.57 \\
\hline At2g20180 & bHLH & -0.53 & -0.23 \\
\hline At3g23030 & Aux/IAA & 0.77 & 1.53 \\
\hline At3g23050 & Aux/IAA & -0.39 & 0.82 \\
\hline At5g67180 & AP2/EREBP & -0.23 & -0.32 \\
\hline At2g20880 & AP2/EREBP & 5.11 & 7.22 \\
\hline At5g67190 & AP2/EREBP & 0.53 & 1.47 \\
\hline At2g22200 & AP2/EREBP & 2.28 & 3.07 \\
\hline At1g19220 & ARF & 0.14 & -0.07 \\
\hline At2g23340 & AP2/EREBP & 0.86 & 0.80 \\
\hline At1g19850 & ARF & 0.49 & -0.37 \\
\hline At2g25820 & AP2/EREBP & 0.00 & 1.42 \\
\hline At1g30330 & $\mathrm{ARF}$ & -0.01 & 0.08 \\
\hline At2g28550 & AP2/EREBP & 0.34 & 0.56 \\
\hline At2g31230 & AP2/EREBP & 0.80 & 1.51 \\
\hline At2g33710 & AP2/EREBP & 0.95 & 3.51 \\
\hline At2g35700 & AP2/EREBP & 0.17 & 0.93 \\
\hline At2g38340 & AP2/EREBP & 0.45 & -0.20 \\
\hline At2g39250 & AP2/EREBP & 0.76 & 1.64 \\
\hline At3g62100 & Aux/IAA & 0.32 & 0.57 \\
\hline At2g22770 & bHLH & -0.12 & 0.93 \\
\hline At4g14550 & Aux/IAA & -0.28 & 0.76 \\
\hline At2g24260 & bHLH & 0.79 & 0.38 \\
\hline At4g14560 & Aux/IAA & 0.83 & 1.05 \\
\hline At2g27230 & bHLH & -0.04 & 0.21 \\
\hline At4g28640 & Aux/IAA & -0.11 & 0.17 \\
\hline At2g28160 & bHLH & -0.42 & 0.10 \\
\hline At4g29080 & Aux/IAA & -0.18 & 0.62 \\
\hline At4g32280 & Aux/IAA & -1.14 & 0.38 \\
\hline At5g25890 & Aux/IAA & 0.21 & 1.03 \\
\hline At2g31220 & bHLH & -0.84 & -0.45 \\
\hline At5g43700 & Aux/IAA & -0.45 & 0.70 \\
\hline At2g31280 & bHLH & 0.10 & 0.00 \\
\hline At5g65670 & Aux/IAA & -0.05 & 0.63 \\
\hline At2g40200 & bHLH & -0.23 & -0.03 \\
\hline At1g16640 & B3 & 0.06 & 0.46 \\
\hline At2g41130 & $\mathrm{bHLH}$ & 0.08 & 1.11 \\
\hline At2g41240 & bHLH & -0.57 & -0.87 \\
\hline At1g59750 & ARF & 0.07 & 0.03 \\
\hline At2g41710 & AP2/EREBP & 0.18 & 0.38 \\
\hline At2g28350 & ARF & -0.62 & -0.35 \\
\hline At2g44840 & AP2/EREBP & 3.55 & 6.34 \\
\hline At2g33860 & ARF & 0.69 & -1.21 \\
\hline At2g44940 & AP2/EREBP & -1.71 & 0.13 \\
\hline At2g46530 & ARF & 0.16 & 0.35 \\
\hline
\end{tabular}

(Continued)
Table A2 | Continued

\begin{tabular}{|c|c|c|c|}
\hline \multirow[t]{2}{*}{ AGI } & \multirow[t]{2}{*}{ Gene family } & \multicolumn{2}{|c|}{$\log 2 \mathrm{FCh}$} \\
\hline & & $0.5 \mathrm{~h}$ WT & $0.5 \mathrm{~h} \mathrm{GO}$ \\
\hline At2g46310 & AP2/EREBP & 0.82 & 0.82 \\
\hline At3g61830 & ARF & 0.10 & 0.06 \\
\hline At2g47520 & AP2/EREBP & 0.66 & 0.34 \\
\hline At4g23980 & ARF & 0.23 & 0.39 \\
\hline At3g11020 & AP2/EREBP & 2.08 & 1.74 \\
\hline At4g30080 & ARF & -0.25 & 0.49 \\
\hline At3g14230 & AP2/EREBP & -0.02 & 0.72 \\
\hline At3g15210 & AP2/EREBP & 3.50 & 4.06 \\
\hline At5g37020 & ARF & 0.16 & 0.28 \\
\hline At1g49480 & B3 & -0.09 & 0.45 \\
\hline At2g42280 & bHLH & 0.28 & 0.96 \\
\hline At2g42300 & $\mathrm{bHLH}$ & -0.56 & -0.31 \\
\hline At2g24650 & B3 & -0.39 & -0.14 \\
\hline At2g43010 & bHLH & -0.31 & 0.16 \\
\hline At2g24680 & B3 & -0.08 & -0.28 \\
\hline At2g43140 & $\mathrm{bHLH}$ & 0.57 & -0.38 \\
\hline At2g24690 & B3 & -0.13 & 0.18 \\
\hline At2g46510 & bHLH & 0.71 & 1.44 \\
\hline At2g24700 & B3 & 0.73 & -1.17 \\
\hline At2g46810 & bHLH & -0.30 & 0.56 \\
\hline At2g35310 & B3 & -0.37 & -1.10 \\
\hline At2g46970 & $\mathrm{bHLH}$ & -0.05 & 0.23 \\
\hline At3g06160 & B3 & -0.09 & -0.37 \\
\hline At2g47270 & $\mathrm{bHLH}$ & 2.01 & 2.21 \\
\hline At3g06220 & B3 & 0.29 & -1.37 \\
\hline At3g05800 & $\mathrm{bHLH}$ & 0.95 & 2.40 \\
\hline At3g06120 & bHLH & -0.05 & 0.15 \\
\hline At3g18960 & B3 & -7.62 & -0.50 \\
\hline At3g06590 & bHLH & -0.13 & 0.39 \\
\hline At3g07340 & $\mathrm{bHLH}$ & -0.64 & -0.30 \\
\hline At1g03970 & bZIP & 0.13 & 0.69 \\
\hline At3g17100 & $\mathrm{bHLH}$ & -0.45 & 0.12 \\
\hline At1g06070 & bZIP & 0.42 & 0.19 \\
\hline At3g19500 & $\mathrm{bHLH}$ & -0.26 & 1.20 \\
\hline At1g06850 & bZIP & -0.43 & -0.02 \\
\hline At3g19860 & $\mathrm{bHLH}$ & 0.41 & 0.25 \\
\hline At3g20640 & $\mathrm{bHLH}$ & 0.33 & 0.92 \\
\hline At1g13600 & bZIP & -1.07 & 0.97 \\
\hline At3g21330 & $\mathrm{bHLH}$ & 0.35 & 0.61 \\
\hline At1g19490 & bZIP & 0.84 & 0.90 \\
\hline At3g22100 & $\mathrm{bHLH}$ & 1.18 & 3.16 \\
\hline At1g22070 & bZIP & -0.40 & 0.67 \\
\hline At3g23210 & $\mathrm{bHLH}$ & 0.99 & 0.86 \\
\hline At1g32150 & bZIP & 0.47 & 0.72 \\
\hline At3g23690 & $\mathrm{bHLH}$ & -0.16 & 0.26 \\
\hline At3g24140 & bHLH & 0.40 & 0.37 \\
\hline At3g25710 & $\mathrm{bHLH}$ & 0.75 & 0.89 \\
\hline At1g43700 & bZIP & -0.04 & 0.56 \\
\hline At2g24790 & C2C2(Zn) CO-like & 0.18 & 0.97 \\
\hline At1g65110 & $\mathrm{C} 2 \mathrm{H} 2$ & -0.67 & 1.69 \\
\hline
\end{tabular}


Table A2 | Continued

\begin{tabular}{|c|c|c|c|}
\hline \multirow[t]{2}{*}{ AGI } & \multirow[t]{2}{*}{ Gene family } & \multicolumn{2}{|c|}{$\log 2 \mathrm{FCh}$} \\
\hline & & $0.5 \mathrm{~h} W T$ & $0.5 \mathrm{~h} \mathrm{GO}$ \\
\hline At2g31380 & C2C2(Zn) CO-like & 0.59 & 0.81 \\
\hline At2g33500 & C2C2(Zn) CO-like & 0.11 & 0.65 \\
\hline At1g01930 & $\mathrm{C} 2 \mathrm{H} 2$ & 0.09 & 0.61 \\
\hline At2g47890 & C2C2(Zn) CO-like & 1.09 & 0.50 \\
\hline At1g02030 & $\mathrm{C} 2 \mathrm{H} 2$ & 0.55 & 0.82 \\
\hline At1g02040 & $\mathrm{C} 2 \mathrm{H} 2$ & -0.50 & 0.39 \\
\hline At3g07650 & C2C2(Zn) CO-like & 0.87 & 1.08 \\
\hline At1g03840 & $\mathrm{C} 2 \mathrm{H} 2$ & -0.66 & -0.15 \\
\hline At3g21150 & C2C2(Zn) CO-like & 2.51 & 2.93 \\
\hline At1g04445 & $\mathrm{C} 2 \mathrm{H} 2$ & 2.53 & 0.68 \\
\hline At3g21880 & C2C2(Zn) CO-like & 2.16 & 2.79 \\
\hline At1g04990 & $\mathrm{C} 2 \mathrm{H} 2$ & 0.57 & 0.90 \\
\hline At3g21890 & C2C2(Zn) CO-like & 2.59 & 3.55 \\
\hline At1g08290 & $\mathrm{C} 2 \mathrm{H} 2$ & 0.59 & 0.38 \\
\hline At1g11490 & $\mathrm{C} 2 \mathrm{H} 2$ & -0.51 & 0.33 \\
\hline At3g26744 & bHLH & 0.13 & 0.20 \\
\hline At1g45249 & bZIP & 0.80 & 1.01 \\
\hline At3g47640 & bHLH & 0.72 & 0.61 \\
\hline At1g49720 & bZIP & 0.49 & 0.83 \\
\hline At1g58110 & bZIP & 0.45 & 0.86 \\
\hline At3g56220 & bHLH & -1.25 & 0.07 \\
\hline At1g68640 & bZIP & -1.16 & 0.31 \\
\hline At3g56770 & bHLH & -0.24 & 2.17 \\
\hline At1g68880 & bZIP & -0.67 & 2.34 \\
\hline At3g56970 & $\mathrm{bHLH}$ & 0.11 & 0.05 \\
\hline At1g75390 & bZIP & -0.43 & -0.27 \\
\hline At3g56980 & bHLH & 0.00 & -1.18 \\
\hline At1g77920 & bZIP & -0.42 & 1.26 \\
\hline At3g57800 & bHLH & -0.13 & 0.19 \\
\hline At2g04038 & bZIP & -0.54 & -0.49 \\
\hline At3g59060 & bHLH & 0.26 & 0.45 \\
\hline At3g61950 & bHLH & -0.02 & -0.58 \\
\hline At3g62090 & bHLH & -1.46 & 1.29 \\
\hline At2g13150 & bZIP & 0.01 & 1.62 \\
\hline At4g27310 & C2C2(Zn) CO-like & 0.45 & 0.48 \\
\hline At4g38960 & C2C2(Zn) CO-like & 0.48 & 1.05 \\
\hline At1g14580 & $\mathrm{C} 2 \mathrm{H} 2$ & 2.14 & 0.20 \\
\hline At4g39070 & C2C2(Zn) CO-like & 0.25 & 1.79 \\
\hline At1g24625 & $\mathrm{C} 2 \mathrm{H} 2$ & -0.61 & 0.31 \\
\hline At5g15840 & C2C2(Zn) CO-like & 0.78 & 0.61 \\
\hline At1g24630 & $\mathrm{C} 2 \mathrm{H} 2$ & -0.54 & 0.33 \\
\hline At5g15850 & C2C2(Zn) CO-like & 0.53 & 1.05 \\
\hline At1g25250 & $\mathrm{C} 2 \mathrm{H} 2$ & 0.37 & 0.91 \\
\hline At5g24930 & C2C2(Zn) CO-like & 0.28 & 0.89 \\
\hline At1g26590 & $\mathrm{C} 2 \mathrm{H} 2$ & -1.62 & 0.50 \\
\hline At5g48250 & C2C2(Zn) CO-like & -0.69 & 0.48 \\
\hline At1g26610 & $\mathrm{C} 2 \mathrm{H} 2$ & 0.12 & 1.22 \\
\hline At5g54470 & C2C2(Zn) CO-like & 1.52 & 1.54 \\
\hline At1g27730 & $\mathrm{C} 2 \mathrm{H} 2$ & 0.82 & 5.18 \\
\hline At5g57660 & C2C2(Zn) CO-like & 0.19 & 0.82 \\
\hline
\end{tabular}

(Continued)
Table A2 | Continued

\begin{tabular}{|c|c|c|c|}
\hline \multirow[t]{2}{*}{ AGI } & \multirow[t]{2}{*}{ Gene family } & \multicolumn{2}{|c|}{$\log 2 \mathrm{FCh}$} \\
\hline & & $0.5 \mathrm{~h} W T$ & $0.5 \mathrm{~h} \mathrm{GO}$ \\
\hline At1g07640 & C2C2(Zn) DOF & 0.08 & -0.17 \\
\hline At1g29600 & $\mathrm{C} 2 \mathrm{H} 2$ & 0.08 & -0.17 \\
\hline At1g30970 & $\mathrm{C} 2 \mathrm{H} 2$ & 0.68 & -0.31 \\
\hline At1g26790 & C2C2(Zn) DOF & 3.01 & -0.64 \\
\hline At1g34370 & $\mathrm{C} 2 \mathrm{H} 2$ & 0.69 & 0.88 \\
\hline At4g00050 & bHLH & 0.72 & 0.13 \\
\hline At2g16770 & bZIP & -0.20 & 0.52 \\
\hline At2g17770 & bZIP & 0.58 & -0.17 \\
\hline At $4 \mathrm{~g} 00480$ & bHLH & -0.33 & 0.45 \\
\hline At2g18160 & bZIP & -0.71 & -0.12 \\
\hline At4g00870 & bHLH & 0.28 & -0.84 \\
\hline At2g21230 & bZIP & -0.06 & 0.48 \\
\hline At4g01460 & bHLH & 0.42 & 0.87 \\
\hline At4g02590 & bHLH & 0.46 & 0.34 \\
\hline At2g22850 & bZIP & 0.04 & 0.88 \\
\hline At4g05170 & bHLH & -0.31 & 0.75 \\
\hline At2g31370 & bZIP & -0.02 & 0.42 \\
\hline At4g09180 & bHLH & -0.09 & 0.20 \\
\hline At4g09820 & bHLH & -0.41 & 5.10 \\
\hline At2g35530 & bZIP & 0.91 & 0.48 \\
\hline At4g14410 & bHLH & 0.02 & 0.67 \\
\hline At2g36270 & bZIP & 1.10 & -1.17 \\
\hline At4g16430 & bHLH & 0.11 & 0.77 \\
\hline At2g40620 & bZIP & 0.26 & 0.07 \\
\hline At4g17880 & bHLH & -0.77 & 0.12 \\
\hline At2g40950 & bZIP & 0.28 & 0.42 \\
\hline At1g28310 & C2C2(Zn) DOF & -0.03 & 0.26 \\
\hline At1g29160 & C2C2(Zn) DOF & 0.11 & 0.40 \\
\hline At1g43850 & $\mathrm{C} 2 \mathrm{H} 2$ & 0.68 & 0.58 \\
\hline At1g43860 & $\mathrm{C} 2 \mathrm{H} 2$ & -0.09 & 0.69 \\
\hline At1g47655 & C2C2(Zn) DOF & 0.24 & 0.22 \\
\hline At1g47860 & $\mathrm{C} 2 \mathrm{H} 2$ & 0.41 & 0.36 \\
\hline At1g51700 & C2C2(Zn) DOF & 1.89 & 2.29 \\
\hline At1g64620 & C2C2(Zn) DOF & 0.58 & 0.47 \\
\hline At1g55110 & $\mathrm{C} 2 \mathrm{H} 2$ & 1.08 & 1.07 \\
\hline At1g69570 & C2C2(Zn) DOF & -0.38 & 0.90 \\
\hline At1g65120 & $\mathrm{C} 2 \mathrm{H} 2$ & 0.37 & 0.81 \\
\hline At2g28510 & $\mathrm{C} 2 \mathrm{C} 2(\mathrm{Zn}) \mathrm{DOF}$ & 0.91 & 0.81 \\
\hline At1g65130 & $\mathrm{C} 2 \mathrm{H} 2$ & 0.21 & 2.67 \\
\hline At2g28810 & C2C2(Zn) DOF & 0.55 & 0.14 \\
\hline At1g66140 & $\mathrm{C} 2 \mathrm{H} 2$ & -0.06 & 0.25 \\
\hline At2g34140 & C2C2(Zn) DOF & -0.27 & 0.52 \\
\hline At1g67030 & $\mathrm{C} 2 \mathrm{H} 2$ & 0.79 & 0.65 \\
\hline At2g37590 & C2C2(Zn) DOF & 0.52 & 0.87 \\
\hline At1g68130 & $\mathrm{C} 2 \mathrm{H} 2$ & 0.45 & 0.38 \\
\hline At2g46590 & $\mathrm{C} 2 \mathrm{C} 2(\mathrm{Zn}) \mathrm{DOF}$ & -0.20 & 0.11 \\
\hline At1g68360 & $\mathrm{C} 2 \mathrm{H} 2$ & -0.13 & 0.27 \\
\hline At4g20970 & bHLH & -0.07 & 0.90 \\
\hline At2g41070 & bZIP & 0.53 & 0.53 \\
\hline At2g42380 & bZIP & -0.86 & 0.03 \\
\hline
\end{tabular}


Table A2 | Continued

\begin{tabular}{|c|c|c|c|}
\hline \multirow[t]{2}{*}{ AGI } & \multirow[t]{2}{*}{ Gene family } & \multicolumn{2}{|c|}{$\log 2$ FCh } \\
\hline & & $0.5 \mathrm{~h} \mathrm{WT}$ & $0.5 \mathrm{~h} \mathrm{GO}$ \\
\hline At2g46270 & bZIP & 1.20 & 1.64 \\
\hline At3g10800 & bZIP & 0.40 & 0.74 \\
\hline At4g25410 & bHLH & -0.12 & 0.27 \\
\hline At3g12250 & bZIP & 0.20 & 0.05 \\
\hline At4g28790 & bHLH & -0.73 & 0.03 \\
\hline At3g17609 & bZIP & 0.95 & 1.16 \\
\hline At3g19290 & bZIP & 0.69 & 0.77 \\
\hline At4g29100 & bHLH & 0.23 & 0.41 \\
\hline At4g29930 & bHLH & 0.81 & 1.31 \\
\hline At4g30180 & $\mathrm{bHLH}$ & -0.72 & 1.33 \\
\hline At3g51960 & bZIP & 0.19 & 0.90 \\
\hline At4g30980 & $\mathrm{bHLH}$ & 1.72 & 0.14 \\
\hline At3g54620 & bZIP & 0.29 & 0.62 \\
\hline At3g21270 & C2C2(Zn) DOF & -0.33 & 0.48 \\
\hline At1g68480 & $\mathrm{C} 2 \mathrm{H} 2$ & 1.49 & -0.70 \\
\hline At3g45610 & C2C2(Zn) DOF & 0.40 & 0.68 \\
\hline At1g72050 & $\mathrm{C} 2 \mathrm{H} 2$ & 0.28 & 0.53 \\
\hline At3g47500 & $\mathrm{C} 2 \mathrm{C} 2(\mathrm{Zn}) \mathrm{DOF}$ & 0.49 & 0.62 \\
\hline At1g75710 & $\mathrm{C} 2 \mathrm{H} 2$ & 0.00 & 0.15 \\
\hline At3g50410 & C2C2(Zn) DOF & -0.05 & 0.48 \\
\hline At3g52440 & $\mathrm{C} 2 \mathrm{C} 2(\mathrm{Zn}) \mathrm{DOF}$ & 1.88 & 5.20 \\
\hline At2g01940 & $\mathrm{C} 2 \mathrm{H} 2$ & -0.65 & 0.35 \\
\hline At3g55370 & C2C2(Zn) DOF & 0.29 & 0.63 \\
\hline At2g02070 & $\mathrm{C} 2 \mathrm{H} 2$ & 1.78 & 0.18 \\
\hline At3g61850 & C2C2(Zn) DOF & -0.38 & 0.07 \\
\hline At2g02080 & $\mathrm{C} 2 \mathrm{H} 2$ & 0.73 & 0.09 \\
\hline At4g00940 & C2C2(Zn) DOF & -0.37 & 0.42 \\
\hline At2g24500 & $\mathrm{C} 2 \mathrm{H} 2$ & 0.08 & 0.74 \\
\hline At3g56660 & bZIP & 0.37 & -1.96 \\
\hline At4g34530 & $\mathrm{bHLH}$ & 0.09 & 0.38 \\
\hline At3g56850 & bZIP & 0.60 & 0.69 \\
\hline At4g36060 & $\mathrm{bHLH}$ & 0.04 & 0.50 \\
\hline At3g58120 & bZIP & -1.52 & -0.95 \\
\hline At4g36540 & $\mathrm{bHLH}$ & -0.04 & 0.55 \\
\hline At3g62420 & bZIP & -0.33 & 0.61 \\
\hline At4g36930 & $\mathrm{bHLH}$ & 0.44 & -0.33 \\
\hline At4g01120 & bZIP & 0.23 & 0.87 \\
\hline At4g02640 & bZIP & -0.01 & 0.50 \\
\hline At4g34000 & bZIP & 1.11 & 1.02 \\
\hline At5g01310 & $\mathrm{bHLH}$ & 0.43 & 0.70 \\
\hline At4g34590 & bZIP & -0.18 & 0.39 \\
\hline At4g35040 & bZIP & -0.47 & 0.57 \\
\hline At5g08130 & $\mathrm{bHLH}$ & 1.02 & 0.38 \\
\hline At4g35900 & bZIP & -0.08 & 2.91 \\
\hline At5g09460 & $\mathrm{bHLH}$ & -0.34 & 0.36 \\
\hline At4g36730 & bZIP & 0.26 & 0.51 \\
\hline At4g37730 & bZIP & 0.45 & 0.62 \\
\hline At4g24060 & C2C2(Zn) DOF & -0.08 & 0.64 \\
\hline At2g26940 & $\mathrm{C} 2 \mathrm{H} 2$ & 0.02 & 0.88 \\
\hline At4g38000 & C2C2(Zn) DOF & -0.99 & 1.49 \\
\hline
\end{tabular}

(Continued)

Table A2 | Continued

AGI Gene family log2 FCh

\begin{tabular}{cc}
\hline $\mathbf{0 . 5}$ h WT & $\mathbf{0 . 5} \mathbf{h ~ G O}$ \\
\hline 0.54 & -0.21 \\
0.21 & 0.68
\end{tabular}

\begin{tabular}{lllr}
\hline At2g27100 & C2H2 & 0.54 & -0.21 \\
At5g02460 & C2C2(Zn) DOF & 0.21 & 0.68 \\
At5g39660 & $\mathrm{C} 2 \mathrm{C} 2(\mathrm{Zn}) \mathrm{DOF}$ & 0.40 & 1.33
\end{tabular}

At5g39660

At2g28200

At5g60200

At2g28710

At5g60850

At2g29660

At5g62430

At2g32930

At5g62940

At2g36480

At5g65590

At2g36930

At5g66940

At2g37430

At1g08000

At1g08010

At2g41940

At5g10570

At4g38900

At5g15160

At5g04840

At5g38860

At5g06950

At5g39860

At5g06960

At5g41315

At5g10030

At5g46690

At5g11260

At5g46760

At5g15830

At5g46830

At5g24800

At5g48560

At5g28770

At1g51600

At2g18380

At2g45120

At2g28340

At2g45050

At3g01460

At3g06740

At3g02790

At3g16870

At3g02830

At3g05760

At3g21175

At3g24050
C2C2(Zn) DOF

$\mathrm{C} 2 \mathrm{H} 2$

C2C2(Zn) DOF

$\mathrm{C} 2 \mathrm{H} 2$

C2C2(Zn) DOF

$\mathrm{C} 2 \mathrm{H} 2$

C2C2(Zn) DOF

$\mathrm{C} 2 \mathrm{H} 2$

C2C2(Zn) DOF

$\mathrm{C} 2 \mathrm{H} 2$

C2C2(Zn) DOF

$\mathrm{C} 2 \mathrm{H} 2$

C2C2(Zn) DOF

$\mathrm{C} 2 \mathrm{H} 2$

C2C2(Zn) GATA

C2C2(Zn) GATA

$\mathrm{C} 2 \mathrm{H} 2$

bHLH

bZIP

bHLH

bZIP

bHLH

bZIP

bHLH

bZIP

bHLH

bZIP

bHLH

bZIP

bHLH

bZIP

bHLH

bZIP

bHLH

bZIP

C2C2(Zn) GATA

C2C2(Zn) GATA

$\mathrm{C} 2 \mathrm{H} 2$

C2C2(Zn) GATA

C2C2(Zn) GATA

$\mathrm{C} 2 \mathrm{H} 2$

C2C2(Zn) GATA

$\mathrm{C} 2 \mathrm{H} 2$

C2C2(Zn) GATA

$\mathrm{C} 2 \mathrm{H} 2$

$\mathrm{C} 2 \mathrm{H} 2$

C2C2(Zn) GATA

C2C2(Zn) GATA
0.40

0.07

0.27

$-0.51$

0.19

$-0.46$

0.67

1.70

0.06

1.21

$-0.42$

0.44

$-0.38$

0.89

0.96

1.05

$-0.76$

$-0.02$

0.12

$-0.19$

$-0.06$

$-0.35$

$-3.42$

0.12

$-0.07$

1.22

0.35

$-0.39$

0.99

$-0.05$

$-0.61$

$-1.47$

0.20

0.03

$-0.12$

0.23

0.38

0.20

0.97

$-0.39$

1.21

$-1.20$

0.01

0.02

0.22

0.05

0.07

0.60
1.33
0.17

0.77

0.59

0.86

0.39

1.18

0.92

0.71

0.13

1.18

0.09

$-0.49$

6.33

0.62

0.41

$-0.76$

0.94

0.61

0.27

0.25

0.30

0.81

0.52

0.40

1.01

0.31

$-0.34$

1.14

0.14

0.39

0.32

1.07

0.29

0.14

0.85

0.38

0.28

$-0.02$

0.90

0.34

$-0.64$

0.28

$-0.47$

0.54

0.63

0.55

0.45

(Continued) 
Table A2 | Continued

\begin{tabular}{|c|c|c|c|}
\hline \multirow[t]{2}{*}{ AGI } & \multirow[t]{2}{*}{ Gene family } & \multicolumn{2}{|c|}{$\log 2 \mathrm{FCh}$} \\
\hline & & $0.5 \mathrm{~h} W T$ & $0.5 \mathrm{~h} \mathrm{GO}$ \\
\hline At3g10470 & $\mathrm{C} 2 \mathrm{H} 2$ & 0.41 & -0.30 \\
\hline At3g13810 & $\mathrm{C} 2 \mathrm{H} 2$ & 0.29 & 1.00 \\
\hline At3g50870 & C2C2(Zn) GATA & 0.44 & -0.02 \\
\hline At3g14740 & $\mathrm{C} 2 \mathrm{H} 2$ & 0.23 & 0.41 \\
\hline At3g51080 & $\mathrm{C} 2 \mathrm{C} 2(\mathrm{Zn}) \mathrm{GATA}$ & 0.43 & 0.39 \\
\hline At3g19580 & $\mathrm{C} 2 \mathrm{H} 2$ & 2.44 & 2.95 \\
\hline At5g50010 & bHLH & -0.53 & 0.99 \\
\hline At5g50915 & $\mathrm{bHLH}$ & 0.50 & 1.15 \\
\hline At5g51780 & bHLH & 0.72 & 2.43 \\
\hline At5g44080 & bZIP & 0.05 & 0.31 \\
\hline At5g51790 & $\mathrm{bHLH}$ & -0.57 & 0.21 \\
\hline At5g49450 & bZIP & -0.04 & 1.02 \\
\hline At5g60830 & bZIP & 2.50 & 1.55 \\
\hline At5g54680 & bHLH & 0.45 & 0.44 \\
\hline At5g65210 & bZIP & -0.10 & 0.17 \\
\hline At5g56960 & bHLH & 2.39 & 3.26 \\
\hline At1g19350 & BZR & 0.89 & 0.72 \\
\hline At5g57150 & bHLH & 0.27 & 0.55 \\
\hline At1g75080 & BZR & 1.20 & 0.95 \\
\hline At1g78700 & BZR & 1.74 & 0.50 \\
\hline At5g61270 & bHLH & 0.44 & 0.46 \\
\hline At3g50750 & BZR & -0.10 & 0.34 \\
\hline At5g62610 & bHLH & 0.28 & 0.85 \\
\hline At4g18890 & BZR & 0.53 & 0.42 \\
\hline At5g64340 & bHLH & -0.31 & -0.18 \\
\hline At4g36780 & $\mathrm{BZR}$ & 0.65 & 0.53 \\
\hline At3g54810 & C2C2(Zn) GATA & -0.02 & -0.20 \\
\hline At3g60530 & $\mathrm{C} 2 \mathrm{C} 2(\mathrm{Zn}) \mathrm{GATA}$ & -0.45 & 0.31 \\
\hline At4g17570 & C2C2(Zn) GATA & -0.05 & 0.49 \\
\hline At4g24470 & C2C2(Zn) GATA & 0.48 & 0.09 \\
\hline At4g26150 & C2C2(Zn) GATA & 0.65 & 0.37 \\
\hline At3g44750 & $\mathrm{C} 2 \mathrm{H} 2$ & 0.06 & 0.23 \\
\hline At4g32890 & C2C2(Zn) GATA & 0.18 & -0.17 \\
\hline At3g45260 & $\mathrm{C} 2 \mathrm{H} 2$ & -0.02 & 0.11 \\
\hline At4g34680 & C2C2(Zn) GATA & 0.23 & 0.40 \\
\hline At4g36240 & C2C2(Zn) GATA & 0.02 & 0.26 \\
\hline At3g46080 & $\mathrm{C} 2 \mathrm{H} 2$ & 1.17 & 3.27 \\
\hline At4g36620 & C2C2(Zn) GATA & 0.51 & 0.01 \\
\hline At3g46090 & $\mathrm{C} 2 \mathrm{H} 2$ & 2.29 & 3.65 \\
\hline At5g25830 & $\mathrm{C} 2 \mathrm{C} 2(\mathrm{Zn}) \mathrm{GATA}$ & -0.11 & -0.10 \\
\hline At3g47890 & $\mathrm{C} 2 \mathrm{H} 2$ & -0.01 & 0.20 \\
\hline At5g26930 & C2C2(Zn) GATA & -0.49 & 3.26 \\
\hline At3g49930 & $\mathrm{C} 2 \mathrm{H} 2$ & 0.75 & 0.06 \\
\hline At5g47140 & C2C2(Zn) GATA & 0.04 & 0.70 \\
\hline At3g50700 & $\mathrm{C} 2 \mathrm{H} 2$ & -0.32 & 1.30 \\
\hline At5g65320 & bHLH & -0.83 & -0.16 \\
\hline At1g06040 & C2C2(Zn) CO-like & 0.05 & 0.86 \\
\hline At5g65640 & bHLH & 0.04 & 0.79 \\
\hline At1g25440 & C2C2(Zn) CO-like & -0.45 & 0.31 \\
\hline At5g67060 & bHLH & -0.44 & 0.21 \\
\hline
\end{tabular}

(Continued)
Table A2 | Continued

\begin{tabular}{|c|c|c|c|}
\hline \multirow[t]{2}{*}{ AGI } & \multirow[t]{2}{*}{ Gene family } & \multicolumn{2}{|c|}{$\log 2 \mathrm{FCh}$} \\
\hline & & $0.5 \mathrm{~h}$ WT & $0.5 \mathrm{~h} \mathrm{GO}$ \\
\hline At1g28050 & C2C2(Zn) CO-like & -0.09 & 1.01 \\
\hline At5g67110 & bHLH & 0.27 & -0.20 \\
\hline At1g49130 & C2C2(Zn) CO-like & -0.17 & 1.01 \\
\hline At1g14685 & $\mathrm{BPC} / \mathrm{BRR}$ & 0.13 & 0.32 \\
\hline At1g68120 & $\mathrm{BPC} / \mathrm{BRR}$ & 0.25 & 0.02 \\
\hline At1g68190 & C2C2(Zn) CO-like & -0.39 & 0.54 \\
\hline At2g21240 & $\mathrm{BPC} / \mathrm{BRR}$ & -0.01 & 0.58 \\
\hline At1g68520 & C2C2(Zn) CO-like & -0.58 & 0.18 \\
\hline At2g35550 & $\mathrm{BPC} / \mathrm{BRR}$ & 0.12 & 0.92 \\
\hline At1g73870 & C2C2(Zn) CO-like & 0.59 & 0.68 \\
\hline At4g01930 & $\mathrm{BPC} / \mathrm{BRR}$ & 0.85 & 1.64 \\
\hline At1g75540 & C2C2(Zn) CO-like & -0.40 & 2.37 \\
\hline At1g78600 & C2C2(Zn) CO-like & 0.62 & 0.33 \\
\hline At5g42520 & $\mathrm{BPC} / \mathrm{BRR}$ & 0.34 & 0.40 \\
\hline At2g21320 & C2C2(Zn) CO-like & -0.09 & 0.69 \\
\hline At5g49300 & C2C2(Zn) GATA & -0.24 & 1.01 \\
\hline At3g53600 & $\mathrm{C} 2 \mathrm{H} 2$ & 2.47 & 3.37 \\
\hline At5g56860 & C2C2(Zn) GATA & -0.18 & 0.00 \\
\hline At5g66320 & $\mathrm{C} 2 \mathrm{C} 2(\mathrm{Zn}) \mathrm{GATA}$ & 2.87 & 0.64 \\
\hline At3g57480 & $\mathrm{C} 2 \mathrm{H} 2$ & 0.08 & 0.73 \\
\hline At1g08465 & C2C2(Zn) YABBY & -0.20 & 0.56 \\
\hline At3g57670 & $\mathrm{C} 2 \mathrm{H} 2$ & 0.41 & 0.16 \\
\hline At3g58070 & $\mathrm{C} 2 \mathrm{H} 2$ & 0.09 & 1.07 \\
\hline At3g60580 & $\mathrm{C} 2 \mathrm{H} 2$ & -0.19 & 0.51 \\
\hline At2g26580 & $\mathrm{C} 2 \mathrm{C} 2(\mathrm{Zn}) \mathrm{YABBY}$ & 0.37 & 0.81 \\
\hline At3g62240 & $\mathrm{C} 2 \mathrm{H} 2$ & 1.63 & 0.15 \\
\hline At2g45190 & C2C2(Zn) YABBY & 0.77 & 0.16 \\
\hline At4g02670 & $\mathrm{C} 2 \mathrm{H} 2$ & 0.69 & 0.56 \\
\hline At4g00180 & $\mathrm{C} 2 \mathrm{C} 2(\mathrm{Zn}) \mathrm{YABBY}$ & 0.58 & 0.26 \\
\hline At4g12240 & $\mathrm{C} 2 \mathrm{H} 2$ & -0.34 & 0.18 \\
\hline At1g13400 & $\mathrm{C} 2 \mathrm{H} 2$ & -0.19 & -0.76 \\
\hline At4g15420 & $\mathrm{C} 2 \mathrm{H} 2$ & 0.12 & 0.83 \\
\hline At4g16610 & $\mathrm{C} 2 \mathrm{H} 2$ & 0.00 & 0.90 \\
\hline At4g17810 & $\mathrm{C} 2 \mathrm{H} 2$ & -0.51 & 0.32 \\
\hline At3g14020 & CCAAT-HAP2 & 1.21 & 0.92 \\
\hline At4g25610 & $\mathrm{C} 2 \mathrm{H} 2$ & 0.40 & -0.74 \\
\hline At3g20910 & CCAAT-HAP2 & 0.32 & 0.82 \\
\hline At5g06510 & CCAAT-HAP2 & 0.02 & -0.06 \\
\hline At4g27240 & $\mathrm{C} 2 \mathrm{H} 2$ & -0.26 & -0.11 \\
\hline At5g12840 & CCAAT-HAP2 & 0.72 & 0.84 \\
\hline At4g31420 & $\mathrm{C} 2 \mathrm{H} 2$ & -0.12 & 0.80 \\
\hline At2g13570 & CCAAT-HAP3 & -0.16 & 0.24 \\
\hline At2g27470 & CCAAT-HAP3 & 0.09 & -0.03 \\
\hline At5g01160 & $\mathrm{C} 2 \mathrm{H} 2$ & 0.90 & 0.52 \\
\hline At2g37060 & CCAAT-HAP3 & 0.13 & 0.74 \\
\hline At2g38880 & CCAAT-HAP3 & 0.42 & 0.78 \\
\hline At5g03150 & $\mathrm{C} 2 \mathrm{H} 2$ & 0.34 & -0.17 \\
\hline At1g52150 & $\mathrm{HB}$ & 1.63 & -0.43 \\
\hline At3g46640 & GARP-G2-like & -0.17 & -0.95 \\
\hline At1g62360 & $\mathrm{HB}$ & -2.54 & -1.92 \\
\hline
\end{tabular}


Table A2 | Continued

\begin{tabular}{|c|c|c|c|}
\hline \multirow[t]{2}{*}{ AGI } & \multirow[t]{2}{*}{ Gene family } & \multicolumn{2}{|c|}{$\log 2 \mathrm{FCh}$} \\
\hline & & $0.5 \mathrm{~h} W T$ & $0.5 \mathrm{~h} \mathrm{GO}$ \\
\hline At1g62990 & $\mathrm{HB}$ & 0.07 & 0.92 \\
\hline At4g13640 & GARP-G2-like & 0.27 & 0.30 \\
\hline At1g69780 & $\mathrm{HB}$ & -0.93 & 0.70 \\
\hline At1g70920 & $\mathrm{HB}$ & 0.28 & 1.29 \\
\hline At4g28610 & GARP-G2-like & 0.50 & 0.62 \\
\hline At1g73360 & $\mathrm{HB}$ & -0.50 & 0.20 \\
\hline At4g37180 & GARP-G2-like & 0.53 & 1.36 \\
\hline At1g75410 & $\mathrm{HB}$ & 0.09 & 0.62 \\
\hline At5g05090 & GARP-G2-like & -0.21 & 0.30 \\
\hline At5g06800 & GARP-G2-like & 0.46 & 0.73 \\
\hline At1g79840 & $\mathrm{HB}$ & -0.06 & 0.26 \\
\hline At5g16560 & GARP-G2-like & -0.68 & -0.18 \\
\hline At2g01430 & $\mathrm{HB}$ & 0.89 & -0.31 \\
\hline At5g03510 & $\mathrm{C} 2 \mathrm{H} 2$ & -0.33 & -0.01 \\
\hline At3g53340 & CCAAT-HAP3 & -1.44 & 2.69 \\
\hline At5g03740 & $\mathrm{C} 2 \mathrm{H} 2$ & 0.13 & 0.28 \\
\hline At4g14540 & CCAAT-HAP3 & -0.19 & 0.56 \\
\hline At5g04340 & $\mathrm{C} 2 \mathrm{H} 2$ & 3.93 & 5.44 \\
\hline At5g47640 & CCAAT-HAP3 & 0.91 & 1.44 \\
\hline At5g04390 & $\mathrm{C} 2 \mathrm{H} 2$ & -0.65 & -1.44 \\
\hline At5g47670 & CCAAT-HAP3 & 0.54 & -0.21 \\
\hline At1g07980 & CCAAT-HAP5 & -0.06 & 0.39 \\
\hline At1g08970 & CCAAT-HAP5 & 0.23 & 0.74 \\
\hline At5g06650 & $\mathrm{C} 2 \mathrm{H} 2$ & 0.41 & -0.09 \\
\hline At1g54830 & CCAAT-HAP5 & 0.67 & 0.82 \\
\hline At5g09740 & $\mathrm{C} 2 \mathrm{H} 2$ & 0.15 & 0.51 \\
\hline At1g56170 & CCAAT-HAP5 & 0.58 & 0.90 \\
\hline At5g10970 & $\mathrm{C} 2 \mathrm{H} 2$ & -1.15 & -0.37 \\
\hline At3g12480 & CCAAT-HAP5 & 0.65 & 0.46 \\
\hline At3g48590 & CCAAT-HAP5 & 0.52 & 0.54 \\
\hline At5g14140 & $\mathrm{C} 2 \mathrm{H} 2$ & -0.05 & 1.09 \\
\hline At5g27910 & CCAAT-HAP5 & -1.06 & 1.11 \\
\hline At5g38140 & CCAAT-HAP5 & -0.17 & -0.05 \\
\hline At5g18240 & GARP-G2-like & 0.09 & 0.67 \\
\hline At5g29000 & GARP-G2-like & 0.10 & 0.92 \\
\hline At2g02540 & $\mathrm{HB}$ & 0.05 & 0.06 \\
\hline At5g42630 & GARP-G2-like & -1.15 & 0.23 \\
\hline At2g16400 & $\mathrm{HB}$ & 0.65 & 0.56 \\
\hline At5g44190 & GARP-G2-like & 0.01 & 0.22 \\
\hline At5g45580 & GARP-G2-like & -0.96 & 0.18 \\
\hline At2g18550 & $\mathrm{HB}$ & -1.44 & 1.14 \\
\hline At5g59570 & GARP-G2-like & 0.60 & 0.87 \\
\hline At2g22430 & $\mathrm{HB}$ & 1.79 & 1.63 \\
\hline At2g22800 & $\mathrm{HB}$ & 0.69 & 0.49 \\
\hline At1g44810 & GeBP & -0.70 & 0.32 \\
\hline At2g23760 & $\mathrm{HB}$ & 0.03 & 0.55 \\
\hline At1g61730 & GeBP & 0.28 & 0.49 \\
\hline At2g27990 & $\mathrm{HB}$ & -1.10 & 0.32 \\
\hline At2g28610 & $\mathrm{HB}$ & -0.64 & 0.68 \\
\hline At2g25650 & GeBP & -0.03 & 0.63 \\
\hline
\end{tabular}

(Continued)
Table A2 | Continued

AGI Gene family $\quad \log 2 \mathrm{FCh}$

At5g16470

At5g43250

At5g16540

At5g50470

At5g18550

At5g50480

At5g63470

At5g25160

At5g26610

At4g01350

At5g37890

At5g39550

At2g20110

At3g04850

At5g40710

At3g16160

At2g36340

At3g04930

At2g34710

At4g00250

At2g35940

At4g00270

At2g36610

At4g00270

At2g44910

At4g00390

At2g46680

At3g01220

At3g01470

At4g25210

At5g14280

At3g03660

At5g28040

At3g11260

At5g28040

At3g18010

At3g22760

At5g43170

At3g22780

At5g43540

At4g14770

At5g44160

At4g29000

At5g25790

At5g52010

At1g47870

At2g36010

At3g01330

At5g54630

At3g48160
$0.5 \mathrm{~h} \mathrm{WT}$

$0.5 \mathrm{~h} \mathrm{GO}$

$\mathrm{C} 2 \mathrm{H} 2$
CCAAT-HAP
C2H2
CCAAT-HAP
C2H2

CCAAT-HAP5

CCAAT-HAP5

$\mathrm{C} 2 \mathrm{H} 2$

$\mathrm{C} 2 \mathrm{H} 2$

CHP-rich

$\mathrm{C} 2 \mathrm{H} 2$

$\mathrm{C} 2 \mathrm{H} 2$

$\mathrm{CPP}(\mathrm{Zn})$

$\mathrm{CPP}(\mathrm{Zn})$

$\mathrm{C} 2 \mathrm{H} 2$

$\mathrm{CPP}(\mathrm{Zn})$

GeBP

GeBP

$\mathrm{HB}$

GeBP

$\mathrm{HB}$

GeBP

$\mathrm{HB}$

GeBP

$\mathrm{HB}$

GeBP

$\mathrm{HB}$

$\mathrm{HB}$

$\mathrm{HB}$

GeBP

GeBP

$\mathrm{HB}$

GeBP

$\mathrm{HB}$

GeBP

$\mathrm{HB}$

CPP $(Z n)$

$\mathrm{C} 2 \mathrm{H} 2$

$\mathrm{CPP}(\mathrm{Zn})$

$\mathrm{C} 2 \mathrm{H} 2$

$\mathrm{CPP}(\mathrm{Zn})$

$\mathrm{C} 2 \mathrm{H} 2$

$\mathrm{CPP}(\mathrm{Zn})$

$\mathrm{CPP}(\mathrm{Zn})$

$\mathrm{C} 2 \mathrm{H} 2$

E2F/DP

E2F/DP

E2F/DP

$\mathrm{C} 2 \mathrm{H} 2$

E2F/DP

$-0.01 \quad 0.53$

$-0.08 \quad 0.78$
0.15

$0.15 \quad 0.85$

$1.23 \quad 0.96$

$\begin{array}{ll}1.57 & 0.12\end{array}$

$1.61 \quad 0.40$

$\begin{array}{lr}-0.08 & 0.94\end{array}$

$-1.33 \quad-0.40$

$0.09 \quad 0.31$

$0.70 \quad 2.21$

$0.30 \quad 0.61$

$0.42 \quad 0.01$

$0.14-0.03$

$-0.01 \quad 0.08$
-0.13

$-0.13 \quad 0.95$

$-0.23 \quad 0.67$

$-0.40 \quad 0.23$
0.10

$0.10 \quad 0.87$

$\begin{array}{ll}0.04 & 0.32\end{array}$

$-1.42 \quad 2.65$
0.53

$0.53 \quad 0.95$

$0.08 \quad 1.08$

$\begin{array}{ll}-3.29 & 1.15\end{array}$

$-0.40 \quad 0.57$

$-0.16 \quad-0.13$

$0.62 \quad 1.34$

$\begin{array}{ll}0.05 & 1.08\end{array}$

$0.78 \quad 1.01$

$0.33 \quad 0.28$

$0.14 \quad 0.80$

$0.06 \quad 0.25$

$0.86 \quad 0.97$

$0.49 \quad 0.46$

$0.27-0.71$

$0.46 \quad 0.71$

$0.78 \quad 1.05$

$\begin{array}{ll}-0.35 & 0.13\end{array}$

$0.48 \quad 1.24$

$0.13 \quad 0.19$

$\begin{array}{ll}0.134 & 1.69\end{array}$

$0.27 \quad 0.00$

$0.35 \quad 0.50$

$0.27 \quad 0.47$

$0.21 \quad 1.24$

$0.11 \quad 0.44$

$0.33 \quad 0.46$

$0.62 \quad 0.57$

$-0.37 \quad-0.25$

$-0.29 \quad 0.21$

$-0.08 \quad 0.23$

(Continued) 
Table A2 | Continued

\begin{tabular}{|c|c|c|c|}
\hline \multirow[t]{2}{*}{ AGI } & \multirow[t]{2}{*}{ Gene family } & \multicolumn{2}{|c|}{$\log 2 \mathrm{FCh}$} \\
\hline & & $0.5 \mathrm{~h} W T$ & $0.5 \mathrm{~h} \mathrm{GO}$ \\
\hline At5g56200 & $\mathrm{C} 2 \mathrm{H} 2$ & -3.54 & 3.86 \\
\hline At5g02470 & E2F/DP & -0.34 & 1.65 \\
\hline At5g57520 & $\mathrm{C} 2 \mathrm{H} 2$ & -1.45 & -0.52 \\
\hline At5g03415 & E2F/DP & 0.41 & 0.22 \\
\hline At5g59820 & $\mathrm{C} 2 \mathrm{H} 2$ & 1.49 & 4.74 \\
\hline At5g14960 & $\mathrm{E} 2 \mathrm{~F} / \mathrm{DP}$ & 1.08 & 0.27 \\
\hline At1g05055 & General Transcription & 0.47 & 0.27 \\
\hline At3g19510 & $\mathrm{HB}$ & -0.08 & 0.11 \\
\hline At4g26170 & General Transcription & -0.18 & 0.70 \\
\hline At3g49530 & $\mathrm{HB}$ & 1.86 & 2.55 \\
\hline At1g01160 & GIF & 0.22 & 0.35 \\
\hline At4g00850 & GIF & 0.69 & 1.16 \\
\hline At5g28640 & GIF & -0.23 & 0.13 \\
\hline At1g07520 & GRAS & 1.57 & 2.32 \\
\hline At3g56560 & $\mathrm{HB}$ & 1.09 & 2.02 \\
\hline At1g07530 & GRAS & 0.23 & 0.71 \\
\hline At3g60390 & $\mathrm{HB}$ & 0.53 & 1.21 \\
\hline At1g14920 & GRAS & 0.18 & -0.11 \\
\hline At3g61150 & $\mathrm{HB}$ & 0.73 & 0.72 \\
\hline At1g21450 & GRAS & 0.23 & 1.07 \\
\hline At3g61890 & $\mathrm{HB}$ & 1.26 & 1.68 \\
\hline At1g50420 & GRAS & 0.21 & 0.69 \\
\hline At1g50600 & GRAS & 0.17 & 0.95 \\
\hline At4g00730 & $\mathrm{HB}$ & 0.50 & 0.57 \\
\hline At5g60470 & $\mathrm{C} 2 \mathrm{H} 2$ & -0.13 & 1.25 \\
\hline At5g22220 & E2F/DP & 0.47 & 0.72 \\
\hline At1g73730 & EIL & 1.23 & 0.52 \\
\hline At5g63280 & $\mathrm{C} 2 \mathrm{H} 2$ & -0.03 & 0.21 \\
\hline At2g27050 & EIL & -0.16 & 0.35 \\
\hline At5g64610 & $\mathrm{C} 2 \mathrm{H} 2$ & -0.18 & 0.52 \\
\hline At3g20770 & EIL & 0.08 & 0.88 \\
\hline At5g66730 & $\mathrm{C} 2 \mathrm{H} 2$ & 0.28 & 0.22 \\
\hline At5g67450 & $\mathrm{C} 2 \mathrm{H} 2$ & 2.15 & 3.36 \\
\hline At1g32360 & $\mathrm{C} 3 \mathrm{H}$ & 0.19 & 0.70 \\
\hline At1g60700 & FHA & -0.01 & 0.07 \\
\hline At1g68200 & $\mathrm{C} 3 \mathrm{H}$ & 0.27 & 0.51 \\
\hline At2g19810 & $\mathrm{C} 3 \mathrm{H}$ & 0.75 & 1.30 \\
\hline At3g07220 & $\mathrm{FHA}$ & 0.37 & 0.45 \\
\hline At2g25900 & $\mathrm{C} 3 \mathrm{H}$ & -0.44 & 0.97 \\
\hline At3g07260 & $\mathrm{FHA}$ & -0.25 & 4.25 \\
\hline At2g35430 & $\mathrm{C} 3 \mathrm{H}$ & 0.11 & 0.74 \\
\hline At3g54350 & FHA & 0.28 & 0.42 \\
\hline At1g55580 & GRAS & -0.24 & -1.77 \\
\hline At4g01520 & $\mathrm{HB}$ & 0.88 & 1.90 \\
\hline At1g63100 & GRAS & -0.14 & -0.04 \\
\hline At4g01550 & $\mathrm{HB}$ & -0.43 & 1.47 \\
\hline At1g66350 & GRAS & -0.06 & 0.34 \\
\hline At4g02560 & $\mathrm{HB}$ & 0.48 & 0.40 \\
\hline At2g01570 & GRAS & 0.21 & 0.34 \\
\hline At4g03250 & $\mathrm{HB}$ & 0.32 & 0.63 \\
\hline
\end{tabular}

(Continued)
Table A2 | Continued

AGI Gene family log2 FCh

\begin{tabular}{|c|c|c|c|}
\hline & & \\
\hline & & $0.5 \mathrm{~h}$ WT & $0.5 \mathrm{~h} \mathrm{GO}$ \\
\hline At2g04890 & GRAS & -0.18 & 0.67 \\
\hline At4g04890 & $\mathrm{HB}$ & 0.38 & 0.19 \\
\hline At2g37650 & GRAS & 0.28 & 0.40 \\
\hline At2g45160 & GRAS & 0.09 & 0.04 \\
\hline At4g16780 & $\mathrm{HB}$ & 0.80 & 1.65 \\
\hline At3g03450 & GRAS & -0.19 & 0.08 \\
\hline At4g17460 & $\mathrm{HB}$ & -1.60 & -0.47 \\
\hline At3g13840 & GRAS & 0.16 & 1.57 \\
\hline At3g46600 & GRAS & 1.92 & 2.71 \\
\hline At4g21750 & $\mathrm{HB}$ & 0.60 & 0.64 \\
\hline At3g49950 & GRAS & 0.50 & -0.70 \\
\hline At2g40140 & $\mathrm{C} 3 \mathrm{H}$ & 3.19 & 3.95 \\
\hline At2g41900 & $\mathrm{C} 3 \mathrm{H}$ & 0.16 & 0.46 \\
\hline At1g67710 & GARP-ARR-B & -0.71 & 0.17 \\
\hline At3g06410 & $\mathrm{C} 3 \mathrm{H}$ & 0.98 & 0.96 \\
\hline At2g01760 & GARP-ARR-B & -0.85 & 0.18 \\
\hline At3g12130 & $\mathrm{C} 3 \mathrm{H}$ & 0.44 & 0.68 \\
\hline At2g25180 & GARP-ARR-B & 0.26 & -0.07 \\
\hline At3g12680 & $\mathrm{C} 3 \mathrm{H}$ & 0.33 & 0.26 \\
\hline At3g16857 & GARP-ARR-B & 0.16 & -0.01 \\
\hline At3g19360 & $\mathrm{C} 3 \mathrm{H}$ & 0.64 & 0.38 \\
\hline At3g48440 & $\mathrm{C} 3 \mathrm{H}$ & 0.68 & 0.39 \\
\hline At4g16110 & GARP-ARR-B & -0.01 & 0.37 \\
\hline At3g51120 & $\mathrm{C} 3 \mathrm{H}$ & -0.03 & 0.35 \\
\hline At4g31920 & GARP-ARR-B & -0.21 & 0.10 \\
\hline At3g55980 & $\mathrm{C} 3 \mathrm{H}$ & 0.90 & 3.97 \\
\hline At5g07210 & GARP-ARR-B & 1.57 & 0.85 \\
\hline At4g00305 & $\mathrm{C} 3 \mathrm{H}$ & 0.46 & 0.93 \\
\hline At4g01020 & $\mathrm{C} 3 \mathrm{H}$ & 0.93 & 0.40 \\
\hline At4g29190 & $\mathrm{C} 3 \mathrm{H}$ & 0.72 & 1.36 \\
\hline At1g13300 & GARP-G2-like & 1.44 & 0.56 \\
\hline At3g50650 & GRAS & 0.15 & -0.27 \\
\hline At4g29940 & $\mathrm{HB}$ & 0.07 & 0.46 \\
\hline At3g54220 & GRAS & 0.61 & 0.37 \\
\hline At4g32040 & $\mathrm{HB}$ & 0.01 & 0.84 \\
\hline At3g60630 & GRAS & 0.16 & 0.50 \\
\hline At4g32880 & $\mathrm{HB}$ & 1.66 & 0.24 \\
\hline At4g00150 & GRAS & 0.57 & 0.58 \\
\hline At4g32980 & $\mathrm{HB}$ & -0.66 & 0.12 \\
\hline At4g08250 & GRAS & 2.11 & 2.28 \\
\hline At4g34610 & $\mathrm{HB}$ & 0.27 & 0.20 \\
\hline At4g17230 & GRAS & 4.77 & 2.92 \\
\hline At4g35550 & $\mathrm{HB}$ & 0.22 & 0.40 \\
\hline At4g36710 & GRAS & 0.22 & 0.75 \\
\hline At4g37650 & GRAS & 0.29 & 0.47 \\
\hline At4g36870 & $\mathrm{HB}$ & 0.11 & 0.05 \\
\hline At5g17490 & GRAS & 0.26 & 1.26 \\
\hline At4g37790 & $\mathrm{HB}$ & 1.19 & 1.58 \\
\hline At5g41920 & GRAS & 0.10 & 0.47 \\
\hline At4g40060 & $\mathrm{HB}$ & -0.01 & 0.70 \\
\hline
\end{tabular}


Table A2 | Continued

\begin{tabular}{|c|c|c|c|}
\hline \multirow[t]{2}{*}{ AGI } & \multirow[t]{2}{*}{ Gene family } & \multicolumn{2}{|c|}{$\log 2 \mathrm{FCh}$} \\
\hline & & $0.5 \mathrm{~h}$ WT & $0.5 \mathrm{~h} \mathrm{GO}$ \\
\hline At5g48150 & GRAS & 0.42 & 0.67 \\
\hline At5g02030 & $\mathrm{HB}$ & 0.12 & 0.55 \\
\hline At5g52510 & GRAS & 0.08 & 0.98 \\
\hline At5g03790 & $\mathrm{HB}$ & -0.21 & 0.18 \\
\hline At5g06420 & $\mathrm{C} 3 \mathrm{H}$ & -0.39 & 0.04 \\
\hline At1g14600 & GARP-G2-like & 0.32 & 0.97 \\
\hline At5g06770 & $\mathrm{C} 3 \mathrm{H}$ & 0.55 & 0.30 \\
\hline At1g25550 & GARP-G2-like & 1.12 & 1.73 \\
\hline At5g07060 & $\mathrm{C} 3 \mathrm{H}$ & 0.17 & 1.35 \\
\hline At1g32240 & GARP-G2-like & 0.08 & 0.67 \\
\hline At5g07500 & $\mathrm{C} 3 \mathrm{H}$ & 0.91 & 2.80 \\
\hline At1g49560 & GARP-G2-like & -0.29 & 0.60 \\
\hline At5g12850 & $\mathrm{C} 3 \mathrm{H}$ & 1.02 & 0.22 \\
\hline At1g68670 & GARP-G2-like & 0.47 & 1.19 \\
\hline At5g44260 & $\mathrm{C} 3 \mathrm{H}$ & -0.37 & -0.47 \\
\hline At1g69580 & GARP-G2-like & 0.03 & 0.48 \\
\hline At5g58620 & $\mathrm{C} 3 \mathrm{H}$ & 1.06 & 1.15 \\
\hline At1g79430 & GARP-G2-like & 0.39 & 0.03 \\
\hline At4g16150 & CAMTA & 0.23 & 1.05 \\
\hline At2g01060 & GARP-G2-like & 0.56 & 0.68 \\
\hline At1g67310 & CAMTA & 0.52 & 0.74 \\
\hline At2g02060 & GARP-G2-like & 0.25 & 0.47 \\
\hline At1g67910 & CAMTA & 0.33 & 0.68 \\
\hline At2g03500 & GARP-G2-like & 0.93 & -0.19 \\
\hline At2g22300 & CAMTA & 0.44 & 1.20 \\
\hline At2g20400 & GARP-G2-like & 0.26 & 0.40 \\
\hline At2g22900 & CAMTA & -0.41 & 0.60 \\
\hline At2g20570 & GARP-G2-like & 0.51 & 0.46 \\
\hline At5g59450 & GRAS & 1.21 & 1.78 \\
\hline At5g66770 & GRAS & -0.12 & -0.01 \\
\hline At5g06710 & $\mathrm{HB}$ & 0.66 & 0.31 \\
\hline At2g06200 & GRF & -1.16 & -1.07 \\
\hline At5g11060 & $\mathrm{HB}$ & 0.00 & 0.76 \\
\hline At2g22840 & GRF & 0.20 & -0.25 \\
\hline At5g11270 & $\mathrm{HB}$ & 0.13 & 0.33 \\
\hline At2g36400 & GRF & 0.03 & 0.56 \\
\hline At5g15150 & $\mathrm{HB}$ & -1.34 & -0.12 \\
\hline At2g45480 & GRF & -0.05 & -0.23 \\
\hline At3g13960 & GRF & 0.16 & 0.03 \\
\hline At3g52910 & GRF & -0.03 & 0.64 \\
\hline At5g19520 & $\mathrm{HB}$ & -1.33 & 1.17 \\
\hline At4g24150 & GRF & 0.35 & 0.22 \\
\hline At5g25220 & $\mathrm{HB}$ & 0.55 & 1.12 \\
\hline At4g37740 & GRF & 0.97 & -0.01 \\
\hline At5g53660 & GRF & -1.00 & 1.00 \\
\hline At5g46880 & $\mathrm{HB}$ & 1.22 & 0.16 \\
\hline At1g05230 & $\mathrm{HB}$ & 0.28 & 0.17 \\
\hline At5g60690 & $\mathrm{HB}$ & 0.21 & 0.33 \\
\hline At3g16940 & CAMTA & 1.12 & 1.06 \\
\hline At2g38300 & GARP-G2-like & 0.10 & 0.95 \\
\hline
\end{tabular}

(Continued)
Table A2 | Continued

AGI Gene family $\quad \log 2 \mathrm{FCh}$

\begin{tabular}{lccc} 
& & $\mathbf{0 . 5} \mathbf{h ~ W T}$ & $\mathbf{0 . 5} \mathbf{h ~ G O}$ \\
\hline At5g09410 & CAMTA & 0.51 & 0.60
\end{tabular}

At2g40260

At5g64220

At2g40970

At5g08190

At5g23090

At3g04030

At1g17590

At3g04450

At1g30500

At3g10760

At1g54160

At3g12730

At1g72830

At3g13040

At2g34720

At3g05690

At3g24120

At1g17920

At1g20693

At1g19700

At1g20696

At1g20700

At2g17560

At2g34450

At1g23380

At3g28730

At1g26960

At3g51880

At1g27050

At4g11080

At1g28420

At4g23800

At1g30490

At4g35570

At5g23420

At1g46480

At5g56780

At1g32330

At1g46264

At1g67970

At3g54340

At1g74250

At3g57230

At1g77570

At3g57390

At2g26150

At3g58780

GARP-G2-like

0.10

0.09

CAMTA

GARP-G2-like

0.29

0.82

CCAAT-DR 1

CCAAT-DR1

GARP-G2-like

0.23

0.85

CCAAT-HAP2

0.01

0.22

$-0.08$

0.65

GARP-G2-like

CCAAT-HAP2

0.06

$-0.23$

0.04

0.59

$-0.09$

0.61

GARP-G2-like

CCAAT-HAP2

0.08
-0.58

0.60

GARP-G2-like

CCAAT-HAP2

GARP-G2-like

CCAAT-HAP2

CCAAT-HAP2

GARP-G2-like

$\mathrm{HB}$

HMG

$\mathrm{HB}$

HMG

$\mathrm{HB}$

HMG

HMG

$\mathrm{HB}$

HMG

$\mathrm{HB}$

HMG

$\mathrm{HB}$

HMG

$\mathrm{HB}$

HMG

$\mathrm{HB}$

HMG

HMG

HB

HRT-like

HSF

HSF

HSF

MADS

HSF

MADS

HSF

MADS

HSF

MADS

-0.58
0.71

$-0.19$

0.35

$-0.59$

$-0.06$

$-0.27$

$-0.04$

0.51

0.79

0.08

0.77

0.25

$-0.71$

0.09

0.25

0.12

0.24

0.01

0.28

$-0.88$

0.80

$-0.45$

0.10

0.49

$-0.35$

$-0.31$

0.21

0.09

0.18

0.00

$-0.16$

$-0.12$

0.43

$-0.15$

1.40

$-0.63$

0.02

0.04

0.15

$-0.14$

0.06

$-0.13$

0.97

2.41
HSF

HSF
$-0.43$

0.59

$-0.02$

0.62

0.60

0.51

0.40

0.52

0.23

1.05

0.27

1.02

0.53

0.55

0.29

0.62

$-0.23$

$-0.23$

0.53

0.63

0.19

0.31

0.53

$-0.27$

2.26

$-1.55$

0.25

0.67

1.19

0.40

0.46

0.61

1.27

2.91

(Continued) 
Table A2 | Continued

\begin{tabular}{|c|c|c|c|}
\hline \multirow[t]{2}{*}{ AGI } & \multirow[t]{2}{*}{ Gene family } & \multicolumn{2}{|c|}{$\log 2$ FCh } \\
\hline & & $0.5 \mathrm{~h}$ WT & $0.5 \mathrm{~h} \mathrm{GO}$ \\
\hline At4g11250 & MADS & 3.71 & 2.40 \\
\hline At5g02320 & MYB & 0.03 & 0.74 \\
\hline At5g03780 & MYB & -0.17 & 0.43 \\
\hline At1g73410 & MYB & 0.81 & -0.27 \\
\hline At5g04110 & MYB & 0.04 & 0.24 \\
\hline At1g74080 & MYB & -1.03 & 2.02 \\
\hline At5g06100 & MYB & 0.33 & 0.38 \\
\hline At1g74430 & MYB & -0.15 & 1.02 \\
\hline At5g06110 & MYB & 0.30 & 0.61 \\
\hline At1g74650 & MYB & -0.10 & 0.98 \\
\hline At5g07690 & MYB & -0.55 & 0.45 \\
\hline At1g79180 & MYB & 0.43 & 1.73 \\
\hline At5g07700 & MYB & -0.27 & 0.92 \\
\hline At2g02820 & MYB & -0.09 & 0.79 \\
\hline At5g10280 & MYB & 0.85 & 0.40 \\
\hline At2g03470 & MYB & -0.26 & 0.94 \\
\hline At5g11510 & MYB & 0.34 & 0.01 \\
\hline At3g51910 & HSF & 0.45 & 0.79 \\
\hline At4g11880 & MADS & -1.34 & 0.22 \\
\hline At4g18960 & MADS & -0.27 & -0.42 \\
\hline At4g11660 & HSF & 0.41 & 0.50 \\
\hline At4g22950 & MADS & -0.32 & -0.37 \\
\hline At4g13980 & HSF & -0.12 & -0.47 \\
\hline At4g24540 & MADS & 0.11 & 0.42 \\
\hline At4g17600 & HSF & 0.15 & 0.65 \\
\hline At4g36590 & MADS & -1.41 & 1.10 \\
\hline At4g17750 & HSF & 0.42 & 0.38 \\
\hline At4g37940 & MADS & -0.17 & 1.43 \\
\hline At4g18880 & HSF & 0.70 & 2.89 \\
\hline At5g10140 & MADS & -1.26 & 0.83 \\
\hline At4g36990 & HSF & 0.06 & 1.02 \\
\hline At5g13790 & MADS & -0.09 & 0.52 \\
\hline At5g03720 & HSF & 0.69 & 1.22 \\
\hline At5g15800 & MADS & 0.06 & -2.27 \\
\hline At5g16820 & $\mathrm{HSF}$ & 0.53 & 0.95 \\
\hline At5g20240 & MADS & -1.28 & -3.08 \\
\hline At2g16720 & MYB & 0.32 & 1.27 \\
\hline At5g14750 & MYB & -1.85 & 0.49 \\
\hline At2g23290 & MYB & -1.90 & -1.21 \\
\hline At5g15310 & MYB & 0.05 & 0.29 \\
\hline At5g16600 & MYB & 0.75 & 0.84 \\
\hline At5g16770 & MYB & 0.76 & -0.23 \\
\hline At5g17800 & MYB & -0.71 & -0.65 \\
\hline At2g31180 & MYB & -0.09 & 1.35 \\
\hline At5g18620 & MYB & 0.93 & -1.05 \\
\hline At5g23000 & MYB & -0.74 & -2.44 \\
\hline At2g33610 & MYB & -0.16 & 0.22 \\
\hline At5g23650 & MYB & 0.40 & -0.73 \\
\hline At2g36890 & MYB & -0.40 & 1.54 \\
\hline At5g26660 & MYB & -0.40 & 1.47 \\
\hline
\end{tabular}

(Continued)
Table A2 | Continued

AGI Gene family $\quad \log 2 \mathrm{FCh}$

\begin{tabular}{cccc} 
& & $\mathbf{0 . 5} \mathbf{h} \mathbf{W T}$ & $\mathbf{0 . 5} \mathbf{h ~ G O}$ \\
\hline At2g36960 & MYB & 0.12 & 0.37
\end{tabular}

At5g35550

MYB

MYB

HSF

MADS

HSF

MADS

HSF

JUMONJI

MADS

JUMONJI

MADS

MADS

MADS

JUMONJI

JUMONJI

JUMONJI

MADS

MYB

MYB

MYB

MYB

MYB

MYB

MYB

MYB

MYB

MYB

MYB

MYB

MYB

MYB

MYB

MYB

MYB

MYB

MYB

MYB

JUMONJI

$-0.24$

$-0.93$

0.24
1.40

0.21

1.08

1.36

0.00

2.43

0.21

0.73

$-0.68$

0.91

0.86

1.65

0.44

$-0.06$

0.43

1.91

0.82

1.01

0.40

$-2.59$

0.51

3.03

$-0.01$

1.39

0.45

1.48

0.64

0.30

0.46

0.09

$-0.19$

0.07

$-0.58$

$-0.40$

0.38

0.15

1.82

0.23

0.22

1.31

0.44

0.30

2.58

0.52

0.58

0.10

0.26

$-1.20$

1.24

$-0.21$

0.71

$-0.10$

0.15

1.34

2.40
-0.14

0.93

0.53

0.40

1.13

At5g52260

At3g05380

At5g52600

At3g06490

At5g54230

At5g04240

At5g46910

At5g37415

At5g63080

At1g01780

At1g10200

At2g39900

At2g45800

At3g55770

At5g48670

At4g32551

At5g49420

JUMONJI

MADS

JUMONJI

LIM

LIM

LIM

LIM

LIM

MADS

LUG

MADS

$-0.05$

2.22

$-0.13$

$-1.43$

$-1.74$

$-2.33$

1.21

$-1.03$

0.65

1.37

3.14

0.56

0.41

0.71

0.21

0.84

0.57

0.54

0.39

0.07 
Table A2 | Continued

\begin{tabular}{|c|c|c|c|}
\hline \multirow[t]{2}{*}{ AGI } & \multirow[t]{2}{*}{ Gene family } & \multicolumn{2}{|c|}{$\log 2$ FCh } \\
\hline & & $0.5 \mathrm{~h}$ WT & $0.5 \mathrm{~h} \mathrm{GO}$ \\
\hline At5g65070 & MADS & -0.07 & 0.94 \\
\hline At5g51860 & MADS & 1.09 & 0.89 \\
\hline At3g08500 & MYB & -0.72 & -0.10 \\
\hline At5g55020 & MYB & 2.33 & 5.47 \\
\hline At3g09370 & MYB & 0.32 & 0.47 \\
\hline At3g10113 & MYB & -0.54 & -0.73 \\
\hline At3g11440 & MYB & 0.67 & 0.76 \\
\hline At5g60890 & MYB & 0.94 & 1.21 \\
\hline At3g11450 & MYB & -0.14 & 1.07 \\
\hline At5g61420 & MYB & -0.22 & 0.34 \\
\hline At3g12560 & MYB & 0.20 & 0.13 \\
\hline At5g62320 & MYB & 0.21 & 1.80 \\
\hline At5g62470 & MYB & 1.39 & 2.19 \\
\hline At3g12820 & MYB & -0.50 & -0.05 \\
\hline At5g65230 & MYB & 0.79 & 1.02 \\
\hline At3g13540 & MYB & 0.80 & 1.04 \\
\hline At5g67300 & MYB & 0.70 & 1.61 \\
\hline At1g18750 & MADS & 0.75 & 0.66 \\
\hline At1g22590 & MADS & 0.89 & 0.28 \\
\hline At5g60440 & MADS & -0.25 & 0.00 \\
\hline At1g24260 & MADS & -0.54 & -0.31 \\
\hline At5g60910 & MADS & 0.69 & 0.02 \\
\hline At5g62165 & MADS & -1.47 & -1.31 \\
\hline At1g28450 & MADS & -1.54 & 1.09 \\
\hline At5g65050 & MADS & 0.05 & 0.25 \\
\hline At1g28460 & MADS & -0.17 & 1.43 \\
\hline At5g65060 & MADS & 0.51 & 0.20 \\
\hline At1g29960 & MADS & -0.15 & 0.61 \\
\hline At5g65080 & MADS & 0.62 & -0.97 \\
\hline At2g42680 & MBF1 & -0.05 & 0.84 \\
\hline At3g24500 & MBF1 & -0.19 & 0.35 \\
\hline At3g15320 & MYB & -0.12 & 0.63 \\
\hline At1g01060 & MYB-related & 0.19 & 0.95 \\
\hline At3g18100 & MYB & 0.27 & 0.44 \\
\hline At1g01380 & MYB-related & -0.22 & 0.91 \\
\hline At3g23250 & MYB & 2.02 & 4.29 \\
\hline At1g01520 & MYB-related & 1.62 & 1.67 \\
\hline At1g09770 & MYB-related & 0.41 & 0.38 \\
\hline At3g27220 & MYB & -1.04 & -0.13 \\
\hline At1g15720 & MYB-related & 0.34 & 0.39 \\
\hline At1g17460 & MYB-related & 0.71 & 0.61 \\
\hline At3g27810 & MYB & 0.79 & 1.76 \\
\hline At3g27920 & MYB & 0.15 & 0.47 \\
\hline At1g18330 & MYB-related & -0.49 & -0.63 \\
\hline At1g19000 & MYB-related & -0.21 & 1.13 \\
\hline At3g28910 & MYB & 0.20 & 0.99 \\
\hline At1g49950 & MYB-related & -0.08 & 0.73 \\
\hline At1g70000 & MYB-related & -0.29 & 0.22 \\
\hline At1g71030 & MYB-related & -0.27 & 0.77 \\
\hline At1g33070 & MADS & 0.19 & 1.12 \\
\hline
\end{tabular}

(Continued)
Table A2 | Continued

AGI Gene family $\quad \log 2 \mathrm{FCh}$

\begin{tabular}{lccc} 
& $\mathbf{0 . 5} \mathbf{h} \mathbf{~ W T}$ & $\mathbf{0 . 5} \mathbf{h ~ G O}$ \\
\hline At3g58680 & MBF1 & 0.11 & 0.85
\end{tabular}

At1g47760

MADS

$-0.02$

0.30

At1g06180

At1g48150

At1g06910

At1g54760

At1g59810

At1g08810

At1g09540

At1g09710

At1g13880

At1g14350

At1g16490

At1g17950

At3g46130

At1g72650

At3g47600

At1g72740

At3g47680

At1g74840

At3g48920

At1g75250

At3g49690

At2g21650

At3g50060

At3g52250

At2g30420

At2g38090

At3g55730

At2g46410

At3g57980

At2g46830

At3g60460

At3g09600

At3g61250

At1g18570

At1g69540

At1g18710

At1g71692

At1g18960

At1g19510

At1g77080

At1g21700

At1g22640

At2g03060

At1g26580

At2g03710

At2g14210

At2g22540

MYB

MADS

MYB

MADS

MADS

MYB

MYB

MYB

MYB

MYB

MYB

MYB

MYB

MYB-related

MYB

MYB-related

MYB

MYB-related

MYB

MYB-related

MYB

MYB-related

MYB

MYB

MYB-related

MYB-related

MYB

MYB-related

MYB

MYB-related

MYB

MYB-related

MYB

MYB

MADS

MYB

MADS

MYB

MYB

MADS

MYB

MYB

MADS

MYB

MADS

MADS

MADS

MYB-related
0.39

$-3.43$

0.95

3.53

$-0.54$

$-0.22$

2.23

0.83

$-0.17$

0.09

$-0.25$

0.48

$-0.32$

$-0.27$

0.27

0.41

0.34

0.11

2.56

0.57

0.14

0.06

0.62

0.16

0.31

$-0.26$

$-0.11$

$-0.19$

0.10

0.09

2.21

0.55

1.85

1.06

$-1.70$

0.67

0.30

1.43

$-1.33$

0.99

0.63

0.85

0.55

$-0.09$

0.56

0.89

0.92

0.06

0.96

2.79

0.81

0.48

0.47

1.24

0.70

$-0.02$

0.52

0.52

0.79

0.08

0.65

$-1.95$

0.46

$-0.69$

1.43

$-0.17$

3.26

0.11

2.64

1.13

2.42

0.54

0.37

0.32

1.00

0.51

0.26

0.89

$-0.08$

0.50

0.27

(Continued) 
Table A2 | Continued

\begin{tabular}{|c|c|c|c|}
\hline \multirow[t]{2}{*}{ AGI } & \multirow[t]{2}{*}{ Gene family } & \multicolumn{2}{|c|}{$\log 2$ FCh } \\
\hline & & $0.5 \mathrm{~h}$ WT & $0.5 \mathrm{~h} \mathrm{GO}$ \\
\hline At3g11280 & MYB-related & -0.04 & 0.62 \\
\hline At4g01680 & MYB & -0.95 & 0.94 \\
\hline At3g16350 & MYB-related & 1.18 & 0.64 \\
\hline At4g01980 & MYB & 1.15 & -0.75 \\
\hline At3g24870 & MYB-related & -0.34 & 0.16 \\
\hline At4g05100 & MYB & 1.03 & 2.63 \\
\hline At3g49850 & MYB-related & -0.32 & 0.38 \\
\hline At4g09460 & MYB & 0.75 & 1.86 \\
\hline At4g01060 & MYB-related & -0.77 & 0.32 \\
\hline At4g12350 & MYB & 1.00 & 0.22 \\
\hline At4g01280 & MYB-related & 0.45 & 0.96 \\
\hline At4g16420 & MYB & 0.12 & 0.48 \\
\hline At4g11400 & MYB-related & 0.16 & 0.67 \\
\hline At4g36570 & MYB-related & -0.93 & 0.12 \\
\hline At4g17785 & MYB & 0.95 & 1.66 \\
\hline At4g39250 & MYB-related & 1.23 & -0.59 \\
\hline At5g01200 & MYB-related & -0.30 & 0.17 \\
\hline At1g48000 & MYB & 0.32 & 3.79 \\
\hline At1g49010 & MYB & 0.04 & -0.22 \\
\hline At2g26880 & MADS & 1.64 & 0.81 \\
\hline At1g56650 & MYB & -0.73 & 3.60 \\
\hline At2g28700 & MADS & -1.04 & 1.44 \\
\hline At1g57560 & MYB & 0.14 & 1.31 \\
\hline At2g34440 & MADS & 0.35 & 0.09 \\
\hline At1g58220 & MYB & 0.97 & 0.51 \\
\hline At1g63910 & MYB & 0.06 & -0.06 \\
\hline At2g42830 & MADS & -2.35 & -1.26 \\
\hline At1g66230 & MYB & -0.64 & 0.17 \\
\hline At2g45650 & MADS & 1.77 & -2.34 \\
\hline At2g45660 & MADS & 0.07 & 0.45 \\
\hline At1g66380 & MYB & 0.89 & 5.32 \\
\hline At3g02310 & MADS & 5.56 & -3.02 \\
\hline At1g66390 & MYB & 0.04 & -0.20 \\
\hline At4g21440 & MYB & 1.72 & 2.48 \\
\hline At5g02840 & MYB-related & -0.12 & 0.57 \\
\hline At4g22680 & MYB & 0.57 & 1.29 \\
\hline At5g04760 & MYB-related & 0.64 & 1.18 \\
\hline At5g05790 & MYB-related & -0.26 & 0.39 \\
\hline At4g26930 & MYB & -1.50 & 2.20 \\
\hline At5g08520 & MYB-related & 0.58 & -0.03 \\
\hline At4g28110 & MYB & 1.18 & 2.55 \\
\hline At5g17300 & MYB-related & 0.42 & 1.05 \\
\hline At4g32730 & MYB & 0.83 & 0.08 \\
\hline At5g37260 & MYB-related & 2.68 & 3.28 \\
\hline At4g34990 & MYB & 0.24 & 0.09 \\
\hline At5g52660 & MYB-related & 0.73 & 1.50 \\
\hline At4g37260 & MYB & 0.31 & 1.47 \\
\hline At5g53200 & MYB-related & 0.34 & 0.57 \\
\hline At5g56840 & MYB-related & -0.33 & 0.62 \\
\hline At4g38620 & MYB & 0.41 & 0.47 \\
\hline
\end{tabular}

(Continued)
Table A2 | Continued

AGI Gene family $\quad \log 2 \mathrm{FCh}$

\begin{tabular}{lccc} 
& $\mathbf{0 . 5} \mathbf{h} \mathbf{~ W T}$ & $\mathbf{0 . 5} \mathbf{h}$ Go \\
\hline At5g58900 & MYB-related & 0.09 & 0.41
\end{tabular}

At5g47370

NAC

MYB-related

0.73

0.99

At5g67580

At1g01010

At5g53950

At1g01720

At5g53980

At5g56620

At1g02220

At5g59340

At5g61430

At5g62380

At5g63790

At1g12260

At5g64060

At5g64530

At1g19790

At2g18120

At1g66600

At2g21400

At1g69310

At3g54430

At1g69810

At4g36260

At5g12330

At1g80840

At5g33210

At2g03340

At5g66350

At2g04880

At1g05690

At1g25580

At5g65310

At5g66300

At1g28470

At1g32510

At5g39690

At5g50820

At1g32870

At1g33060

At1g20640

NAC

NAC

NAC

NAC

NAC

NAC

$\mathrm{HB}$

NAC

NAC

NAC

NAC

NAC

NAC

SRS

SRS

WRKY

SRS

WRKY

SRS

WRKY

SRS

SRS

WRKY

SRS

WRKY

SRS

WRKY

TAZ

NAC

NAC

NAC

NAC

NAC

NAM

NAM

NAC

NAC

NIN-like

NAC

NIN-like

At1g64530

At1g34190

At1g74480

At1g52880

At1g76350

At1g52890

At2g17150

At4g37610
NAC

NIN-like

NAC

NIN-like

NAC

NIN-like

TAZ
-0.17
0.48

1.56

2.88

0.30

0.93

$-0.30$

2.22

0.49

0.14

1.41

9.20

$-0.12$

0.08

$-0.88$

0.43

0.53

$-0.27$

0.63

$-0.14$

0.89

0.33

$-2.00$

1.49

0.21

0.12

$-0.18$

0.04

$-0.02$

0.08

$-0.10$

0.03

$-0.82$

0.43

1.18

0.53

0.38

0.16

0.52

0.22

0.25

0.11

$-2.56$

$-0.10$

$-0.30$

2.82

0.82

0.17
0.60

1.17

$-1.00$

2.70

$-0.46$

1.00

0.77

1.42

$-0.05$

0.82

3.14

0.96

$-0.11$

1.20

$-0.17$

0.73

1.60

1.28

0.51

0.26

1.49

0.12

0.13

6.06

0.79

0.13

0.07

0.72

0.84

0.68

0.20

0.77

0.54

0.42

1.50

0.50

0.81

0.31

$-0.06$

0.15

0.25

0.92

1.54

0.56

0.48

3.69

$-0.12$

2.27

(Continued) 
Table A2 | Continued

\begin{tabular}{|c|c|c|c|}
\hline \multirow[t]{2}{*}{ AGI } & \multirow[t]{2}{*}{ Gene family } & \multicolumn{2}{|c|}{$\log 2 \mathrm{FCh}$} \\
\hline & & $0.5 \mathrm{~h}$ WT & $0.5 \mathrm{~h} \mathrm{GO}$ \\
\hline At2g23320 & WRKY & 2.07 & 3.14 \\
\hline At5g63160 & $\mathrm{TAZ}$ & 2.00 & 2.10 \\
\hline At2g24570 & WRKY & 0.55 & 0.82 \\
\hline At5g67480 & $\mathrm{TAZ}$ & -0.44 & 1.05 \\
\hline At2g25000 & WRKY & -0.33 & 0.07 \\
\hline At1g30210 & $\mathrm{TCP}$ & -0.05 & 0.41 \\
\hline At2g30250 & WRKY & 0.63 & 2.13 \\
\hline At1g35560 & $\mathrm{TCP}$ & 0.03 & 0.91 \\
\hline At2g30590 & WRKY & -0.44 & 0.40 \\
\hline At1g53230 & $\mathrm{TCP}$ & 0.24 & 0.83 \\
\hline At1g58100 & TCP & 0.14 & 0.37 \\
\hline At2g37260 & WRKY & -0.50 & 0.63 \\
\hline At1g67260 & $\mathrm{TCP}$ & -2.70 & -0.70 \\
\hline At2g38470 & WRKY & 1.50 & 5.33 \\
\hline At1g68800 & $\mathrm{TCP}$ & -0.10 & 1.83 \\
\hline At2g40740 & WRKY & 0.70 & -0.15 \\
\hline At1g69690 & $\mathrm{TCP}$ & -0.80 & 0.28 \\
\hline At2g40750 & WRKY & 0.49 & 0.37 \\
\hline At1g72010 & $\mathrm{TCP}$ & 0.43 & 0.61 \\
\hline At2g44745 & WRKY & -1.08 & 0.27 \\
\hline At2g31070 & $\mathrm{TCP}$ & 0.01 & 0.02 \\
\hline At1g54330 & NAC & -0.82 & 0.42 \\
\hline At2g43500 & NIN-like & 0.60 & 1.64 \\
\hline At1g56010 & NAC & -0.50 & 0.39 \\
\hline At2g43500 & NIN-like & 0.46 & 0.49 \\
\hline At3g59580 & NIN-like & -0.41 & 0.14 \\
\hline At4g24020 & NIN-like & 0.79 & 0.45 \\
\hline At4g35270 & NIN-like & 0.54 & 0.54 \\
\hline At4g35590 & NIN-like & 0.71 & 0.81 \\
\hline At1g62700 & NAC & 0.10 & 1.52 \\
\hline At1g64105 & NAC & -0.07 & 0.47 \\
\hline At1g65910 & NAC & 0.50 & 0.67 \\
\hline At4g27330 & NZZ & 1.25 & -5.05 \\
\hline At2g37000 & TCP & 0.43 & 0.10 \\
\hline At2g46400 & WRKY & 1.44 & 4.82 \\
\hline At2g45680 & $\mathrm{TCP}$ & -0.06 & -0.07 \\
\hline At2g47260 & WRKY & 0.30 & 0.53 \\
\hline At3g02150 & $\mathrm{TCP}$ & -0.14 & 1.23 \\
\hline At3g01080 & WRKY & -0.10 & 1.38 \\
\hline At3g15030 & $\mathrm{TCP}$ & -0.20 & -0.06 \\
\hline At3g01970 & WRKY & 0.53 & 1.93 \\
\hline At3g04670 & WRKY & -0.07 & 0.62 \\
\hline At3g27010 & $\mathrm{TCP}$ & 0.50 & 1.13 \\
\hline At3g56400 & WRKY & 0.86 & 1.42 \\
\hline At3g58710 & WRKY & 0.79 & 0.92 \\
\hline At3g47620 & $\mathrm{TCP}$ & 0.33 & 0.89 \\
\hline At4g18390 & TCP & 0.17 & 0.44 \\
\hline At4g01250 & WRKY & 2.23 & 2.87 \\
\hline At5g08070 & $\mathrm{TCP}$ & 0.09 & 0.22 \\
\hline At4g01720 & WRKY & 2.13 & 1.22 \\
\hline
\end{tabular}

(Continued)
Table A2 | Continued

\begin{tabular}{|c|c|c|c|}
\hline \multirow[t]{2}{*}{ AGI } & \multirow[t]{2}{*}{ Gene family } & \multicolumn{2}{|c|}{$\log 2 \mathrm{FCh}$} \\
\hline & & $0.5 \mathrm{~h}$ WT & $0.5 \mathrm{~h} \mathrm{GO}$ \\
\hline At5g08330 & TCP & -0.52 & -0.21 \\
\hline At4g04450 & WRKY & 0.96 & -0.24 \\
\hline At5g23280 & TCP & -0.67 & 0.09 \\
\hline At1g69490 & NAC & 2.94 & 4.59 \\
\hline At1g71930 & NAC & 0.51 & 0.16 \\
\hline At5g35770 & Orphan (SAP) & -2.53 & -1.58 \\
\hline At1g76420 & NAC & -3.79 & -0.14 \\
\hline At1g14410 & PBF-2-like(Whirly) & 0.60 & 0.20 \\
\hline At1g77450 & NAC & 2.40 & 2.71 \\
\hline At1g71260 & PBF-2-like(Whirly) & 0.05 & 0.22 \\
\hline At2g02740 & PBF-2-like(Whirly) & 0.00 & 0.35 \\
\hline At2g02450 & NAC & 0.98 & 1.08 \\
\hline At1g05380 & PHD finger & 0.18 & 0.22 \\
\hline At2g36720 & PHD finger & 0.04 & 0.40 \\
\hline At2g18060 & NAC & 0.14 & -0.31 \\
\hline At3g14980 & PHD finger & -0.05 & 0.09 \\
\hline At2g24430 & NAC & 2.76 & 2.38 \\
\hline At3g53680 & PHD finger & 0.29 & 0.79 \\
\hline At2g27300 & NAC & -0.16 & 1.23 \\
\hline At4g14920 & PHD finger & 0.70 & 0.50 \\
\hline At2g33480 & NAC & -1.81 & 0.06 \\
\hline At5g12400 & PHD finger & 0.91 & 0.58 \\
\hline At2g43000 & NAC & 0.92 & 1.67 \\
\hline At5g22260 & PHD finger & 4.59 & 0.75 \\
\hline At5g41030 & TCP & 0.84 & 1.27 \\
\hline At4g12020 & WRKY & 0.71 & 0.40 \\
\hline At5g51910 & TCP & -0.29 & 0.09 \\
\hline At4g18170 & WRKY & 1.99 & 3.02 \\
\hline At5g60970 & $\mathrm{TCP}$ & 0.14 & 0.27 \\
\hline At1g13450 & Trihelix & 0.07 & 0.60 \\
\hline At4g23550 & WRKY & -0.28 & -0.03 \\
\hline At1g21200 & Trihelix & -0.14 & 0.45 \\
\hline At4g23810 & WRKY & 3.77 & 4.73 \\
\hline At4g24240 & WRKY & 0.88 & 1.69 \\
\hline At1g31310 & Trihelix & 0.89 & 0.55 \\
\hline At1g33240 & Trihelix & -0.65 & -0.47 \\
\hline At4g26640 & WRKY & 1.45 & -0.24 \\
\hline At1g54060 & Trihelix & -0.26 & 0.43 \\
\hline At4g30935 & WRKY & 0.11 & 0.42 \\
\hline At1g76880 & Trihelix & 0.98 & 0.08 \\
\hline At4g31550 & WRKY & 2.07 & 2.38 \\
\hline At1g76890 & Trihelix & -0.54 & -0.10 \\
\hline At4g31800 & WRKY & 1.41 & 2.71 \\
\hline At2g33550 & Trihelix & 0.61 & 0.52 \\
\hline At4g39410 & WRKY & -0.03 & 0.99 \\
\hline At5g35210 & PHD finger & 0.07 & 0.70 \\
\hline At3g01600 & NAC & -0.70 & 1.83 \\
\hline At3g03200 & NAC & -2.55 & 0.74 \\
\hline At5g58610 & PHD finger & -1.39 & -1.08 \\
\hline At3g04060 & NAC & 0.37 & 0.02 \\
\hline
\end{tabular}


Table A2 | Continued

\begin{tabular}{|c|c|c|c|}
\hline \multirow[t]{2}{*}{ AGI } & \multirow[t]{2}{*}{ Gene family } & \multicolumn{2}{|c|}{$\log 2 \mathrm{FCh}$} \\
\hline & & $0.5 \mathrm{~h}$ WT & $0.5 \mathrm{~h} \mathrm{GO}$ \\
\hline At3g04070 & NAC & -0.45 & 0.76 \\
\hline At1g21000 & PLATZ & 0.65 & 1.67 \\
\hline At1g31040 & PLATZ & -1.87 & 0.25 \\
\hline At3g04420 & NAC & -0.17 & 0.64 \\
\hline At1g32700 & PLATZ & -0.16 & 1.10 \\
\hline At1g43000 & PLATZ & 2.53 & 3.44 \\
\hline At3g10480 & NAC & 0.88 & 0.14 \\
\hline At1g76590 & PLATZ & 1.42 & 1.77 \\
\hline At3g10490 & NAC & 0.81 & 0.07 \\
\hline At2g27930 & PLATZ & 1.89 & 1.39 \\
\hline At3g10500 & NAC & 0.26 & 0.94 \\
\hline At3g60670 & PLATZ & -0.09 & 0.31 \\
\hline At3g15170 & NAC & 0.95 & -2.63 \\
\hline At4g17900 & PLATZ & 1.01 & 1.84 \\
\hline At2g35640 & Trihelix & 2.40 & 2.93 \\
\hline At5g01900 & WRKY & 1.78 & 5.60 \\
\hline At2g38250 & Trihelix & 0.84 & 0.37 \\
\hline At5g07100 & WRKY & 2.13 & 1.12 \\
\hline At2g44730 & Trihelix & 0.14 & 0.61 \\
\hline At3g01560 & Trihelix & 1.10 & 0.47 \\
\hline At5g22570 & WRKY & 0.59 & 1.16 \\
\hline At3g10040 & Trihelix & -1.27 & -0.35 \\
\hline At5g24110 & WRKY & 1.46 & 4.27 \\
\hline At3g11100 & Trihelix & -0.20 & 0.44 \\
\hline At5g26170 & WRKY & -0.25 & 2.65 \\
\hline At3g14180 & Trihelix & 0.07 & 0.81 \\
\hline At5g28650 & WRKY & -0.01 & -0.61 \\
\hline At3g19020 & Trihelix & 1.43 & 1.18 \\
\hline At3g24490 & Trihelix & -0.22 & 0.42 \\
\hline At5g43290 & WRKY & 0.27 & 0.87 \\
\hline At3g24860 & Trihelix & -0.07 & 0.35 \\
\hline At5g45050 & WRKY & 0.37 & 0.28 \\
\hline At3g25990 & Trihelix & 0.10 & 0.31 \\
\hline At5g45270 & WRKY & 0.76 & 0.96 \\
\hline At3g15500 & NAC & 2.51 & 3.62 \\
\hline At5g46710 & PLATZ & 1.85 & 2.23 \\
\hline At3g15510 & NAC & 0.51 & 0.57 \\
\hline At3g17730 & NAC & 0.40 & 1.19 \\
\hline At4g02020 & Polycomb Group (PcG) & 0.28 & 0.50 \\
\hline At3g29035 & NAC & -0.40 & 1.40 \\
\hline At4g16845 & Polycomb Group (PcG) & -0.08 & 0.09 \\
\hline At5g51230 & Polycomb Group (PcG) & 0.26 & 0.22 \\
\hline At3g27700 & RRM-containing & 0.52 & 0.78 \\
\hline At4g01540 & NAC & 0.33 & 2.07 \\
\hline At3g47120 & RRM-containing & 0.11 & 0.39 \\
\hline At4g27410 & NAC & 1.65 & 3.18 \\
\hline At2g37120 & S1Fa-like & -1.00 & 0.63 \\
\hline At4g28500 & NAC & -0.19 & -0.07 \\
\hline At3g53370 & S1Fa-like & 0.11 & 0.66 \\
\hline At4g28530 & NAC & -0.38 & 0.93 \\
\hline
\end{tabular}

(Continued)
Table A2 | Continued

AGI Gene family $\quad \log 2 \mathrm{FCh}$

\begin{tabular}{llcc} 
& & $\mathbf{0 . 5} \mathbf{h} \mathbf{~ W T}$ & $\mathbf{0 . 5} \mathbf{h ~ G O}$ \\
\hline At1g02065 & SBP & 0.44 & -0.72
\end{tabular}

At3g54390

At5g46350

At3g58630

At5g49520

At4g17050

At5g52830

At4g31270

At5g56270

At5g01380

At5g64810

At5g03680

At1g14440

At5g05550

At1g14687

At5g14540

At5g28300

At1g74660

At5g38560

At1g75240

At5g47660

At2g02540

At5g63430

At2g18350

At4g35580

At1g20980

At4g36160

At1g27360

At5g04400

At1g27370

At5g04410

At1g53160

At5g07680

At1g69170

At5g08790

At2g33810

At5g09330

At2g42200

Trihelix

$-0.39$

$-0.11$

WRKY
Trihelix

0.26

1.24

WRKY

Trihelix

WRKY

Trihelix

WRKY

Trihelix

WRKY

Trihelix

ZF-HD

Trihelix

ZF-HD

Trihelix

Trihelix

ZF-HD

Trihelix

ZF-HD

Trihelix

ZF-HD

Trihelix

ZF-HD

NAC

SBP

NAC

SBP

NAC

SBP

NAC

SBP

NAC

SBP

NAC

SBP

NAC

SBP

NAC

SBP

At2g47070

At5g14000

At3g15270

At3g57920

At5g17260

At3g60030

At5g18270

At5g18830

At1g16070

At3g28920

At1g25280

\subsection{4}

$-0.24$

0.93

$-0.37$

$-0.06$

$-0.10$

0.78

$-0.41$

$-0.18$

$-0.01$

0.06

3.11

$-0.18$

$-0.26$

0.48

$-0.45$

0.02

$-0.10$

0.35

0.34

0.59

0.39

0.08

0.91

1.31

0.56

0.21

$-0.51$

$-0.71$

$-0.24$

1.56

$-0.01$

0.76

$-0.45$

$-0.45$

0.22

$-0.57$

$-0.51$

0.27

0.22

0.22

0.31

0.04

$-0.19$

0.06

0.80
0.16

2.73

0.41

1.22

0.59

$-0.03$

2.40

2.26

0.87

$-0.17$

0.38

0.36

0.00

$-0.58$

0.00

0.69

$-0.13$

0.15

0.60

0.47

0.27

0.36

0.60

1.12

0.64

1.79

0.01

0.52

$-0.46$

$-0.44$

0.19

1.81

0.12

0.34

$-0.37$

0.17

0.60

$-0.15$

$-0.35$

$-0.36$

0.79

0.30

0.84

0.26

$-0.25$

0.23

0.36

(Continued) 
Table A2 | Continued

\begin{tabular}{|c|c|c|c|}
\hline \multirow[t]{2}{*}{ AGI } & \multirow[t]{2}{*}{ Gene family } & \multicolumn{2}{|c|}{$\log 2 \mathrm{FCh}$} \\
\hline & & $0.5 \mathrm{~h}$ WT & $0.5 \mathrm{~h} \mathrm{GO}$ \\
\hline At3g50890 & ZF-HD & -0.47 & -0.58 \\
\hline At4g24660 & ZF-HD & -0.36 & -0.01 \\
\hline At1g47270 & TUB & 0.35 & 0.68 \\
\hline At5g15210 & ZF-HD & -0.12 & 0.01 \\
\hline At5g39760 & ZF-HD & 0.84 & 0.07 \\
\hline At5g42780 & ZF-HD & -0.17 & -0.33 \\
\hline At1g76900 & TUB & 1.50 & 0.46 \\
\hline At2g18280 & TUB & 0.19 & 0.55 \\
\hline At5g65410 & ZF-HD & 1.11 & 0.15 \\
\hline At2g47900 & TUB & 1.25 & 0.11 \\
\hline At1g17380 & $\mathrm{ZIM}$ & 1.91 & 3.30 \\
\hline At3g06380 & TUB & -0.02 & 0.64 \\
\hline At1g19180 & $\mathrm{ZIM}$ & 2.60 & 4.54 \\
\hline At5g18680 & TUB & -0.10 & 0.44 \\
\hline At1g30135 & $\mathrm{ZIM}$ & -0.37 & 2.56 \\
\hline At1g48500 & ZIM & 1.18 & 0.17 \\
\hline At5g18300 & NAC & -0.83 & -0.13 \\
\hline At5g43270 & SBP & -0.64 & -0.77 \\
\hline At5g22290 & NAC & 0.28 & 1.92 \\
\hline At5g50570 & SBP & 0.26 & 1.42 \\
\hline At5g22380 & NAC & 3.76 & 4.76 \\
\hline At5g50670 & SBP & 0.30 & 0.91 \\
\hline At5g24590 & NAC & 1.15 & 1.53 \\
\hline At1g05830 & SET-domain & 0.18 & -0.06 \\
\hline At5g39610 & NAC & 0.19 & 2.46 \\
\hline At2g31650 & SET-domain & 0.27 & 0.57 \\
\hline At5g39820 & NAC & 1.91 & 0.05 \\
\hline At4g27910 & SET-domain & 0.29 & 0.60 \\
\hline At5g41410 & NAC & 0.08 & -0.03 \\
\hline At4g30860 & SET-domain & -0.13 & 0.71 \\
\hline At5g09790 & SET-domain & 0.48 & 0.50 \\
\hline At5g24330 & SET-domain & -0.05 & 0.27 \\
\hline At5g46590 & NAC & 0.08 & 1.50 \\
\hline At5g53430 & SET-domain & 0.30 & 0.17 \\
\hline At4g28190 & ULT & -0.26 & 0.02 \\
\hline At1g70700 & ZIM & 0.14 & 1.73 \\
\hline At1g28520 & VOZ & 0.32 & 0.75 \\
\hline At1g72450 & ZIM & -0.27 & 1.16 \\
\hline At2g42400 & VOZ & 0.24 & 0.44 \\
\hline At1g74950 & ZIM & 0.27 & 0.93 \\
\hline At2g34600 & ZIM & -1.53 & 3.07 \\
\hline At3g17860 & $\mathrm{ZIM}$ & 0.10 & 1.25 \\
\hline At1g29280 & WRKY & -0.40 & 2.45 \\
\hline At3g43440 & $\mathrm{ZIM}$ & 0.15 & 0.16 \\
\hline At1g29860 & WRKY & -0.16 & 1.03 \\
\hline At4g14713 & ZIM & 0.94 & -0.11 \\
\hline At4g14720 & ZIM & -0.01 & 0.21 \\
\hline At4g32570 & ZIM & 0.50 & 0.50 \\
\hline At1g62300 & WRKY & 2.04 & 2.08 \\
\hline At5g13220 & $\mathrm{ZIM}$ & 0.10 & 1.75 \\
\hline At5g20900 & ZIM & 0.22 & 1.13 \\
\hline
\end{tabular}

Values are means of two biological replicates. 